\title{
Craniofacial ontogeny in Tylosaurinae
}

\author{
Amelia R Zietlow ${ }^{\text {Corresp. } 1}$ \\ ${ }^{1}$ Department of Biology, Carthage College, Kenosha, Wisconsin, United States \\ Corresponding Author: Amelia R Zietlow \\ Email address: azietlow@carthage.edu
}

Mosasaurs were large, globally distributed aquatic lizards that lived during the Late Cretaceous. Despite numerous specimens of varying maturity, a detailed growth series has not been proposed for any mosasaur taxon. Two taxa-Tylosaurus proriger and $T$. kansasensis/nepaeolicus--have robust fossil records with specimens spanning a wide range of sizes and are thus ideal for studying mosasaur ontogeny. Tylosaurus is a genus of particularly large mosasaurs with long, edentulous anterior extensions of the premaxilla and dentary that lived in Europe and North America during the Late Cretaceous. An analysis of growth in Tylosaurus provides an opportunity to test hypotheses of the synonymy of $T$. kansasensis with $T$. nepaeolicus, sexual dimorphism, anagenesis, and heterochrony. Fifty-nine hypothetical growth characters were identified, including sizedependent, size-independent, and phylogenetic characters, and quantitative cladistic analysis was used to recover growth series for the two taxa. The results supported the synonymy of $T$. kansasensis with $T$. nepaeolicus and that $T$. kansasensis represent juveniles of $T$. nepaeolicus. A Spearman rank-order correlation test resulted in a significant correlation between two measures of size (total skull length and quadrate height) and maturity. Eleven growth changes were shared across both species, neither of the ontogram topologies showed evidence of skeletal sexual dimorphism, and a previous hypothesis of paedomorphy in $T$. proriger was not rejected. Finally, a novel hypothesis of anagenesis in Western Interior Seaway Tylosaurus species, driven by peramorphy, is proposed here. 


\section{Craniofacial Ontogeny in Tylosaurinae}

3

4

5

6

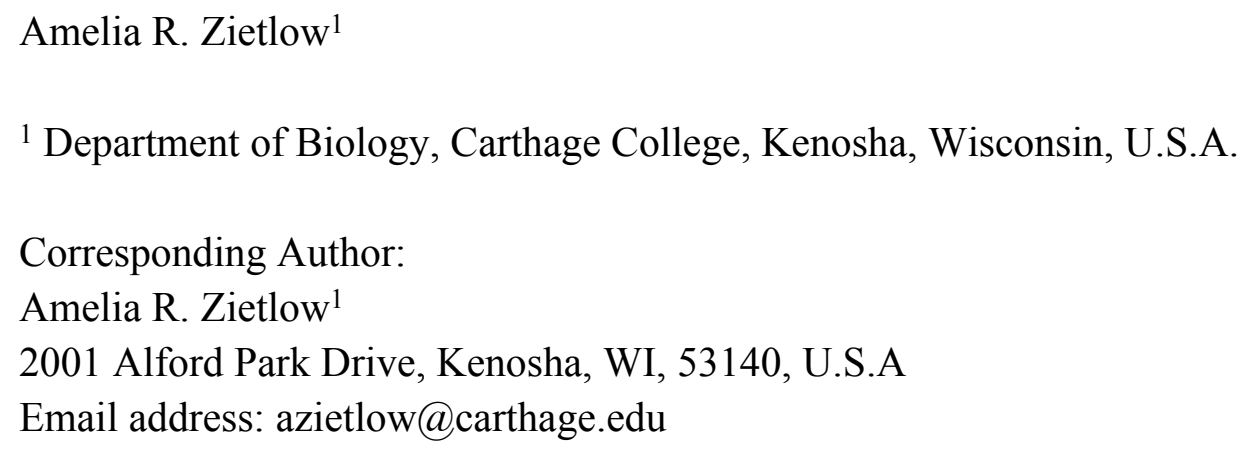

\section{Abstract}

Mosasaurs were large, globally distributed aquatic lizards that lived during the Late Cretaceous. Despite numerous specimens of varying maturity, a detailed growth series has not been proposed for any mosasaur taxon. Two taxa-Tylosaurus proriger and T. kansasensis/nepaeolicus - have robust fossil records with specimens spanning a wide range of sizes and are thus ideal for studying mosasaur ontogeny. Tylosaurus is a genus of particularly large mosasaurs with long, edentulous anterior extensions of the premaxilla and dentary that lived in Europe and North America during the Late Cretaceous. An analysis of growth in Tylosaurus provides an opportunity to test hypotheses of the synonymy of T. kansasensis with T. nepaeolicus, sexual dimorphism, anagenesis, and heterochrony. Fifty-nine hypothetical growth characters were identified, including size-dependent, size-independent, and phylogenetic characters, and quantitative cladistic analysis was used to recover growth series for the two taxa. The results supported the synonymy of T. kansasensis with T. nepaeolicus and that T. kansasensis represent juveniles of T. nepaeolicus. A Spearman rank-order correlation test resulted in a significant correlation between two measures of size (total skull length and quadrate height) and maturity. Eleven growth changes were shared across both species, neither of the ontogram topologies showed evidence of skeletal sexual dimorphism, and a previous hypothesis of paedomorphy in $T$. proriger was not rejected. Finally, a novel hypothesis of anagenesis in Western Interior Seaway Tylosaurus species, driven by peramorphy, is proposed here.

\section{Introduction}

Mosasaur ontogeny. Mosasaurs (Squamata: Mosasauridae) were a group of large, predatory marine lizards with a global distribution that lived during the Late Cretaceous. The fossils of several taxa span a wide range of sizes and therefore are presumably of varying maturity. The first published study of growth in mosasaurs was done by Caldwell (1996), which sought to 
40 determine the patterns of ossification in the autopodial skeleton across mosasauroids and to test

41 the congruence between these growth processes and mosasaur phylogeny. Caldwell (1996) found

42 that many ossified carpals and tarsals is the ancestral condition, whereas more derived species

43 have less ossified carpals and tarsals; also, a low number of ossified carpals and tarsals is

44 characteristic of juveniles.

Pellegrini (2007) published the first study of osteohistology in mosasaur limb bones. By

47

48

49

50

51

52

53

54

55

56

57

58

59

60

61

62

63

64

65

66

67

68

69

70

71

72

73

74

75

76

77

78

79 counting lines of arrested growth in specimens of Tylosaurus, Platecarpus, and Clidastes, they found that mosasaur growth was initially fast, and then slowed when they reached five to seven years old; he also noted that the rate of growth is faster overall than extant terrestrial squamates. The decrease in growth rate is interpreted as the onset of sexual maturity, given that five to seven years is also the onset of sexual maturity in large extant varanid lizards. However, no proxies for maturity beyond chronological age were explicitly given.

Houssaye and Tafforeau (2012) examined vertebral microanatomy to test the hypothesis that juvenile mosasaurs inhabited shallower environments than adults; in other marine reptiles, an ontogenetic shift from shallow habitats to deeper ones was inferred through progressive loss of bone mass (Wiffen et al., 1995). The authors acknowledged that the assessment of maturity is based on size alone, given that skeletochronology is not reliable in mosasaur vertebrae due to a high amount of inner bone resorption (Houssaye \& Tafforeau, 2012). They found that vertebral microstructure is similar between juveniles and adults, which implied that juveniles were as agile swimmers as adults and, therefore, the authors rejected the hypothesis that juvenile mosasaurs were restricted to shallow, sheltered nurseries. They also noted that, relative to other squamates, mosasaur vertebrae seem to be paedomorphic in that there is a general inhibition of bone remodeling.

Harrell and Martin (2015) described a Mosasaurus hoffmannii specimen found in South Dakota, which significantly extended the geographic range of the taxon farther north in the Western Interior Seaway (WIS). In addition to a description of the skull, the authors identified several ontogenetically variable characters, including the shape of the frontal in dorsal view, dentary depth, and the shape of a notch on the anterolateral flange of the coronoid. The abstract mentions that the shape of the supratemporal fenestrae also varies with maturity, but this is not mentioned anywhere else in the article. The authors provided growth series that showed the growth changes associated with frontal shape and the anterolateral notch of the coronoid, but they are limited to three and four specimens, respectively. Although variation in the quadrate is noted, they did not consider it to be ontogenetic.

Jiménez-Huidobro, Simões, and Caldwell (2016) proposed that specimens of two sympatric species of Tylosaurus, T. kansasensis (Everhart, 2005) and T. nepaeolicus, are synonymous, and that $T$. kansasensis specimens are juveniles. They identified several characters in T. kansasensis that purportedly show the juvenile conditions seen in another species of Tylosaurus, T. proriger, and concluded that there are "no differences between the two nominal species that cannot be attributed to size, and thus ontogenetic stage" (Jiménez-Huidobro, Simões, \& Caldwell, 2016:80), and that T. kansasensis are therefore juveniles of T. nepaeolicus. Also, the

PeerJ reviewing PDF | (2020:05:49148:2:0:NEW 11 Sep 2020) 
80

81

82

83

84

85

86

87

88

89

90

91

92

93

94

95

96

97

98

99

100

101

102

103

104

105

106

107

108

109

110

111

112

113

114

115

116

117

118

119

authors suggested that $T$. proriger may be paedomorphic relative to $T$. nepaeolicus due to the presence of a dorsal midline crest on the frontal and convex lateral borders of the parietal table, features purportedly seen in $T$. kansasensis, but not T. nepaeolicus. The authors provided no justification (or references to one) for identifying one T. proriger specimen, RMM 5610, as a juvenile, and all others (e.g., AMNH FARB 4909) as adults. The following characters were proposed to be ontogenetically variable: definition of the parietal nuchal fossa; medial curvature of the quadrate suprastapedial process; thickness of the quadrate suprastapedial process; thickness of the frontal posterolateral processes; shape of the lateral borders of the parietal table; and presence of the frontal dorsal midline crest. Despite identifying these characters, the authors do not propose a growth series of individual specimens.

Carpenter (2017) described the vertebral morphology of several specimens of T. proriger, including a purported juvenile, RMM 5610. The goal was to deduce the method of swimming of this species by analyzing the degree of vertebral mobility. In addition to providing evidence that adult $T$. proriger were carangiform swimmers (propulsion generated by movement of the hips and tail), differences were seen in the vertebral mobility of RMM 5610, suggesting a faster, taildriven method of swimming in juveniles.

Green (2018) proposed a growth series of four specimens of Clidastes sp. that was based on histological data. Using cyclical growth marks, the author concluded that the growth rate in Clidastes was rapid during its first year of life, moderate between the second and sixth years, and slow from the seventh year onward. Based on growth rates, it was hypothesized that mosasaurs were ectothermic. These results are similar to those of Pellegrini (2007), however, like the earlier study, they are limited by a small sample size (number of specimens) and no estimates of maturity beyond size and chronological age.

A description of the smallest known Tylosaurus specimen (FHSM VP-14845) was published by Konishi, Jiménez-Huidobro, and Caldwell (2018). Although it is not identifiable to species, it shares many features with Tylosaurus generally, especially with the juvenile $T$. proriger specimen, RMM 5610. The authors determined that the specimen is most likely a neonate (newborn) using an estimated total body length and neonate-to-maternal body length proportion data from extant varanid lizards. The authors rejected the possibility that the length of the premaxillary predental rostrum is sexually dimorphic due to its presence in this extremely young individual, but they did note that it is proportionally much shorter than what is seen in adult specimens. Also, they note that the second set of premaxillary teeth are posterolateral to the first set, rather than posterior to them, and that the shape of the premaxillary rostrum is a "gently pointed arc" in dorsal view (Konishi, Jiménez-Huidobro, \& Caldwell, 2018:3).

Stewart and Mallon (2018) described two purported subadult specimens of T. proriger (CMN 8162 and CMN 51258-51263) and hypothesized the growth pattern of various skull structures. The study revealed a significant correlation of all individual bone measurements with total skull length (TSL), as well as isometric growth for all characters except quadrate height, which was found to be positively allometric, and premaxillary predental rostrum length, which was found to be negatively allometric. They also rejected the hypothesis that $T$. kansasensis 
120

121

122

123

124

125

126

127

128

129

130

131

132

133

134

135

136

137

138

139

140

141

142

143

144

145

146

147

148

149

150

151

152

153

154

155

156

157

158

represent juveniles of T. nepaeolicus (Jiménez-Huidobro, Simões, \& Caldwell, 2016), stating that the growth trends between T. kansasensis and T. nepaeolicus do not match what is seen in $T$. proriger, and that there is not enough evidence to support the proposed ontogenetic characters.

Assessment. Overall, there is a deficit of literature devoted to growth in any individual mosasaur taxon, and despite the several papers that do address growth in mosasaurs, the topic remains poorly understood. Little to no justification beyond size or histological data is given for determining the relative maturity of specimens, and growth stages are limited to the vague categories of "juvenile," "subadult," and "adult." No study thus far has attempted to combine all types of data-size, proportional, and size-independent (i.e., morphological)-using an objective, quantifiable, and replicable method to recover a growth series for any mosasaur species. In addition to enhancing our understanding of mosasaur ontogeny, such an analysis could prove particularly useful in resolving the validity of certain species (in this case, T. kansasensis) and the presence or absence of sexual dimorphism.

Tylosaurus proriger. T. proriger was a particularly large mosasaur-the largest individual, the "Bunker" specimen (KUVP 5033), has an estimated total skull length (TSL) of $1.7 \mathrm{~m}$ (Table 1)that lived in the Western Interior Seaway (WIS) during the upper Santonian to the middle Campanian, between 84 and 80 million years ago (Ma) (Jiménez-Huidobro \& Caldwell, 2019). The type specimen of $T$. proriger (MCZ 4374) was described by Cope in 1869 and includes a partial snout, cranial fragments, and thirteen vertebrae (Russell, 1967). Cope originally named the species Macrosaurus proriger. The genus was formally changed by Leidy (1873) to Tylosaurus ("knob lizard"), of which T. proriger is the type species (Everhart, 2017).

$T$. proriger is an unquestionably valid taxon diagnosed by the following suite of cranial characters: (1) premaxilla-maxilla suture ends posterior to the fourth maxillary tooth; (2) quadrate suprastapedial process reaches half the length of the complete bone; (3) quadrate infrastapedial process is moderately developed; (4) quadrate tympanic ala is thin; (5) medial crest of the frontal is well-developed; (6) prefrontal overlaps the postorbitofrontal; (7) dorsal, medial, and lateral invasion of the parietal by frontal alae; and (8) teeth that lack flutes (Russell, 1967; Jiménez-Huidobro \& Caldwell, 2019).

Tylosaurus kansasensis and Tylosaurus nepaeolicus. T. kansasensis and T. nepaeolicus are both known from the WIS during the upper Coniacian to the lower Santonian, from 88 to $85 \mathrm{Ma}$ (Everhart, 2017; Jiménez-Huidobro \& Caldwell, 2019). The type specimen of T. nepaeolicus (AMNH FARB 1565) was described by Cope in 1874 and includes a quadrate, jaw fragments, rib fragment, and single dorsal vertebra (Russell, 1967; Jiménez-Huidobro, Simões, \& Caldwell, 2016). The type specimen of T. kansasensis (FHSM VP-2295) was described by Everhart in 2005 and consists of an articulated skull and six associated cervical vertebrae. 
159

160

161

162

163

164

165

166

167

168

169

170

171

172

173

174

175

176

177

178

179

180

181

182

183

184

185

186

187

188

189

190

191

192

193

194

195

196

197

T. nepaeolicus is diagnosed by the following cranial characters: (1) premaxilla-maxilla suture ends posteriorly above midpoint between third and fourth maxillary teeth; (2) prefrontal overlaps the postorbitofrontal; (3) frontal with dorsal midline crest poorly developed or absent in adult; (4) lateral borders of parietal table slightly convex; (5) ectopterygoid does not contact the maxilla; (6) infrastapedial process of quadrate poorly developed or absent; (7) suprastapedial process of quadrate reaches half the length of the complete bone; (8) tympanic ala thick; (9) mandibular condyle of the quadrate mediolaterally broad; and (10) lateral crest of tympanic ala ends posteriorly near mandibular condyle (Jiménez-Huidobro \& Caldwell, 2019).

T. kansasensis is diagnosed by the following cranial characters: (1) premaxilla rostral foramina large; (2) infrastapedial process of quadrate poorly developed or absent; (3) medial ridge of quadrate diverges ventrally; (4) frontal with dorsal midline crest that is high, thin, and well-developed; (5) medial sutural flanges of frontal large, extend long distance onto parietal; (6) parietal foramen adjacent to or invading frontal-parietal suture; (7) dorsal postorbitofrontal with low rounded transverse ridge; (8) posteroventral angle of jugal is 90 degrees; (9) ectopterygoid does not contact maxilla; (10) quadrate suprastapedial process without constriction; (11) quadrate ala thick; (12) alar concavity of quadrate shallow (Everhart, 2005).

\section{Project Goals}

The goals of this project were to use quantitative cladistic analysis to (1) recover growth series of T. proriger and T. kansasensis/nepaeolicus; (2) test whether total skull length (TSL) or quadrate height $(\mathrm{QH})$ are appropriate proxies for relative maturity in these species; (3) test for sexual dimorphism in these species; (4) test the hypothesis that $T$. kansasensis represent juveniles of $T$. nepaeolicus (Jiménez-Huidobro, Simões, \& Caldwell, 2016); (5) test the hypothesis that two character states, the presence of a frontal midline crest and convex lateral borders of the parietal table, in T. proriger are paedomorphic relative to T. nepaeolicus (Jiménez-Huidobro, Simões, \& Caldwell, 2016); (6) test for anagenesis in these species using ontogenetic data; (7) propose revised cranial diagnoses of $T$. proriger and T. nepaeolicus/kansasensis within an ontogenetic context; and (8) identify conserved patterns of growth in Tylosaurus.

\section{Materials \& Methods}

\section{Quantitative Cladistic Analysis}

Size-independent assessment of maturity. In fossil taxa, it is difficult to discern whether morphologically similar, but differently sized, individuals are different species or different growth stages of a single species; adults of a small species may be mistaken for juveniles of a large species, or different growth stages of a single species may be mistaken for separate species altogether (Rozhdestvensky, 1965; Brinkman, 1988; Carr, 1999). Furthermore, although size may help to organize individuals into general categories (e.g., "juveniles," "subadults," "adults"), it is not possible to precisely determine the maturity of the individuals within each of these 
198

199

200

201

202

203

204

205

206

207

208

209

210

211

212

213

214

215

216

217

218

219

220

221

222

223

224

225

226

227

228

229

230

231

232

233

234

235

236

categories using size alone (i.e., the biggest individual is not necessarily the most mature) (Brinkman, 1988; Carr, 2020).

To solve this issue, Brinkman (1988) suggested the identification of size-independent ontogenetically variable characters (i.e., morphological features such as bone shape and texture, suture shape and closure, degree of ossification, etc.). This does not mean that size is completely uninformative, but that it is simply that more information is needed to accurately assess the relative maturities of individuals through character congruence (i.e., multiple lines of evidence) instead of size alone, which is variable (Brinkman, 1988; Carr, 2020). Therefore, both sizedependent and size-independent characters must be considered when proposing hypotheses of growth.

Cladistic analysis of growth. Ontogeny, like evolution, consists of a hierarchical accumulation of changes over time (Brochu, 1996). Thus, in the same way that the evolutionary relationships between taxa are recovered, cladistic analysis can be used to identify the relative maturity of specimens drawn from a sample of a single species. This method allows sizedependent and size-independent data to be combined to recover a high-resolution growth series that is more precise than simply grouping multiple individuals into imprecise sets such as "juveniles," "subadults," and "adults" (Fig. 1).

Separate character matrices were compiled for $T$. proriger and $T$.

kansasensis/nepaeolicus (Data S1, S2). FHSM VP-14845, which is only identifiable to Tylosaurus sp., was included in both datasets given that it was found between the two species stratigraphically and could be referable to either taxon (Konishi, Jiménez-Huidobro, \& Caldwell, 2018). Character states with the immature condition were coded with zeroes and increasingly mature states were coded with progressively higher numbers. Multistate characters were coded for characters that are not binary (three or more states), and all characters were run unordered and equally weighted. A hypothetical embryo, scored with all zeroes, was added as the analogue of the outgroup in each dataset to polarize the characters, since an embryo expresses the least mature condition of all character states and because no single juvenile specimen is coded with all zeroes (Brochu, 1996; Carr \& Williamson, 2004; Frederickson \& Tumarkin-Deratzian, 2014; Carr, 2020).

Growth stages were defined corresponding to the nodes on the ontogram, and the growth characters that diagnose each stage were the optimized synontomorphies (shared growth characters; Frederickson \& Tumarkin-Deratzian, 2014; Carr, 2020). Growth changes that were unambiguously optimized on the branches to individual specimens were considered individual variation. Following the method of Carr and Williamson (2004), Frederickson and TumarkinDeratzian (2014), and Carr (2020), an artificial adult was added a posteriori to identify the most mature specimen of each taxon. The artificial adult was scored with the character states optimized at the most mature node (i.e., the node supported by the most synontomorphies). Should the analysis with the artificial adult fail to recover a single most mature specimen, the 
237

238

239

240

241

242

243

244

245

246

247

248

249

250

251

252

253

254

255

256

257

258

259

260

261

262

263

264

265

266

267

268

269

270

271

272

273

274

275

276

individual specimen with the most growth changes-i.e., with the greatest number of optimized synontomorphies-was considered the most mature (Fig. 2).

Compilation and analysis of the data matrices. This project makes use of data drawn from 79 specimens housed in several North American institutions, as well as one in Japan and one in Germany (Table S1); of those, 50 were studied first-hand at the Field Museum of Natural History (Chicago, IL), Fryxell Geology Museum (Rock Island, IL), American Museum of Natural History (New York, NY), Sternberg Museum of Natural History (Hays, KS), and University of Kansas Museum of Natural History (Lawrence, KS). All others were scored from descriptions and measurements in the literature, and photographs online or in the primary literature (exact sources for coding each specimen are listed in Table S1; analyses run including only specimens studied first-hand are shown in Supplemental Figure S1A-C). The total numbers of specimens scored for each taxon are as follows: 5 Tylosaurus sp.; 39 T. proriger; $21 \mathrm{~T}$. kansasensis; and 14 T. nepaeolicus. Several specimens of each taxon (i.e., "wildcard" specimens which resulted in multiple equally parsimonious ontograms) were removed from the final analyses due to incomplete or redundant coding following the method of Carr (2020) (Table S2), and any characters that were not scored for more than a single specimen were excluded from the analyses.

Hypothetical growth characters were identified by the author and in the literature, and include both diagnostic characters (e.g., Bell, 1997; Jiménez-Huidobro \& Caldwell, 2019) and characters explicitly proposed to be ontogenetically variable (e.g., Harrell \& Martin, 2015; Jiménez-Huidobro, Simões, \& Caldwell, 2016; Stewart \& Mallon, 2018). Characters are described in detail in Data S3, and measurements and tooth counts are listed in Tables 1 and 2, respectively. A total of 59 characters were identified, which includes two measures of size (TSL and $\mathrm{QH})$, seven proportional characters, 19 size-independent characters, and 30 phylogenetic characters (e.g., characters that are either diagnostic for one of the species or that are purportedly ontogenetically variable and are also phylogenetic characters of Bell (1997)) (Data S3; see Fig. S2 for exemplars of select morphological characters and their states). Of the phylogenetic characters, 11 were not figured in the sources that identify them, and so they could not be identified with certainty nor scored consistently by the author (noted in Data S3); therefore, while they are included in the data matrices and the character list, they were excluded from all of the analyses, and any codes for those characters are from the literature.

Proportions were calculated and rounded to the nearest whole percent, and those that seemed to show variation due to growth (e.g., a difference of $3 \%$ or more between specimens of purportedly different maturities) were coded using specimens referred to by the literature as “juveniles" (e.g., CMN 8162, RMM 5610) and "adults" (e.g., AMNH FARB 4909, FHSM VP3). Size characters (TSL and QH) were rounded to the nearest whole millimeter and states were coded as roughly equal bins spanning the known range of sizes of both taxa (Table 1; Data S3).

Continuous variables, such as size, are potentially problematic in phylogenetic analyses for several reasons, namely, that variations due to ontogeny or sexual dimorphism may obscure 
277 evolutionary relationships, and it is difficult to determine the ancestral state of size characters, or 278 partition continuous variables in general, without introducing personal biases (Rae, 1998; Simões 279 et al., 2016). However, in this work (a specimen-by-specimen analysis of ontogeny), these 280 concerns are irrelevant; variation in topology due to ontogeny and sexual dimorphism is exactly 281 what is sought by this type of analysis, and unlike in phylogenetic studies, the ancestral states of 282 size characters are not ambiguous or arbitrary, given that it is not unreasonable to assume that 283 animals will generally get larger as they mature, and the analysis itself tests if that hypothesis is 284 defensible or not through character congruence. To test the effect of the size characters on

285

286

287

288

289

290

291

292

293

294

295

296

297

298

299

300

301

302

303

304

305

306

307

308

309

310

311

312

313

314

315

316 ontogram topology, the analyses were also run excluding them (Supplemental Figure S1D-I).

Most phylogenetic character states were coded as they are in Bell (1997), and ontogenetic characters were coded according to literature descriptions or naïvely according to patterns uncovered in this project (i.e., the state seen in individuals proposed to be immature by other work (e.g., FHSM VP-14845, RMM 5610, CMN 8162, FHSM VP-15632) was coded as the less developed state, and the state seen in individuals proposed to be more mature by other work (e.g., AMNH FARB 1555, FHSM VP-3, AMNH FARB 124/134) was coded as the more developed state). Data matrices were compiled in Mesquite (Maddison \& Maddison, 2018) and analyzed in TNT (Goloboff \& Catalano, 2016) and PAUP (Swofford, 2003). TNT was used to recover the ontogram topology and number of most parsimonious trees using a new technology search followed by a traditional search; the topology was then loaded as a constraint into PAUP, which recovered the synontomorphies using branch-and-bound searches.

\section{Testing Congruence Between Size and Maturity}

Size alone is often not a reliable indicator of relative maturity (Rozhdestvensky, 1965; Brinkman, 1988; Brochu, 1996; Carr, 2020). To test this hypothesis in mosasaurs, once the growth series were recovered, the congruence between size (TSL) and maturity in each taxon was tested using the method of Frederickson and Tumarkin-Deratzian (2014) and Carr (2020), where the growth stages and TSL measurements for each specimen were converted into ranks and then analyzed in SPSS (IBM Corp., 2019) using a Spearman rank-order correlation test. If size and maturity are congruent (i.e., larger individuals tend to be more mature), the correlation will be positive and statistically significant $(p<0.05)$. Because mosasaur skulls are not always complete enough for an accurate measurement or estimate of TSL, the same method was used to test the congruence between $\mathrm{QH}$ and maturity. The normality of the growth ranks, size ranks, and measurement data were tested using a Shapiro-Wilk test.

\section{Testing Sexual Dimorphism and Taxon Validity}

The ontogram recovered by a cladistic analysis can be used to test for the presence of sexual dimorphism (Frederickson \& Tumarkin-Deratzian, 2014). If no evidence for sexual dimorphism is recovered, the ontogram will be linear (i.e., one specimen per node; Fig. 3A). If, however, sexual dimorphism is present, the ontogram hypothetically will bifurcate (i.e., a single node will have two groups of multiple specimens) into two groups of specimens, corresponding to each 
317 sex, after one or more juvenile stages (Fig. 3B, C). It is also possible that the ontogram is linear 318 and sexual dimorphism is instead recovered as two homologous sets of individual variation (Fig. 319 3D). Following the reasoning of Frederickson and Tumarkin-Deratzian (2014), if a bifurcation 320 (or set of individual variation) represents sexual dimorphism, each sex should (1) independently

321

322

323

324

325

326

327

328

329

330

331

332

333

334

335

336

337

338

339

340

341

342

343

344

345

346

347

348

349

350

351

352

353

354

355 develop a shared sequence of growth changes, since they are the same taxon, in addition to (2) developing unique morphological features that are hypothetically used for sexual display.

The growth series will also be used to test the validity of specimens assigned to each taxon. If specimens assigned to the taxon actually represent two or more different species, the ontogram hypothetically will bifurcate into two or more groups (Fig. 3B, C) or it will be linear and recover two or more groups defined by shared sets of individual variation (Fig. 3D).

Test of synonymy between $T$. kansasensis and $T$. nepaeolicus. To test the hypothesis that $T$. kansasensis are juveniles of $T$. nepaeolicus, a single matrix including specimens of both taxa was constructed. Summaries of potential results are shown in Figure 4. This is not the first study that has used a cladistic analysis of ontogeny to test a hypothesis regarding synonymy; Longrich and Field (2012) used the same approach to test, and reject, the hypothesis that specimens of the genus Torosaurus represent adults of another genus of North American horned dinosaur, Triceratops.

\section{Test of Anagenesis and Heterochrony in Tylosaurus}

Anagenesis-evolution within a single lineage (i.e., without branching into multiple new clades) over time-has been studied in several nonavian dinosaur taxa as a mechanism for producing species diversity, particularly in ceratopsians and tyrannosaurs (Horner, Varricchio, \& Goodwin, 1992; Scannella et al., 2014; Carr et al., 2017; Wilson, Ryan, \& Evans, 2020). In order for anagenesis to be defensible, the taxa in question must meet the following criteria: (1) they do not overlap stratigraphically; (2) they have a close phylogenetic relationship; (3) some specimens have intermediate morphology; and (4) they inhabited the same location (Carr et al., 2017; Wilson, Ryan, \& Evans, 2020).

No previous study has proposed anagenesis as a mechanism of speciation in mosasaurs. Because of the large sample size and potential for high-resolution growth series, they are an ideal taxon for testing hypotheses of evolutionary processes, particularly anagenesis (Carr et al., 2017). In this project, the novel hypothesis that the Tylosaurus of the WIS (T. proriger and $T$. kansasensis/nepaeolicus) are a single, anagenetic lineage will be tested. The two Tylosaurus taxa meet each criterion for anagenesis outlined above: (1) T. kansasensis/nepaeolicus and T. proriger do not overlap stratigraphically; (2) they are sister taxa (Jiménez-Huidobro \& Caldwell, 2019); (3) some specimens have intermediate morphology (e.g., the quadrate infrastapedial process is absent or weak in T. kansasensis and T. nepaeolicus, and it is always present and well-developed in T. proriger); and (4) they both lived in the WIS (it is important to note, however, that the WIS was connected to the oceans; although fossils of these species have thus far never been found 
356

357

358

359

360

361

362

363

364

365

366

367

368

369

370

371

372

373

374

375

376

377

378

379

380

381

382

383

384

385

386

387

388

389

390

391

392

393

394

395

outside the WIS, the possibility of them occasionally leaving the WIS to recolonize elsewhere cannot be ruled out).

If the cladistic analysis of growth based on the dataset including specimens of $T$. kansasensis and T. nepaeolicus supports their synonymy, then a single data matrix including specimens of all three taxa (i.e., T. kansasensis, T. nepaeolicus and T. proriger) will be compiled and analyzed. If the hypothesis of anagenesis is supported, and speciation in WIS Tylosaurus was driven by peramorphy (extension or acceleration of growth; Reilly, Wiley, \& Meinhardt, 1997), then the ontogram will show a progression from T. kansasensis/nepaeolicus to $T$. proriger, and if speciation was driven by paedomorphy (truncation or deceleration of growth), the ontogram will either show a progression from T. proriger to T. kansasensis/nepaeolicus or a progression from T. kansasensis/nepaeolicus to $T$. proriger that includes many character reversals. If anagenesis is not supported, specimens of both taxa will be interspersed with one another on the ontogram or the ontogram will bifurcate basally (Fig. 3C).

Furthermore, testing for anagenesis using ontogenetic data allows for another hypothesis to be tested: heterochrony as a driver of evolution in mosasaurs. Heterochrony is differences in the timing of developmental events (i.e., the developmental consequences of a truncation, extension, acceleration, or deceleration of growth in one taxon relative to another) that produce the morphological differences between a descendent taxon from its ancestor (Reilly, Wiley, \& Meinhardt, 1997). If heterochrony is an evolutionary mechanism in Tylosaurus, and the Tylosaurus species of the WIS are a single anagenetic lineage, then a cladistic analysis of growth will recover the specific developmental changes that produced $T$. proriger-the descendent-from T. kansasensis/nepaeolicus-the ancestor.

Finally, Jiménez-Huidobro, Simões, and Caldwell (2016) also proposed that the presence of a frontal dorsal midline crest and convex lateral borders of the parietal table are paedomorphic in $T$. proriger relative to T. nepaeolicus because of the purported absence of the frontal crest and straight borders of the parietal table in adult $T$. nepaeolicus. These hypotheses were tested here by comparing the growth patterns for that trait between both species; if these characters in $T$. proriger are paedomorphic relative to T. nepaeolicus, then they will be the same (i.e., crest present and borders convex) in all T. proriger specimens and in juvenile T. nepaeolicus, and different (i.e., crest absent and borders straight) in mature T. nepaeolicus.

\section{Results}

\section{Growth Series of $T$. proriger}

One ontogram was recovered with a length of 82 steps, consistency index (CI) of 0.65 , homoplasy index $(\mathrm{HI})$ of 0.35 , retention index (RI) of 0.76 , and rescaled consistency index (RC) of 0.49 (Fig. 5). The topology was assessed using a Bremer decay index approach, and resolution was lost after the addition of one step. A total of 17 growth stages were identified; the analysis with the artificial adult and all 23 specimens did not recover a single most mature specimen, but a second analysis with the artificial adult which only included the three most mature specimens 
396 (i.e., those that were sister to the artificial adult in the analysis with all 23 specimens: FMNH 397 P15144, FHSM VP-3, and AMNH FARB 1555) identified FHSM VP-3 as the most mature 398 individual. Optimized synontomorphies that support each node (i.e., growth stage) are listed in 399 Table 3, and character states that were unambiguously optimized as individual variation are 400 listed in Table S3. The following growth stages are recovered based on the unambiguously 401 optimized synontomorphies that support each node on the ontogram:

402

403

404

405

406

407

408

409

410

411

412

413

414

415

416

417

418

419

420

421

422

423

424

425

426

427

428

429

430

431

432

433

434

435

Stage 1. This stage is recovered as sister to the other specimens (exemplar: Tylosaurus sp. neonate FHSM VP-14845).

Stage 2. The $\mathrm{QH}$ is between 50 and $99 \mathrm{~mm}$ and the mandibular condyle of the quadrate is completely ossified (exemplar: CMN 51258-51263).

Stage 3. The quadrate tympanic ala is thick (Fig. 6) (exemplar: AMNH FARB 1592).

Stage 4. The quadrate alar concavity is shallow (Fig. 6) (exemplar: FMNH UR902).

Stage 5. The occipital condyle is completely ossified (exemplar: AMNH FARB 2160).

Stage 6. The foramina on the premaxillary rostrum are small (Fig. 7) (exemplar: RMM 5610).

Stage 7. The premaxilla-maxilla suture is m-shaped (Fig. 8) and the mandibular condyle of the quadrate is rounded (Fig. 6) (exemplar: KUVP 66129).

Stage 8. The infrastapedial process of the quadrate is rounded (Fig. 6) (exemplar: CMN 8162).

Stage 9. The $\mathrm{QH}$ is $\geq 13 \% \mathrm{TSL}$ and the dentary is deep (i.e., $\leq 6$ times longer than tall) (exemplars: AMNH FARB 4909, KUVP 28705, KUVP 1033, and TMP 1982.050.0010). At this stage, the exemplar specimens share a distance between the first and sixth dentary teeth that is $\leq$ $23 \%$ TSL and $\leq 35 \%$ dentary length; KUVP 28705, KUVP 1033, and TMP 1982.050.0010 share a reversal to foramina on the premaxillary rostrum that are large and frontal medial suture flanges that are large (Fig. 9); and KUVP 1033 and TMP 1982.050.0010 share a TSL that is between 800 and $999 \mathrm{~mm}$.

Stage 10. The frontal posterolateral processes are thick (Fig. 10) and the dorsal ridge on the predental process of the dentary is present (Fig. 11) (exemplars: USNM 6086 and USNM 8898).

Stage 11. This stage is diagnosed by a TSL that is between 1000 and $1499 \mathrm{~mm}$, a QH that is between 150 and $199 \mathrm{~mm}$, and a dentary length that is $\leq 55 \%$ lower jaw length (exemplar: FFHM 1997-10). 
436

437

438

439

440

441

442

443

444

445

446

447

448

449

450

451

452

453

454

455

456

457

458

459

460

461

462

463

464

465

466

467

468

469

470

471

472

473

Stage 12. The premaxillary rostrum is distinctly knobbed (Fig. 7) (exemplar: KUVP 50090).

Stage 13. The distance between the first and sixth dentary teeth is $\leq 23 \%$ TSL (exemplar: KUVP 1032).

Stage 14. The quadrate suprastapedial process is thick (Fig. 6) (exemplars: ROM 7906, GSM 1, and AMNH FARB 221). At the stage, the exemplar specimens share a distance between the first and sixth maxillary teeth that is $\geq 25 \%$ TSL and a reversal to a QH between 100 and $149 \mathrm{~mm}$.

Stage 15. The distance between the first and sixth dentary teeth is $\leq 35 \%$ dentary length, a reversal to a dentary length that is between 60 and 56\% lower jaw length, and the coronoid posteroventral process is present and fan-like (Fig. 12) (exemplar: FMNH P15144).

Stage 16. This stage is not unambiguously diagnosed by any character states, but the node is ambiguously supported by a reversal to a premaxilla-maxilla suture that is u-shaped and a deep dentary (exemplar: AMNH FARB 1555).

Stage 17 This stage is diagnosed by a reversal to a quadrate alar concavity that is deep (Fig. 6) (exemplar: FHSM VP-3).

\section{Growth Series of T. kansasensis and T. nepaeolicus}

One ontogram was recovered with a length of 87 steps, a CI of 0.59 , an HI of 0.41 , an RI of 0.62 , and an RC of 0.36 (Fig. 13). The tree topology was assessed using a Bremer decay index approach, and resolution was lost after the addition of one step. A total of 12 growth stages were identified; the analysis with the artificial adult and all 19 specimens recovered YPM 3970 and FHSM VP-2209 as the most mature individuals (a comparison of the number of growth changes could not determine which of these two specimens is the most mature). Notably, although the holotype of T. nepaeolicus is recovered as more mature (stage 9) than the holotype of $T$. kansasensis (stage 8), there are no unambiguously optimized synontomorphies that distinguish them (Fig. 13, Table 4). Optimized synontomorphies that support each growth stage are listed in Table 4, and character states that were unambiguously optimized as individual variation are listed in Table S3. The following growth stages are recovered based on the unambiguously optimized synontomorphies that support each node on the ontogram:

Stage 1. This stage is recovered as sister to the other specimens (exemplar: Tylosaurus sp. neonate FHSM VP-14845). 
474 Stage 2. This stage is not unambiguously diagnosed by any character states, but the node is

475 ambiguously supported by a quadrate tympanic ala that is thick and shallow (exemplar: $T$.

476 kansasensis FHSM VP-17206).

477

478

479

480

481

482

483

484

485

486

487

488

489

490

491

492

493

494

495

496

497

498

499

500

501

502

503

504

505

506

507

508

509

510

511

512

Stage 3. The premaxilla-maxilla suture is u-shaped (Fig. 8) (exemplars: T. kansasensis FHSM VP-9350 and T. kansasensis FHSM VP-2495). At this stage, the exemplar specimens share a deep dentary.

Stage 4. The foramina on the premaxillary rostrum are small (Fig. 7) and the quadrate mandibular condyle is rounded (exemplar: T. kansasensis FHSM VP-78).

Stage 5. The QH is $\geq 13 \% \mathrm{TSL}$, the quadrate ala rim is defined, and the dorsal ridge on the predental process of the dentary is present (Fig. 11) (exemplar: T. kansasensis FHSM VP15632).

Stage 6. The QH is between 50 and $99 \mathrm{~mm}$ and the quadrate mandibular condyle is completely ossified (exemplar: T. kansasensis FHSM VP-3366, T. kansasensis FHSM VP-18520, and $T$. nepaeolicus FHSM VP-7262). At this stage, the exemplar specimens share a decrease in dentary teeth (from 13 to 12 ).

Stage 7. The foramina on the premaxillary rostrum reverse from small to large (exemplar: $T$. kansasensis FHSM VP-15631).

Stage 8. The posteroventral angle of the jugal is obtuse and the coronoid posteroventral process is present as a bump (Fig. 12) (exemplar: T. kansasensis holotype FHSM VP-2295).

Stage 9. This stage is not unambiguously diagnosed by any character states, but the node is ambiguously supported by parietal lateral borders that are straight (exemplar: T. nepaeolicus holotype AMNH FARB 1565).

Stage 10. The quadrate suprastapedial process is thick (Fig. 6) and the coronoid anterolateral notch is present and shallow (exemplars: T. kansasensis FMNH PR2103, T. kansasensis FGM V43, and T. nepaeolicus AMNH FARB 2167). At this stage, the exemplar specimens share a quadrate suprastapedial process that is not curved medially, and FGM V-43 and AMNH FARB 2167 share a quadrate suprastapedial process that is long.

Stage 11. The premaxillary rostrum is distinctly knobbed (Fig. 7), the frontal posterolateral processes are thick (Fig. 9), and there is an increase in dentary teeth (from 13 to 14) (exemplars: T. nepaeolicus YPM 3974 and T. nepaeolicus AMNH FARB 124/134). At this stage, the 
513 exemplar specimens share an absence of the parietal nuchal fossa and a distance between the first 514 and sixth dentary teeth that is greater than $35 \%$ dentary length.

515

516

Stage 12. This stage is diagnosed by a QH that is between 100 and $149 \mathrm{~mm}$ (exemplars: $T$.

517 nepaeolicus YPM 3970 and T. nepaeolicus FHSM VP-2209).

518

519

Analysis Including T. kansasensis, T. nepaeolicus, and T. proriger

520

Because the synonymy of T. kansasensis and T. nepaeolicus is supported, a data matrix including

521 all three Tylosaurus taxa was analyzed (Data S4). Two most parsimonious trees were recovered,

522 each with a length of 145 steps, a CI of 0.40 , an HI of 0.60 , an RI of 0.60 , and an RC of 0.24

523 (Fig. 14). The tree topology was assessed using a Bremer decay index approach, and resolution

524 was lost after the addition of one step. The analysis with the artificial adult and all 30 specimens

525 did not recover a single most mature individual, but it did identify the group of adult $T$. proriger

526

527 as more mature than that of T. nepaeolicus; a second analysis, which only included the nine individuals that were recovered as sister to the artificial adult in the analysis with all 30

528 specimens (KUVP 1032, KUVP 50090, USNM 8898, FFHM 1997-10, FMNH P15144, ROM 7906, AMNH FARB 221, FHSM VP-3, and KUVP 5033) identified FHSM VP-3 and KUVP 5033 as more mature than the others, and a comparison of the number of growth changes identified KUVP 5033 as the most mature individual.

532

Most of the specimens recovered by this analysis as relatively immature (stages 1 through

533 8) are $T$. proriger and are individuals that were also recovered as relatively immature (i.e., in the

534 lower two thirds of the ontogram) in the individual analysis (Fig. 5). All but two T. kansasensis

535

536 are recovered at growth stages 8 and 9, and all but one specimen referred to T. nepaeolicus are recovered at stage 10. Finally, the most mature individuals (stages 11 through 13) are all large

537

538 (i.e., TSL greater than $1000 \mathrm{~mm}$ and QH greater than $150 \mathrm{~mm}$ ) T. proriger, and all but three were recovered as relatively mature (i.e., in the upper third of the ontogram) in the individual

539 analysis (Fig. 5). Optimized synontomorphies that support each growth stage are listed in Table

540 5 , and character states that were unambiguously optimized as individual variation are listed in

541 Table S4. The following growth stages are recovered based on the unambiguously optimized

542

543

544 synontomorphies that support each node on the ontogram:

Stage 1. This stage is recovered as sister to the other specimens (exemplar: Tylosaurus sp.

545 neonate FHSM VP-14845).

546

547 Stage 2. The quadrate tympanic ala is thick (Fig. 6) (exemplar: T. kansasensis FHSM VP548 9350).

549

550

Stage 3. The $\mathrm{QH}$ is between 50 and $99 \mathrm{~mm}$, the quadrate infrastapedial process is present (Fig. 6 ), the quadrate ala rim is defined, and the quadrate mandibular condyle is completely ossified

552 (exemplars: T. proriger FMNH UR902 and T. proriger AMNH FARB 1592). 
553

554

555

556

557

558

559

560

561

562

563

564

565

566

567

568

569

570

571

572

573

574

575

576

577

578

579

580

581

582

583

584

585

586

587

588

589

590

591

Stage 4. The quadrate suprastapedial process that is intermediate in length (exemplars: $T$. nepaeolicus holotype AMNH FARB 1565 and T. proriger RMM 5610).

Stage 5. The quadrate mandibular condyle is rounded (Fig. 6) (exemplars: T. proriger KUVP 66129).

Stage 6. The premaxillary rostrum is $\geq 5 \% \mathrm{TSL}$, the quadrate infrastapedial process is rounded (Fig. 6), QH is $\geq 13 \%$ TSL, the parietal nuchal fossa is present, and the distance between the first and sixth dentary teeth is $\leq 23 \%$ TSL (exemplar: T. proriger AMNH FARB 4909).

Stage 7. The foramina on the premaxillary rostrum are large (Fig. 7), the frontal-parietal suture flanges are small (Fig. 9), the jugal posteroventral process is present, and the dentary length is between 60 and 56\% lower jaw length (exemplar: T. proriger KUVP 1033).

Stage 8. The parietal posterior pegs are present and small and the pterygoid ectopterygoid process is thick (Fig. 15) (exemplars: T. proriger KUVP 28705, T. kansasensis FGM V-43, T. kansasensis holotype FHSM VP-2295, T. kansasensis FHSM VP-15632, and T. kansasensis FHSM VP-78). At this stage, all four T. kansasensis share a reversal to a premaxillary rostrum that is less than 5\% TSL and FHSM VP-2295, FHSM VP-15632, and FHSM VP-78 share a reversal to a quadrate infrastapedial process that is absent.

Stage 9. This stage is diagnosed by a reversal to frontal-parietal suture flanges that are large and a dentary length that is $\leq 55 \%$ lower jaw length (exemplars: T. kansasensis FHSM VP-15631 and T. kansasensis FHSM VP-2495).

Stage 10. The premaxillary rostrum is distinctly knobbed (Fig. 7), the frontal posterolateral processes are thick (Fig. 10), there is a reversal to parietal posterior pegs that are absent, and the coronoid anterolateral notch is present and shallow (exemplars: T. nepaeolicus YPM 3974, T. nepaeolicus AMNH FARB 124/134, T. nepaeolicus FHSM VP-2209, T. nepaeolicus FHSM VP7262, and T. kansasensis FMNH PR2103). At this stage, the exemplar specimens share a quadrate infrastapedial process that is subtle and pointed (Fig. 6), parietal lateral borders that are straight (Fig. 16), and 14 dentary teeth.

Stage 11. The TSL is between 1000 and $1499 \mathrm{~mm}$ and the QH is between 150 and $199 \mathrm{~mm}$ (exemplars: T. proriger KUVP 1032, T. proriger KUVP 50090, T. proriger USNM 8898, $T$. proriger FFHM 1997-10, T. proriger FMNH P15144, T. proriger ROM 7906, and T. proriger AMNH FARB 221). At this stage, the exemplar specimens share a premaxilla-maxilla suture that is m-shaped (Fig. 8), and the relatively mature individuals (as recovered by the individual

Peer] reviewing PDF | (2020:05:49148:2:0:NEW 11 Sep 2020) 
592 analysis (Fig. 5); FMNH P15144, ROM 7906, and AMNH FARB 221) share a reversal to a 593 slender dentary.

594

595

596

Stage 12. The quadrate alar concavity is deep (Fig. 6) and the coronoid posteroventral process is present and fan-like (Fig. 12) (exemplar: T. proriger FHSM VP-3).

597

598

599

Stage 13. This stage is diagnosed by a TSL that is $\geq 1500 \mathrm{~mm}$ and a QH that is $\geq 200 \mathrm{~mm}$

600

\section{1}

602

603

604 (exemplar: T. proriger KUVP 5033).

605

\section{Congruence Between Size and Maturity}

When the analyses were run excluding size characters, resolution was lost but the same relative positions of specimens on the ontograms was recovered (Supplemental Figure S1D-I).

606 Scatterplots of size rank (TSL and QH) and growth rank data (Tables S5, S6, S7) that were used in the Spearman rank-order correlation tests are shown in Figures 17 through 19. A Shapiro-Wilk test was used to determine if there was sampling bias (i.e., skewed left or right) and revealed that

608 all the growth rank, size rank, and measurement data, except for $\mathrm{QH}$ growth rank data for $T$.

609 nepaeolicus, are normally distributed (Figs. 17, 18, 19). The Spearman rank-order test found a significant correlation between growth stage and both measures of size in $T$. proriger and $T$. nepaeolicus, both in the individual analyses (Figs. 17, 18) and the analysis used to test for anagenesis (Fig. 19). All correlations between size and maturity are positive. Therefore, both TSL and QH and maturity usually covary in Tylosaurus.

614

615

616

\section{Discussion}

617 The growth series of $T$. proriger has two bifurcations, at stages nine and 14 (Fig. 5). The

618 bifurcation at stage 14, in which three specimens share a distance between the first and sixth 619 maxillary teeth that is $\geq 25 \%$ TSL and a reversal to a QH between $100-149 \mathrm{~mm}$, does not meet 620 the criteria of Frederickson \& Tumarkin-Deratzian (2014) for sexual dimorphism. The group of 621 specimens at stage nine share a distance between the first and sixth dentary teeth that is $\leq 23 \%$ 622 TSL and $\leq 35 \%$ dentary length, which develop independently at stages 13 and 15 , respectively; 623 however, none of the growth characters separating the specimens at stage nine from those at 624 stages ten through 17 are obviously correlated with any kind of sexual display (e.g., thickening 625 of the quadrate suprastapedial and frontal posterolateral processes, presence of dentary predental 626 dorsal ridge, and knobbed premaxillary rostrum). If, however, these characters are correlated 627 with being larger, it is possible that $T$. proriger was sexually dimorphic with respect to size-the 628 TSL of the specimens at stage nine range from $610 \mathrm{~mm}$ to $813 \mathrm{~mm}$ (average: $712 \mathrm{~mm}$ ), whereas 629 the TSL of specimens from stage ten to stage 17 are generally larger, ranging from $585 \mathrm{~mm}$ to $6301300 \mathrm{~mm}$ (average: $1032 \mathrm{~mm}$ ). 
631

632

633

634

635

636

637

638

639

640

641

642

643

644

645

646

647

\section{8}

649

650

651

652

653

654

655

656

657

658

659

660

661

662

663

664

665

666

667

668

669

The major growth changes of $T$. proriger are: development of processes on the premaxilla (Fig. 7), frontal (Fig. 10), jugal, pterygoid (Fig. 15), quadrate (Figs. 6, 20), coronoid (Fig. 12), and dentary (Fig. 11); decrease in premaxillary foramina size (Fig. 7); change in shape of the premaxilla-maxilla suture (Fig. 8); ossification of the quadrate and basioccipital; enlargement of tooth crowns relative to skull size; and a progressive deepening and enlargement of the skull. The identification of RMM 5610 as a young individual in previous work is supported, but the identification (e.g., Jiménez-Huidobro, Simões, \& Caldwell, 2016; Stewart \& Mallon, 2018; Jiménez-Huidobro \& Caldwell, 2019) of AMNH FARB 4909 as a relatively mature individual is not (Fig. 5).

The Spearman rank-order test revealed a significant correlation between size rank and growth stage rank for both TSL $\left(r_{S(0.05,18)}=0.824, p<0.001\right)$ and QH $\left(r_{S(0.05,17)}=0.897, p<\right.$ 0.001 ), suggesting that both measures are reliable proxies for relative maturity in $T$. proriger (Fig. 17). This result is unexpected, given the oversampling of relatively mature individuals: apart from the Tylosaurus sp. neonate (FHSM VP-14845), this analysis only includes large (TSL greater than $500 \mathrm{~mm}$ ) individuals. The correlation between size and maturity can be tested with the addition of significantly smaller, presumably less mature, specimens.

\section{Growth Series of T. kansasensis and T. nepaeolicus}

The ontogram does not bifurcate and so it does not show evidence for sexual dimorphism, whereas the synonymy of T. kansasensis with T. nepaeolicus (Jiménez-Huidobro, Simões, \& Caldwell, 2016) is supported (Figs. 3, 4, 13). Most significantly, many of the diagnostic characters for T. kansasensis (Everhart, 2005) that could be identified (premaxilla foramina size, quadrate infrastapedial process, frontal midline crest, jugal posteroventral angle, quadrate ala thickness, quadrate alar concavity depth) were found to be immature characters and were also present in both $T$. nepaeolicus and T. proriger. Therefore, both taxa will be referred to as $T$. nepaeolicus henceforth. Although synonymy is supported, previous hypotheses of growth patterns are not, given that $T$. kansasensis specimens are interspersed among those of $T$. nepaeolicus at the terminus of the ontogram. Notably, the holotype of T. nepaeolicus (stage 9) is recovered as more mature than the holotype of T. kansasensis (stage 8) (Fig. 13); their separation is ambiguously supported by straight lateral borders of the parietal (Table 4).

The major growth trends in T. nepaeolicus include: enlargement of processes on the premaxilla (Fig. 7), frontal (Fig. 10), quadrate (Figs. 6, 20), coronoid (Fig. 12), and dentary (Fig. 11); change in shape of the quadrate (Figs. 6, 20) and pterygoid (Fig. 15); changes in size of the premaxillary foramina (Fig. 7); change in shape of the premaxilla-maxilla suture (Fig. 8); ossification of the quadrate; enlargement of tooth crowns relative to skull size; and an increase in the number of dentary teeth by one.

The Spearman rank-order test revealed a significant correlation between size rank and growth stage rank for TSL $\left(r_{S(0.05,8)}=0.874, p=0.005\right)$ and $\mathrm{QH}\left(r_{S(0.05,15)}=0.719, p=0.003\right)$, suggesting that both are reliable proxies for relative maturity in this taxon (Fig. 18). Unlike $T$.

Peer] reviewing PDF | (2020:05:49148:2:0:NEW 11 Sep 2020) 
670 proriger, multiple specimens in this dataset are relatively small (TSL less than $500 \mathrm{~mm}$, QH less

671 than $50 \mathrm{~mm}$ ), suggesting a better representation of immature individuals than in T. proriger.

672

673 Paedomorphy in T. proriger. Paedomorphy is the truncation of development in a descendent 674 taxon relative to an ancestral taxon (Reilly, Wiley, \& Meinhardt, 1997). In the analysis including

675 all three taxa, the lateral borders of the parietal table (Fig. 16) are straight in the relatively mature 676 specimens of T. nepaeolicus (YPM 3974, AMNH FARB 124/134, FHSM VP-2209, FHSM VP677 7262, and FMNH PR2103; Table S4), whereas they are distinctly convex in relatively immature 678 T. nepaeolicus and all T. proriger. Jiménez-Huidobro, Simões, \& Caldwell (2016) suggested that 679 the borders become straight in mature individuals due to elongation of the bone; truncation of 680 this lengthening in T. proriger is consistent with the hypothesis of paedomorphy. Therefore, 681 paedomorphy of this character in T. proriger is not rejected, but future work investigating this 682 character (parietal lateral border shape) in other taxa (e.g., an outgroup to Tylosaurus) is 683 necessary to thoroughly test this hypothesis.

684 Absence of the frontal dorsal midline crest was recovered as ambiguously diagnostic of 685 stage 11 in the ontogram of T. nepaeolicus (Table 4), and both specimens in which the crest is 686 absent (AMNH FARB 124/134 and YPM 3974; Data S2) are recovered as relatively mature 687 individuals (Fig. 13). However, given that the crest is only absent in two T. nepaeolicus 688 specimens out of the 35 that were scored, more data are necessary to test the hypothesis of 689 paedomorphy of this character in T. proriger. If the addition of more characters and specimens of 690 T. nepaeolicus recovers absence of the crest as an unambiguously mature character, then the 691 addition of basal mosasaurs, such as the mosasauroid Aigialosaurus, as well as other derived 692 russelosaurine taxa (e.g., Plioplatecarpus) can help to trace the evolution of frontal crest 693 development across the clade and for a more rigorous test of the hypothesis of paedomorphy of 694 this character in $T$. proriger.

695

696

697

698

699

700

701

702

703

704

705

706

707

708

709

\section{Anagenesis in T. nepaeolicus and T. proriger}

The ontogram recovered by the analysis of both species supports the hypothesis of anagenesis in the clade (Fig. 14). The least mature individuals in the ontogram are nearly all relatively immature $T$. proriger, the specimens of intermediate maturity are relatively mature $T$. nepaeolicus, and the most mature individuals are large, relatively mature $T$. proriger. Furthermore, the placement of all but one T. kansasensis as less mature than T. nepaeolicus and among immature $T$. proriger is consistent with the hypothesis that $T$. kansasensis are juvenile $T$. nepaeolicus.

Several growth changes recovered in this analysis were also recovered in the individual analyses: thickening of the quadrate ala, quadrate mandibular condyle ossifies and becomes rounded, QH increases relative to TSL, premaxilla rostrum foramina size changes, and the frontal posterolateral processes thicken. Finally, the knobbed premaxillary rostrum (Fig. 7) after which the genus is named develops relatively late in ontogeny (at stage 11 in both individual analyses, and stage 10 in the analysis with all three taxa); therefore, not only is this character 
710 unique to Tylosaurus, but to the late stages of its growth, and so it is possible that young animals

711 lacking this feature may be misidentified.

$712 \quad$ Anagenesis in WIS Tylosaurus was driven by peramorphosis (acceleration and/or

713 extension of growth) in the following characters: skull size (TSL) and depth (QH) (Fig. 19),

714 premaxillary rostrum length (greater than 5\% TSL does not occur until relatively late in

715 ontogeny in T. nepaeolicus, whereas it is present in immature T. proriger), overall quadrate

716 shape (Figs. 6, 20; the quadrates of the most mature T. nepaeolicus, e.g. AMNH FARB 124/134,

717 are morphologically most similar to immature $T$. proriger, e.g. FMNH UR902), quadrate

718 suprastapedial process thickness, and coronoid posteroventral process shape (from single bump

719 to fan-like; Fig. 12). One character, lateral borders of the parietal table (Fig. 16), appears to be

720 paedomorphic in $T$. proriger, given that it is distinctly convex in all $T$. proriger specimens as

721 well as immature $T$. nepaeolicus, and nearly straight in relatively mature $T$. nepaeolicus. The

722 hypothesis of anagenesis in North American Tylosaurus can be further tested by recovering

723 growth series for $T$. saskatchewanensis and T. pembinensis, which lived after T. proriger during

724 the middle Campanian (Jiménez-Huidobro \& Caldwell, 2019).

725

726

727

Revised diagnoses of T. nepaeolicus and T. proriger. Based on the growth patterns

728 uncovered by this work (Figs. 5, 14, 20), the following revisions to the diagnoses of T. proriger

729 by Jiménez-Huidobro and Caldwell (2019) are proposed: (1) premaxilla-maxilla suture ends

730 posterior to the fourth maxillary tooth; (2) the overall shape of the quadrate is columnar and

731 distinctly taller than wide throughout growth; (3) quadrate infrastapedial process is well-

732

733 developed and is subtle and pointed in juveniles and distinct, broad, and semicircular in adults; (4) quadrate tympanic ala is thin, wide, and flat throughout growth; (5) lateral borders of parietal table distinctly convex; (6) 13 maxillary teeth; (7) 13 dentary teeth; and (8) ten pterygoid teeth. Based on the growth patterns uncovered by this work (Figs. 13, 14, 20), the following revisions to the diagnoses of T. nepaeolicus by Jiménez-Huidobro and Caldwell (2019) are proposed: (1) premaxilla-maxilla suture ends posteriorly above midpoint between third and fourth maxillary teeth; (2) frontal dorsal midline crest generally present except in some relatively mature individuals; (3) lateral borders of parietal table convex in immature individuals and slightly convex to straight in mature individuals; (4) the overall shape of the quadrate is semicircular and hook-like in immature individuals, and relatively more dorsoventrally elongate

742 in mature individuals; (5) quadrate infrastapedial process absent in juveniles and present but poorly developed in adults; (6) 12 to 13 maxillary teeth; and (7) eight to ten pterygoid teeth in

744 adults, possibly 11 or more in juveniles.

746

747

748

749

\section{Sexual Dimorphism}

The growth series did not recover evidence of skeletal sexual dimorphism in either species. This does not necessarily mean that Tylosaurus was not sexually dimorphic, only that the characters in this analysis are not dimorphic or the sample size (i.e., number of specimens) is too low for a clear pattern to be recovered (Hone et al., 2020). The hypothesis that the premaxillary predental 
750

751

752

753

754

755

756

757

758

759

760

761

762

763

764

765

766

767

768

769

770

771

772

773

774

775

776

777

778

779

780

781

782

783

784

785

786

787

788

789

rostrum is an ontogenetic, but not sexual, characteristic in Tylosaurus (Konishi, JiménezHuidobro, \& Caldwell, 2018) was not rejected. These results are consistent with the absence of evidence for sexual dimorphism in any mosasaur, which itself is somewhat surprising given the frequency of sexual dimorphism in extant squamates (Schwarzkopf, 2005; Aplin, Fitch, \& King, 2006; Openshaw \& Keogh, 2014), including ocean-going species such as sea snakes and marine iguanas (Wikelski \& Trillmich, 1997; Shine et al., 2002). Excluding size, examples of sexually dimorphic characters in extant squamates include head width, trunk length (i.e., number of presacral vertebrae), and limb length (Schwarzkopf, 2005). The absence of morphological sexual dimorphism in mosasaurs will be tested further with the addition of more growth charactersespecially from the postcranial skeleton-as well as more specimens and taxa.

It is also possible that sexual dimorphism in mosasaurs could be present in histological data. In 2010, Frynta et al. found that adult male monitor lizards (Varanus indicus) are larger than females because the period of rapid growth is extended; if this is also the case in mosasaurs, these differences in growth rates are seen in histological analyses of limb bones (Pellegrini, 2007; Green, 2018). Another instance of sexual dimorphism in extant monitor lizards is bone density: in males, density tends to increase over time, whereas in females it decreases (de Buffrénil \& Francillon-Vieillot, 2001). However, because this decrease in females is caused by skeletal calcium being used to produce eggshells, this is unlikely to be seen in mosasaurs, which gave live birth (Caldwell \& Lee, 2001; Field et al., 2015).

\section{Cladistic Analysis of Growth as a Method to Test Taxon Validity}

Besides traditional comparison of morphological characters, no thorough, objective tests of taxon validity using growth data have been attempted for any mosasaur taxon to date. By recovering growth changes and identifying instances of individual variation in multiple taxa, cladistic analysis of growth provides a robust and independent test of taxon validity and the characters that purportedly diagnose them. Taxon validity is a major problem in mosasaurs for multiple reasons, including insufficient descriptions and later loss or destruction of type specimens, paraphyly of genera, poor stratigraphic data, incompleteness of specimens, and past researchers' desire to name as many species as possible (Lively, 2019). This problem is only made worse by a lack of growth studies that include morphological data, which could be contributing to purported differences between taxa, and a general deficiency of recent hypothesis-driven work.

For example, Mosasaurus is a particularly problematic group with respect to taxonomy and for which this approach could prove very useful in determining which species are valid and which are not. Mulder (1999) proposed that M. maximus-found along the east coast of the United States-and M. hoffmannii-found in western Africa, Russia, and across Europe-are a single, transatlantic taxon based on many morphological similarities. In addition to M. maximus, two other Mosasaurus taxa, M. lemonnieri and M. conodon, have been proposed to be synonymous with M. hoffmannii (Russell, 1967; Lingham-Soliar, 1995; Lingham-Soliar, 2000; Ikejiri \& Lucas, 2015; Street \& Caldwell, 2017); specimens of M. lemonnieri in particular have the potential to represent immature $M$. hoffmannii, given that the only major difference between

Peer) reviewing PDF | (2020:05:49148:2:0:NEW 11 Sep 2020) 
790

791

792

793

794

795

796

\section{7}

798

799

800

801

802

803

804

805

806

807

808

809

810

811

812

813

814

815

816

817

818

819

820

821

822

823

824

825

826

827

828

829

them is that the skull of M. lemonnieri is generally smaller (around $500 \mathrm{~mm}$-a size currently underrepresented in $M$. hoffmannii) and more slender than that of M. hoffmannii (LinghamSoliar, 2000). By using a single cladistic analysis of growth including specimens of all Mosasaurus species for which synonymy has been proposed, as was done in this project for $T$. kansasensis and T. nepaeolicus, these hypotheses can be tested, refining our understanding of mosasaur growth as well as their actual diversity in the Late Cretaceous.

\section{Conserved Patterns of Growth in Tylosaurus and Future Works}

The cladistic analyses of ontogeny identified 11 growth characters shared by both species; these characters are: (1) premaxilla rostrum becomes distinctly knobbed; (2) change in premaxillary rostrum foramina size; (3) change in premaxilla-maxilla suture shape; (4) increase in QH; (5) thickening of quadrate suprastapedial process; (6) increase in QH relative to TSL; (7) ossification of the quadrate mandibular condyle; (8) mandibular condyle of the quadrate becomes rounded; (9) thickening of frontal posterolateral processes; (10) development of a dorsal ridge on the predentary process of the dentary; and (11) growth of the coronoid posteroventral process.

These results reject previous hypotheses that variation of mosasaur quadrates is ontogenetically uninformative (e.g., Jiménez-Huidobro, Simões, \& Caldwell, 2016; Stewart \& Mallon, 2018), where both species show unambiguous changes to the shape of the quadrate and its processes throughout growth (Figs. 6, 20). This suggests that the quadrate-particularly the thickness of the suprastapedial process, depth and thickness of the tympanic ala, and the presence and shape of the infrastapedial processes-should not be used to diagnose mosasaur taxa without an assessment of maturity. These results are not surprising, given that growth variation is seen in the quadrates of extant squamates (Paluh, Olgun, \& Bauer, 2018). Because the shape of the quadrate in squamates is directly related to hearing ability and skull kinesis (LeBlanc, Caldwell, \& Lindgren, 2013; Paluh, Olgun, \& Bauer, 2018; Palci et al., 2019), future work is necessary to investigate the potential for niche partitioning between mosasaur growth stages.

Although size and maturity covary in both species, there is clearly an oversampling of relatively mature individuals, where multiple individuals are recovered at the same growth stage (Figs. 5, 13, 14). Therefore, more characters must be identified to test these low-resolution results. Several skulls in this project have associated vertebrae and limb bones; future work including histological data could be used to calibrate the growth series recovered here to chronological age and further test hypotheses of the relationship between size, maturity, and age as well as sexual dimorphism and ontogenetic niche partitioning (Wiffen et al., 1995; de Buffrénil \& Francillon-Vieillot, 2001; Pellegrini, 2007; Frynta et al., 2010; Houssaye \& Tafforeau, 2012; Green, 2018).

The size of the foramina on the premaxillary rostrum (Fig. 7) were recovered as ontogenetically variable. Recent work on the tylosaurine Taniwhasaurus antarcticus has found internal branching structures, hypothesized to be part of the neurovascular system, associated with these foramina (Álvarez-Herrera, Agnolin, \& Novas, 2020). Future work can investigate whether these internal structures are also present in other mosasaurs, including Tylosaurus, 
830 whether they vary with growth as well, and, if so, whether these variations in size have 831 functional implications.

832 No pattern of ontogenetic change in pterygoid tooth count was recovered in these 833 analyses, however, the number of pterygoid teeth could potentially be indicators of relative 834 maturity in mosasaurs, given that their presence and number vary ontogenetically in extant 835 lizards (Barahona \& Barbadillo, 1998; Skawiński, Borczyk, \& Turniak, 2017). Mosasaur 836 pterygoid teeth have largely been ignored in the literature with respect to both ontogeny and 837 phylogeny, and so future studies that include them are necessary to better understand their 838 relevance to mosasaur development and evolution, and whether intraspecific differences in the 839 number of pterygoid teeth represent growth, sexual, or individual variation. For example, a basal

840

841

842

843

844

845

846

847

848

849

850

851

852

853

854

855

856

857

858

859

860

861

862

863

864

865

866

867

868

869 russelosaurine, Tethysaurus nopcsai, has nearly double the number of pterygoid teeth than both species of Tylosaurus (Bardet, Suberbiola, \& Jalil, 2003), and a relatively immature $T$.

nepaeolicus specimen (FHSM VP-15632) has more pterygoid teeth (at least 11) than more mature specimens (usually between eight and ten; Table 2).

\section{Synthesis of ontogeny and phylogeny. Despite many studies that have investigated} mosasaur phylogeny (e.g., Russell, 1967; Bell, 1997; Simões et al., 2017; Jiménez-Huidobro \& Caldwell, 2019), the evolutionary relationships within Mosasauroidea remain unclear. In order to completely investigate ancestral patterns of growth in mosasaurs, growth series for basal mosasaurs, such as Aigialosaurus, as well as more derived taxa spanning a greater breadth of the phylogeny (e.g., Mosasaurus, Clidastes, Platecarpus, Prognathodon) must be recovered. Once they are identified, ontogenetic changes that are unique to a taxon can help to recover evolutionary relationships (i.e., growth changes can be used as phylogenetic characters) (Bhullar, 2012); therefore, the identification of shared growth characters can provide evidence to support or reject current hypotheses of relationships between mosasaurs and their extant relatives.

For example, one growth character recovered in this project-decrease of the posteroventral angle of the jugal in T. nepaeolicus throughout growth-was found by Bhullar (2012) to be apomorphic of Varanoidea. Despite the ambiguity with respect to the position of Mosasauroidea within Squamata (Russell, 1967; Carrol \& DeBraga, 1992; Caldwell, Carroll, \& Kaiser, 1995; Lee, 1997; Caldwell, 1999; Gauthier et al., 2012; Reeder et al., 2015; Simões et al., 2017), this character is almost certainly plesiomorphic in the common ancestor of Varanoidea and Mosasauroidea. Furthermore, the recovery of shared patterns of growth that unite mosasaurs with their extant relatives has the potential to provide a comparative point of reference for predicting the growth patterns of fossil taxa with low sample sizes (Witmer, 1995; Bhullar, 2012).

With the addition of extant relatives (e.g., monitor lizards, iguanas, and snakes), ontogenetic data can also be used to hypothesize the phylogenetic position of Mosasauroidea and identify the potential heterochronic processes that shaped the land-sea transition of mosasaur ancestors. For example, in squamates, the overall shape of an animal's quadrate is related to what type of habitat it occupies (e.g., terrestrial, aquatic, or fossorial) (Palci et al., 2019), and 
870 squamate quadrates change in shape throughout ontogeny (Fig. 20; Bhullar, 2012; Paluh, Olgun, $871 \&$ Bauer, 2018). Therefore, through the comparison of patterns of growth between extant

872 terrestrial and semi-aquatic squamates to those seen across Mosasauroidea, the changes in 873 quadrate shape that facilitate the transition from land to sea could be traced.

874 Finally, comparison of growth patterns with other secondarily aquatic taxa, both extant

875 (e.g., sirenians, pinnipeds, cetaceans, turtles) and extinct (e.g., thalattosuchians, plesiosaurs, 876 ichthyosaurs), is necessary to uncover the heterochronic processes that drive amniote land-sea 877 transitions. For example, using anatomical network analysis, Fernández et al. (2020) found that 878 there are two main mechanisms by which secondarily aquatic tetrapods form fins from limbs: 879 persistence of interdigital and superficial connective tissues (seen in mosasaurs and plesiosaurs), 880 and reintegration of the digits with the mesopodium (seen in ichthyosaurs). Additionally, Schwab 881 et al. (2020) found that, in the evolution of thalattosuchians, a lineage of fully aquatic 882 crocodylomorphs, the inner ear labyrinth became more thick and compact gradually; this is 883 different from cetaceans, which evolved relatively small inner ear labyrinths very quickly, and 884 suggests that the semiaquatic phase of thalattosuchian evolution lasted longer than that of 885 cetaceans. The advantage of comparing these and other features associated with an aquatic 886 lifestyle (e.g., shortening of long bones, nostril retraction, increase in orbit size) across lineages 887 and in an ontogenetic context is that it can identify the heterochronic processes that drove each 888 transition and determine whether each instance is novel or convergent with respect to 889 fundamental developmental mechanisms.

890

891

\section{Conclusions}

893 In conclusion: (1) a growth series was recovered for both species; (2) size and growth covary in 894

895

896

897 Tylosaurus; (3) there is no evidence for skeletal sexual dimorphism in $T$. proriger or $T$. nepaeolicus; (4) synonymy of T. kansasensis with T. nepaeolicus and the hypothesis that $T$. kansasensis represent juveniles of T. nepaeolicus is supported; (5) the hypothesis that the convex lateral borders of the parietal table in T. proriger are paedomorphic relative to T. nepaeolicus is

898

899

900

901

902

903

904

905

906

907

908

909 not rejected, and it is unclear whether the presence of a frontal dorsal midline crest in $T$. proriger is paedomorphic relative to T. nepaeolicus; (6) the hypothesis that T. nepaeolicus and T. proriger are a single anagenetic lineage is supported, where speciation was driven mainly by peramorphy; (7) cranial diagnoses of $T$. proriger and T. nepaeolicus including ontogenetic context have been proposed; and (8) 11 shared growth changes were recovered for the genus Tylosaurus.

\section{Institutional Abbreviations}

AMNH, American Museum of Natural History, New York, New York; CMN, Canadian Museum of Nature, Aylmer, Quebec, Canada; FFHM, Fick Fossil and History Museum, Oakley, Kansas; FHSM, Fort Hays Sternberg Museum, Fort Hays, Kansas; FGM, Fryxell Geology Museum, Augustana College, Rock Island, Illinois; FMNH, Field Museum of Natural History, 
910 Chicago, Illinois; GSM, Georgia Southern Museum, Statesboro, Georgia; HMG, Hobetsu

911 Museum, Hokkaido, Japan; IPB, Goldfuss Museum im Institut für Paläontologie, Bonn,

912 Germany; KUVP, University of Kansas Museum of Natural History, Lawrence, Kansas;

913 LACMNH, Los Angeles County Museum, Los Angeles, California; MCZ, Museum of

914 Comparative Zoology, Harvard University, Cambridge, Massachusetts; RMM, Red Mountain

915 Museum, Birmingham, Alabama; ROM, Royal Ontario Museum, Toronto, Ontario, Canada;

916 TMM, Texas Memorial Museum, University of Texas, Austin, Texas; TMP, Royal Tyrrell

917 Museum of Palaeontology, Drumheller, Alberta, Canada; USNM, United States National

918 Museum, Washington, D. C; YPM, Yale Peabody Museum, Yale University, New Haven,

919 Connecticut.

920

921

922

923

924

925

926

927

928

929

930

931

932

933

934

935

936

937

938

\section{Acknowledgements}

I thank T. Carr for mentorship, feedback on this project, and for reviewing the manuscript prior to submission. I also thank T. Burling, T. Gamble, A. Griffing, and B. Holbach for general help, support, and advice. Additionally, I thank M. Everhart (FHSM) for having specimen photos and other resources available on his website and for clarifying information about AMNH FARB 221, FGM V-43, and KUVP 5033. For access to specimens, I thank: W. Simpson, A. Stroup (FMNH); C. Mehling, M. Norell (AMNH); S. Kornreich Wolf (FGM); C. Shelburne (FHSM); and M. Sims, A. Whitaker (KU). I also thank Carthage College for funding travel to present preliminary results of this project at both the $79^{\text {th }}$ Annual Meeting of the Society of Vertebrate Paleontology in Brisbane, Queensland, Australia, and, with permission from J. Mathews, at the $22^{\text {nd }}$ Annual PaleoFest at the Burpee Museum of Natural History in Rockford, IL. I thank J. Mallon (CMN) and T. Konishi (University of Cincinnati) for additional information about FFHM 1997-10 and CMN 8162, respectively, and P. Jiménez-Huidobro for clarifying some of the growth characters. The program TNT was made available by the Willi Hennig Society. Finally, I thank the reviewers (J. Frederickson, A. LeBlanc, T. Konishi) and the primary editor (V. Abdala) for their comments, which greatly improved the clarity and overall quality of this work.

939

940

941

\section{References}

942 Álvarez-Herrera G, Agnolin F, Novas F. 2020. A rostral neurovascular system in the mosasaur 943

944

945

946

947 948 Taniwhasaurus antarcticus. The Science of Nature 107:1-5.

Aplin, KP, Fitch AJ, King DJ. 2006. A new species of Varanus merrem (Squamata: Varanidae) from the Pilbara region of Western Australia, with observations on sexual dimorphism in closely related species. Zootaxa 1313(1313):1-38.

Barahona F, Barbadillo LJ. 1998. Inter-and intraspecific variation in the post-natal skull of some lacertid lizards. Journal of Zoology 245:393-405. 
949 Bardet N, Suberbiola XP, Jalil NE. 2003. A new mosasauroid (Squamata) from the Late

950

951

952

953

954

955

956

957

958

959

960

961

962

963

964

965

966

967

968

969

970

971

972

973

974

975

976

977

978

979

980

981

982

983

984

985

986

987

988

Cretaceous (Turonian) of Morocco. Comptes Rendus Palevol 2:607-616.

Bell GL. 1997. A phylogenetic revision of North American and Adriatic Mosasauroidea; pp. 293-332 in J. M. Callaway and E. Nicholls (eds.), Ancient Marine Reptiles. Academic Press, Cambridge, Massachusetts.

Bhullar BAS. 2012. A phylogenetic approach to ontogeny and heterochrony in the fossil record: cranial evolution and development in anguimorphan lizards (Reptilia: Squamata). Journal of Experimental Zoology Part B: Molecular and Developmental Evolution 318(7):521530.

Brinkman D. 1988. Size-independent criteria for estimating relative age in Ophiacodon and Dimetrodon (Reptilia, Pelycosauria) from the Admiral and lower Belle Plains formations of west-central Texas. Journal of Vertebrate Paleontology 8:172-180.

Brochu CA. 1996. Closure of neurocentral sutures during crocodilian ontogeny: implications for maturity assessment in fossil archosaurs. Journal of Vertebrate Paleontology 16:49-62.

Caldwell MW, Carroll RL, Kaiser H. 1995. The pectoral girdle and forelimb of Carsosaurus marchesetti (Aigialosauridae), with a preliminary phylogenetic analysis of mosasauroids and varanoids. Journal of Vertebrate Paleontology 15:516-531.

Caldwell MW. 1996. Ontogeny and phylogeny of the mesopodial skeleton in mosasauroid reptiles. Zoological Journal of the Linnean Society 116: 407-436.

Caldwell MW. 1999. Squamate phylogeny and the relationships of snakes and mosasauroids. Zoological Journal of the Linnean Society 125:115-147.

Caldwell MW, Lee MS. 2001. Live birth in Cretaceous marine lizards (mosasauroids). Proceedings of the Royal Society of London. Series B: Biological Sciences 268:23972401.

Carpenter JA. 2017. Locomotion and skeletal morphology of Late Cretaceous mosasaur, Tylosaurus proriger. University honors program thesis, Georgia Southern University, Statesboro, Georgia, 28 pp.

Carr TD. 1999. Craniofacial ontogeny in Tyrannosauridae (Dinosauria, Coelurosauria). Journal of Vertebrate Paleontology 19:497-520.

Carr TD, Williamson TE. 2004. Diversity of late Maastrichtian Tyrannosauridae (Dinosauria: Theropoda) from western North America. Zoological Journal of the Linnean Society 142:479-523.

Carr TD, Varricchio DJ, Sedlmayr JC, Roberts EM, Moore JR. 2017. A new tyrannosaur with evidence for anagenesis and crocodile-like facial sensory system. Scientific Reports 7:44942.

Carr TD. 2020. A high-resolution growth series of Tyrannosaurus rex obtained from multiple lines of evidence. PeerJ 8:e9192.

Carroll RL, DeBraga M. 1992. Aigialosaurs: mid-Cretaceous varanoid lizards. Journal of Vertebrate Paleontology 12(1):66-86.

Cope ED. 1869. Remarks on Macrosaurus proriger. In Proceedings of the Academy of Natural

Peer) reviewing PDF | (2020:05:49148:2:0:NEW 11 Sep 2020) 
989

990

991

992

993

994

995

996

997

998

999

1000

1001

1002

1003

1004

1005

1006

1007

1008

1009

1010

1011

1012

1013

1014

1015

1016

1017

1018

1019

1020

1021

1022

1023

1024

1025

1026

1027

1028

Sciences of Philadelphia 11, 123.

Cope ED. 1874. Review of the Vertebrata of the Cretaceous period found west of the Mississippi River. Bulletin of the United States Geological and Geographical Survey of the Territories/Department of the Interior 1/2, pp. 3-48.

de Buffrénil V, Francillon-Vieillot H. 2001. Ontogenetic changes in bone compactness in male and female Nile monitors (Varanus niloticus). Journal of Zoology 254:539-546.

Everhart MJ. 2005. Tylosaurus kansasensis, a new species of tylosaurine (Squamata, Mosasauridae) from the Niobrara Chalk of western Kansas, USA. Netherlands Journal of Geosciences 84:231-240.

Everhart MJ. 2017. Oceans of Kansas: A Natural History of the Western Interior Sea (second edition). Indiana University Press, Bloomington, Indiana, $490 \mathrm{pp}$.

Fernández M. S., V. Evangelos, Buono M. R., Alzugaray L., Campos L., Sterli J., Herrera Y. and Paolucci F. 2020. Fingers zipped up or baby mittens? Two main tetrapod strategies to return to the sea. Biology Letters 16:20200281.

Field DJ, LeBlanc A, Gau A, Behlke AD. 2015. Pelagic neonatal fossils support viviparity and precocial life history of Cretaceous mosasaurs. Paleontology 58:401-407.

Frederickson JA, Tumarkin-Deratzian AR. 2014. Craniofacial ontogeny in Centrosaurus apertus. PeerJ 2, e252.

Frynta D, Frýdlová P, Hnízdo J, Šimková O, Cikánová V, Velenský P. 2010. Ontogeny of sexual size dimorphism in monitor lizards: males grow for a longer period, but not at a faster rate. Zoological Science 27:917-924.

Gauthier JA, Kearney M, Maisano JA, Rieppel O, and Behlke AD. 2012. Assembling the squamate tree of life: perspectives from the phenotype and the fossil record. Bulletin of the Peabody Museum of Natural History 53:3-309.

Goloboff PA, Catalano SA. 2016. TNT version 1.5, including a full implementation of phylogenetic morphometrics. Cladistics 32:221-238.

Green CC. 2018. Osteohistology and skeletochronology of an ontogenetic series of Clidastes (Squamata: Mosasauridae): growth and metabolism in basal mosasaurids. Master's thesis, Fort Hays State University, Hays, Kansas, 51 pp.

Harrell TL, Martin JE. 2015. A mosasaur from the Maastrichtian Fox Hills Formation of the northern Western Interior Seaway of the United States and the synonymy of Mosasaurus maximus with Mosasaurus hoffmanni (Reptilia: Mosasauridae). Netherlands Journal of Geosciences 94:23-37.

Hone D, Mallon JC, Hennessey P, Witmer LM. 2020. Ontogeny of a sexually selected structure in an extant archosaur Gavialis gangeticus (Pseudosuchia: Crocodylia) with implications for sexual dimorphism in dinosaurs. PeerJ 8, e9134.

Horner JR, Varricchio DJ, Goodwin MB. 1992. Marine transgressions and the evolution of Cretaceous dinosaurs. Nature 358:59-61.

Houssaye A, Tafforeau P. 2012. What vertebral microanatomy reveals about the ecology of juvenile mosasaurs (Reptilia, Squamata). Journal of Vertebrate Paleontology 32:1042- 
10291048.

1030

1031

1032

1033

1034

1035

1036

1037

1038

1039

1040

1041

1042

1043

1044

1045

1046

1047

1048

1049

1050

1051

1052

1053

1054

1055

1056

1057

1058

1059

1060

1061

1062

1063

1064

1065

1066

1067

1068

IBM Corp. 2019. IBM SPSS Statistics for Windows, Version 26.0. Armonk, NY: IBM Corp.

Ikejiri T, Lucas SG. 2015. Osteology and taxonomy of Mosasaurus conodon Cope 1881 from the Late Cretaceous of North America. Netherlands Journal of Geosciences 94:39-54.

Jiménez-Huidobro P, Simões TR, Caldwell MW. 2016. Re-characterization of Tylosaurus nepaeolicus (Cope, 1874) and Tylosaurus kansasensis Everhart, 2005: ontogeny or sympatry? Cretaceous Research 65:68-81.

Jiménez-Huidobro P, Caldwell MW. 2019. A new hypothesis of the phylogenetic relationships of the Tylosaurinae (Squamata: Mosasauroidea). Frontiers in Earth Science 7:47.

Konishi T, Jiménez-Huidobro P, Caldwell MW. 2018. The smallest-known neonate individual of Tylosaurus (Mosasauridae, Tylosaurinae) sheds new light on the tylosaurine rostrum and heterochrony. Journal of Vertebrate Paleontology 1-11.

LeBlanc AR, Caldwell MW, Lindgren J. 2013. Aquatic adaptation, cranial kinesis, and the skull of the mosasaurine mosasaur Plotosaurus bennisoni. Journal of Vertebrate Paleontology 33:349-362.

Lee MS. 1997. The phylogeny of varanoid lizards and the affinities of snakes. Philosophical Transactions of the Royal Society of London. Series B: Biological Sciences 352:53-91.

Leidy J. 1873. Contributions to the extinct vertebrate fauna of the western territories (Vol. 1). US Government Printing Office.

Lingham-Soliar T. 1995. Anatomy and functional morphology of the largest marine reptile known, Mosasaurus hoffmanni (Mosasauridae, Reptilia) from the Upper Cretaceous, Upper Maastrichtian of the Netherlands. Philosophical Transactions of the Royal Society of London. Series B: Biological Sciences 347:155-180.

Lingham-Soliar T. 2000. The mosasaur Mosasaurus lemonnieri (Lepidosauromorpha, Squamata) from the Upper Cretaceous of Belgium and The Netherlands. Paleontological Journal 34.

Lively JR. Taxonomy and historical inertia: Clidastes (Squamata: Mosasauridae) as a case study of problematic paleobiological taxonomy. Alcheringa: An Australasian Journal of Palaeontology 42:516-527.

Longrich NR, Field DJ. 2012. Torosaurus is not Triceratops: ontogeny in chasmosaurine ceratopsids as a case study in dinosaur taxonomy. PLOS ONE 7:e32623.

Maddison WP, Maddison DR. 2018. Mesquite: a modular system for evolutionary analysis. Version 3.51. http://www.mesquiteproject.org.

Mulder EW. 1999. Transatlantic latest Cretaceous mosasaurs (Reptilia, Lacertilia) from the Maastrichtian type area and New Jersey. Geologie en Mijnbouw 78:281-300.

Openshaw GH, Keogh JS. 2014. Head shape evolution in monitor lizards (Varanus): interactions between extreme size disparity, phylogeny and ecology. Journal of Evolutionary Biology 27:363-373.

Palci A, Caldwell MW, Hutchinson MN, Konishi T, Lee MS. 2019. The morphological diversity of the quadrate bone in squamate reptiles as revealed by high-resolution computed tomography and geometric morphometrics. Journal of Anatomy.

Peer) reviewing PDF | (2020:05:49148:2:0:NEW 11 Sep 2020) 
1069 Paluh DJ, Olgun K, Bauer AM. 2018. Ontogeny, but not sexual dimorphism, drives the

1070

1071

1072

1073

1074

1075

1076

1077

1078

1079

1080

1081

1082

1083

1084

1085

1086

1087

1088

1089

1090

1091

1092

1093

1094

1095

1096

1097

1098

1099

1100

1101

1102

1103

1104

1105

1106

1107

1108

1109 intraspecific variation of quadrate morphology in Hemidactylus turcicus (Squamata: Gekkonidae). Herpetologica 74:22-28.

Pellegrini R. 2007. Skeletochronology of the limb elements of mosasaurs (Squamata: Mosasauridae). Transactions of the Kansas Academy of Science 110:83-100.

Rae TC. 1998. The logical basis for the use of continuous characters in phylogenetic systematics. Cladistics 14:221-228.

Reeder TW, Townsend TM, Mulcahy DG, Noonan BP, Wood Jr. PL, Sites Jr. PW, Wiens JJ. 2015. Integrated analyses resolve conflicts over squamate reptile phylogeny and reveal unexpected placements for fossil taxa. PLOS ONE 10:e0118199.

Reilly SM, Wiley EO, Meinhardt DJ. 1997. An integrative approach to heterochrony: the distinction between interspecific and intraspecific phenomena. Biological Journal of the Linnean Society 60:119-143.

Rozhdestvensky AK. 1965. Growth changes in Asian dinosaurs and some problems of their taxonomy. Paleontologicheskii Zhurnal 1965:95-100.

Russell DA. 1967. Systematics and morphology of American mosasaurs. Yale University Peabody Museum of Natural History Bulletin 23:1-241.

Scannella JB, Fowler DW, Goodwin MB, Horner JR. 2014. Evolutionary trends in Triceratops from the Hell Creek formation, Montana. Proceedings of the National Academy of Sciences 111:10245-10250.

Schwab JA, Young MT, Neenan JM, Walsh SA, Witmer LM, Herrera Y, Allain R, Brochu CA, Choiniere JN, Clark JM, Dollman KN, Etchesk S, Fritsch G, Gignac PM, Ruebenstahl A, Sachs S, Turner AH, Vignaud P, Wilberg EW, Xu X, Zanno LE, Brusatte SL. 2020. Inner ear sensory system changes as extinct crocodylomorphs transitioned from land to water. Proceedings of the National Academy of Sciences 117:10422-10428.

Schwarzkopf L. 2005. Sexual dimorphism in body shape without sexual dimorphism in body size in water skinks (Eulamprus quoyii). Herpetologica 61:116-123.

Shine R, Reed R, Shetty S, Cogger H. 2002. Relationships between sexual dimorphism and niche partitioning within a clade of sea-snakes (Laticaudinae). Oecologia 133:45-53.

Simões TR, Caldwell MW, Palci A, Nydam RL. 2016. Giant taxon-character matrices: quality of character constructions remains critical regardless of size. Cladistics 33:198-219.

Simões TR, Vernygora O, Paparella I, Jimenez-Huidobro P, Caldwell MW. 2017. Mosasauroid phylogeny under multiple phylogenetic methods provides new insights on the evolution of aquatic adaptations in the group. PLOS ONE 12:e0176773.

Skawiński T, Borczyk B, Turniak E. 2017. Variability of pterygoid teeth in three species of Podarcis lizards and the utility of palatal dentition in lizard systematics. Belgian Journal of Zoology 147(2).

Stewart RF, Mallon JC. 2018. Allometric growth in the skull of Tylosaurus proriger (Squamata: Mosasauridae) and its taxonomic implications. Vertebrate Anatomy Morphology Paleontology 6:75.

Street HP, Caldwell MW. 2017. Rediagnosis and redescription of Mosasaurus hoffmannii

Peer) reviewing PDF | (2020:05:49148:2:0:NEW 11 Sep 2020) 
1110

1111

1112

1113

1114

1115

1116

1117

1118

1119

1120

1121

1122

(Squamata: Mosasauridae) and an assessment of species assigned to the genus Mosasaurus. Geological Magazine 154:521-557.

Swofford DA. 2003. PAUP* 4.0. Sinauer Associates, Sunderland, Massachusetts.

Wiffen J, De Buffrénil V, De Ricqlès A, Mazin JM. 1995. Ontogenetic evolution of bone structure in Late Cretaceous Plesiosauria from New Zealand. Geobios 28:625-640.

Wikelski M, Trillmich F. 1997. Body size and sexual size dimorphism in marine iguanas fluctuate as a result of opposing natural and sexual selection: an island comparison. Evolution 51:922-936.

Wilson JP, Ryan MJ, Evans DC. 2020. A new, transitional centrosaurine ceratopsid from the Upper Cretaceous Two Medicine Formation of Montana and the evolution of the 'Styracosaurus-line' dinosaurs. Royal Society Open Science 7:200284.

Witmer LM. 1995. The extant phylogenetic bracket and the importance of reconstructing soft tissues in fossils. Functional Morphology in Vertebrate Paleontology 1:19-33. 


\section{Figure 1}

Comparison between hypothetical low-resolution and high-resolution growth series.

(A) In a low-resolution growth series, multiple individuals are grouped into vague sets. (B) In a high-resolution growth series, each growth stage only has a single individual.

A

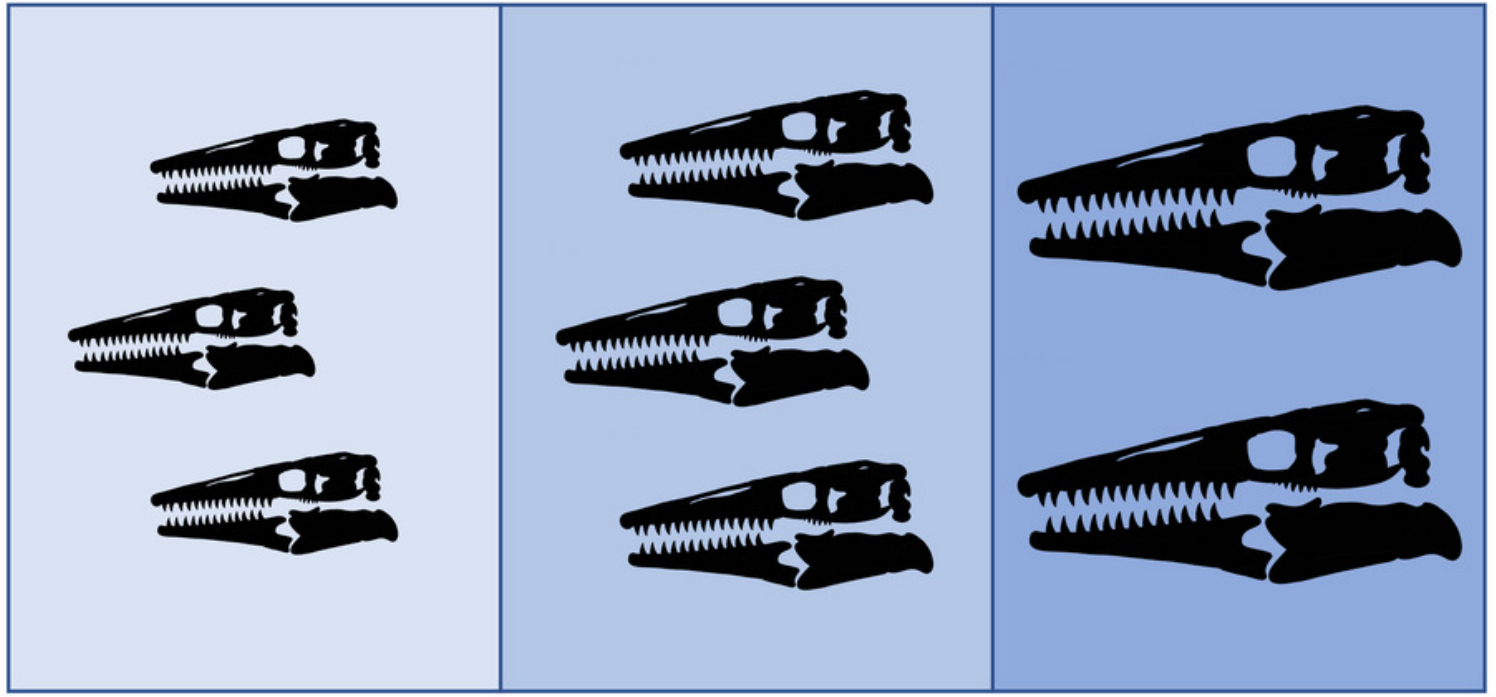

B

\begin{tabular}{ccccc} 
Stage 1 & Stage 2 & Stage 3 & Stage 4 & Stage 5 \\
\hline
\end{tabular}




\section{Figure 2}

Possible scenarios when determining the most mature individual.

In each scenario, a cladistic analysis has recovered hypothetical specimens "Y" (light gray) and " $\mathrm{Z}$ " (black) at the terminus of the ontogram. The most mature individual(s) is indicated by an arrowhead. (A) The analysis with an artificial adult is successful; the artificial adult is recovered closest to specimen " $\mathrm{Y}$," indicating that it is the most mature. (B) The analysis with the artificial adult fails to recover a single most mature specimen; the artificial adult is not closer to specimen " $Y$ " or specimen " $Z$." (C) Should the analysis with the artificial adult fail, the specimen with the most accumulated growth changes (synontomorphies) is considered the most mature; in this scenario, the most mature individual is specimen " $Y$," with a total of four synontomorphies. 
A
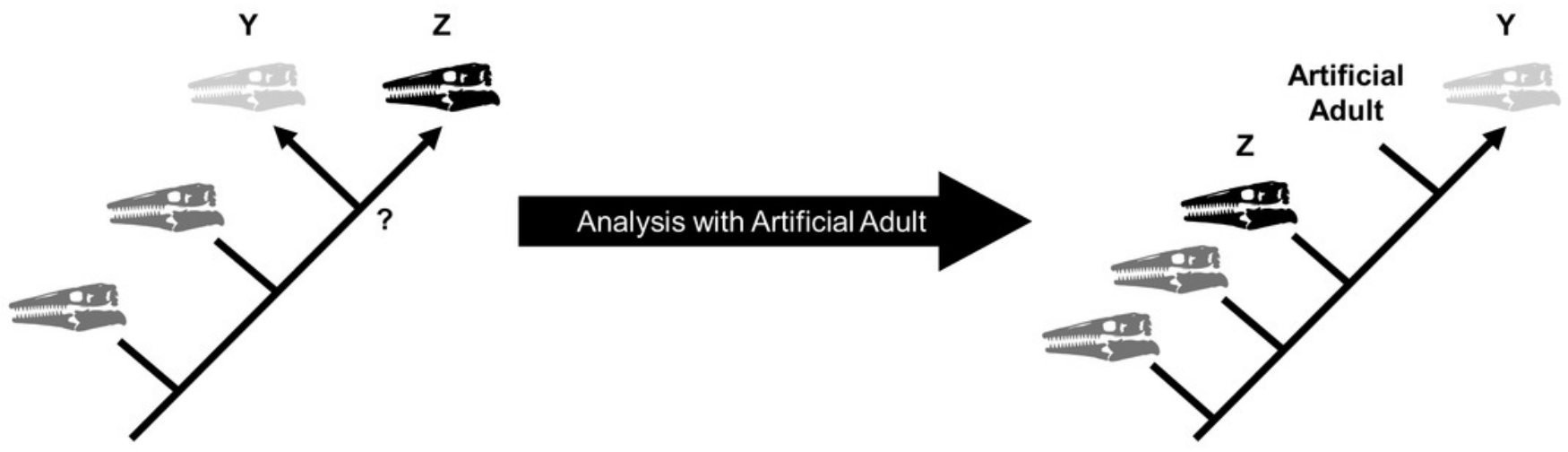

B

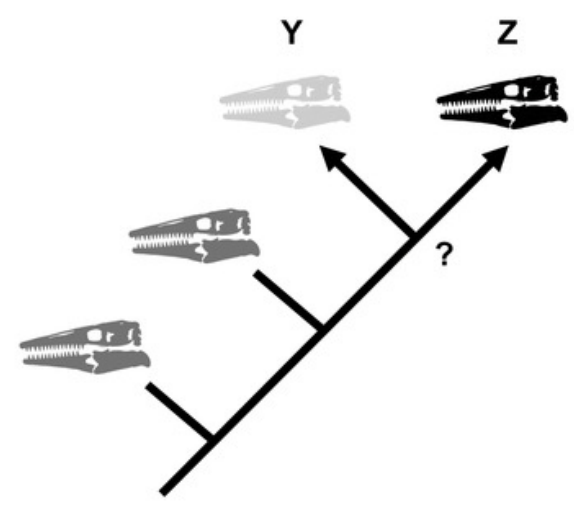

Analysis with Artificial Adult

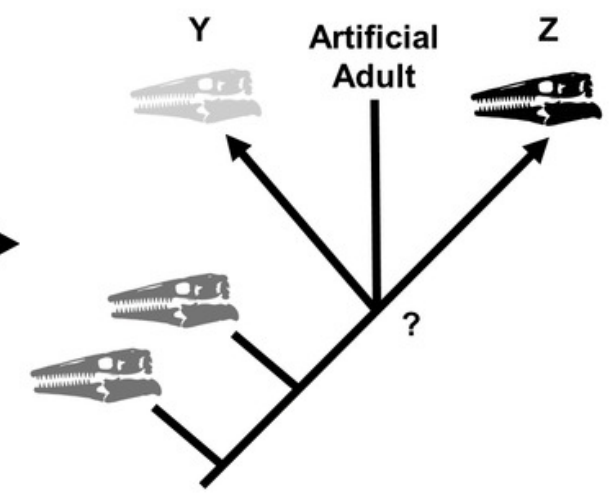

C
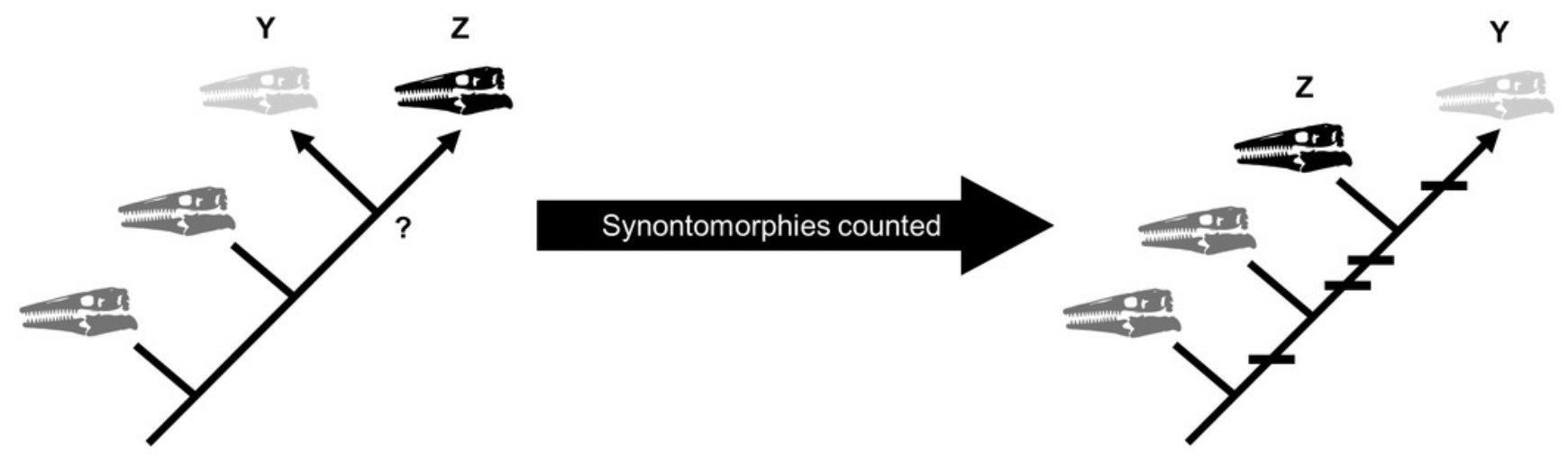


\section{Figure 3}

Summary of potential outcomes for the growth series recovered by the cladistic analysis.

(A) The specimens included in the analysis represent a single taxon without sexual

dimorphism. (B) The specimens in the analysis represent either a single taxon that is sexually dimorphic or two separate taxa with morphologically similar juveniles. (C) The specimens in the analysis represent either a single taxon that is sexually dimorphic with an oversampling of adults or two separate taxa. (D) The analysis recovers two or more groups of specimens defined by shared instances of individual variation; these groups could represent different taxa or sexual dimorphism. 
A

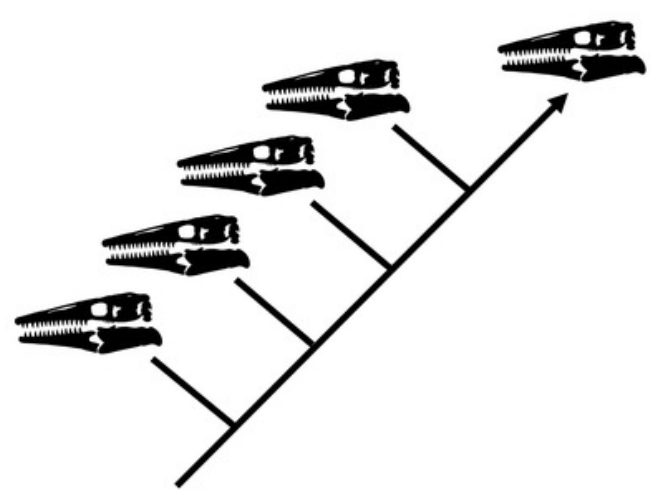

C

$\bigcirc$ or Taxon A $\bigcirc$ or Taxon B

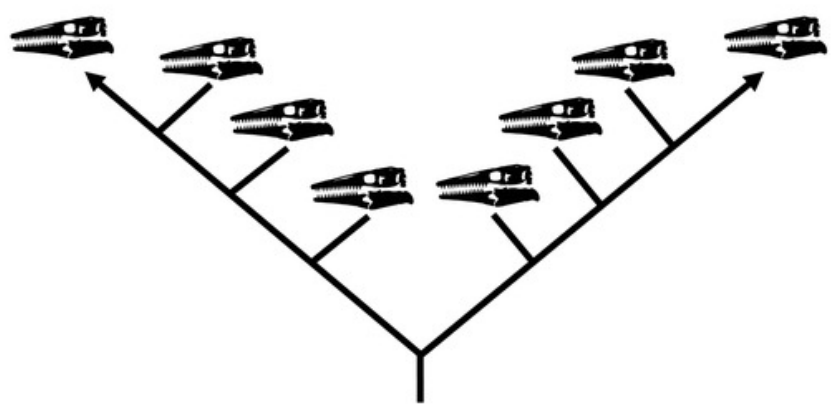

B

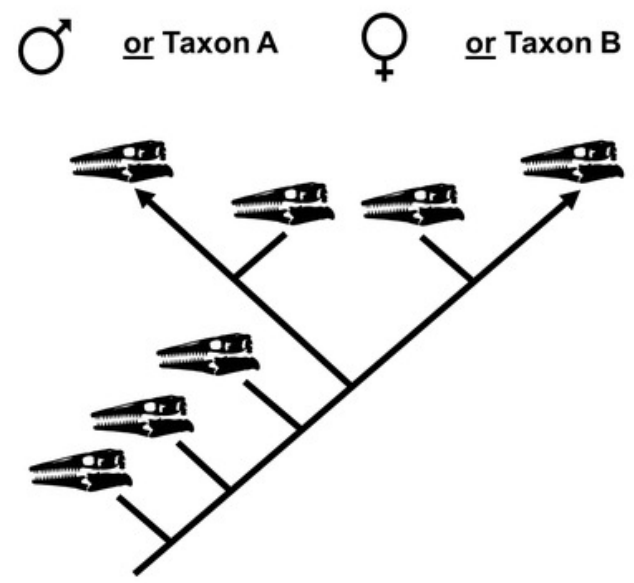

D

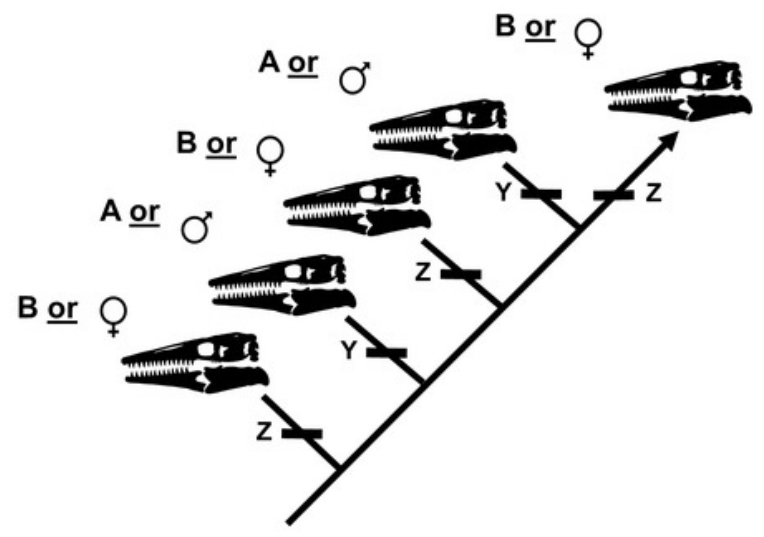




\section{Figure 4}

Summary of potential outcomes for the analysis of the data matrix including Tylosaurus kansasensis and Tylosaurus nepaeolicus.

Hypothetical $T$. nepaeolicus specimens are represented by black skulls and hypothetical $T$. kansasensis specimens are represented by gray skulls. (A) If the current hypothesis is supported and T. kansasensis are juveniles of T. nepaeolicus (Jiménez-Huidobro, Simões, \& Caldwell, 2016), most or all $T$. kansasensis specimens will be recovered as less mature than most or all $T$. nepaeolicus specimens. (B) If $T$. kansasensis are juveniles of $T$. nepaeolicus, and the taxon is sexually dimorphic, most or all $T$. kansasensis specimens will be recovered as less mature than most or all $T$. nepaeolicus specimens and before the onset of sexual maturity (represented by a bifurcation in the ontogram). (C) If $T$. kansasensis and $T$. nepaeolicus are the same taxon but neither is necessarily all adults nor all juveniles, and sexual dimorphism is absent, the specimens will be interspersed with each other on the tree. (D) If $T$. kansasensis and $T$. nepaeolicus are the same taxon but neither is necessarily all adults nor all juveniles, and sexual dimorphism is present, the specimens will be interspersed with each other on the tree and on both branches after the onset of sexual maturity. (E) The tree is linear with specimens of both taxa interspersed with each other, but identical individual variations are unambiguously optimized in several specimens of one taxon and not along the main axis or in specimens of the other taxon; in this case, two groups are recovered and they may represent two taxa or sexual dimorphism. (F) If $T$. kansasensis and $T$. nepaeolicus are opposite sexes of the same taxon, the tree will bifurcate with specimens of $T$. kansasensis on one branch, $T$. nepaeolicus on the other branch, and a mix of specimens near the root. (G) If $T$. kansasensis and $T$. nepaeolicus are two different taxa, the tree will bifurcate at or near the root with all the $T$. kansasensis specimens on one branch and all the $T$. nepaeolicus specimens on the other; this could also represent sexual dimorphism with an 
oversampling of adults in which specimens of $T$. kansasensis represent one sex and specimens of $T$. nepaeolicus represent the other. 
A

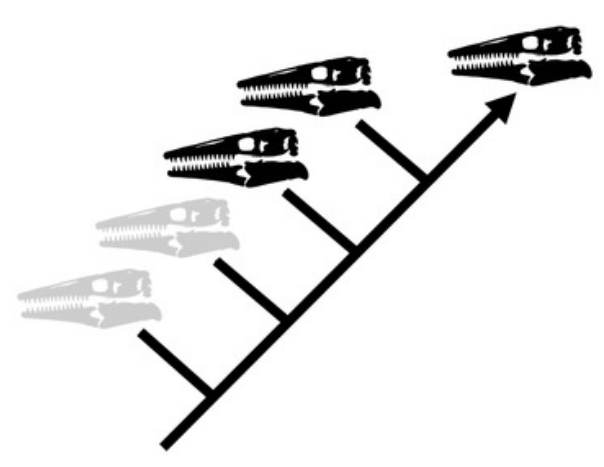

C

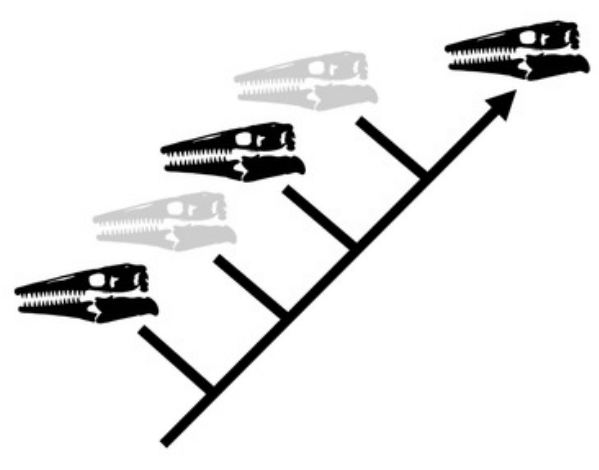

E

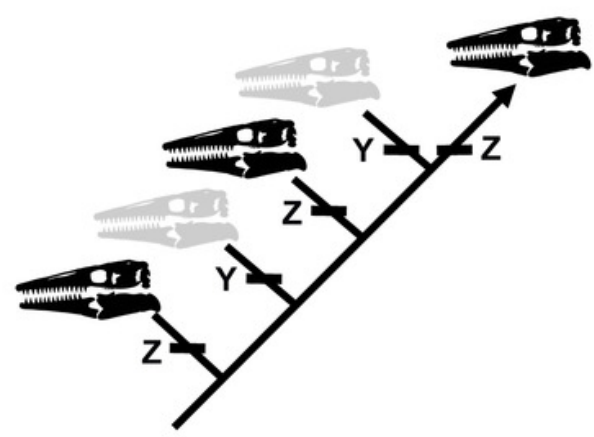

G

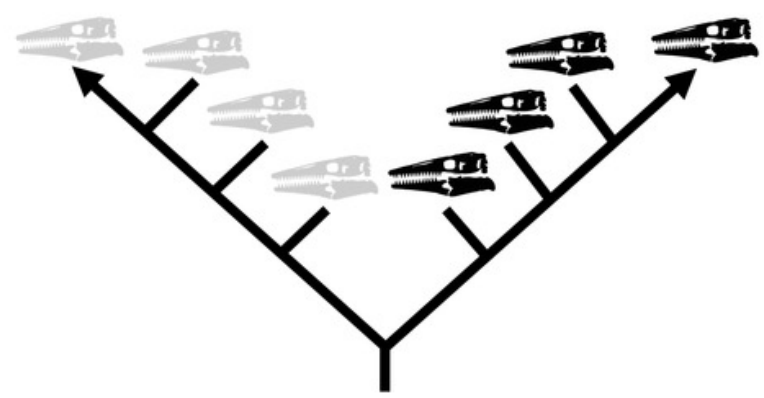

B

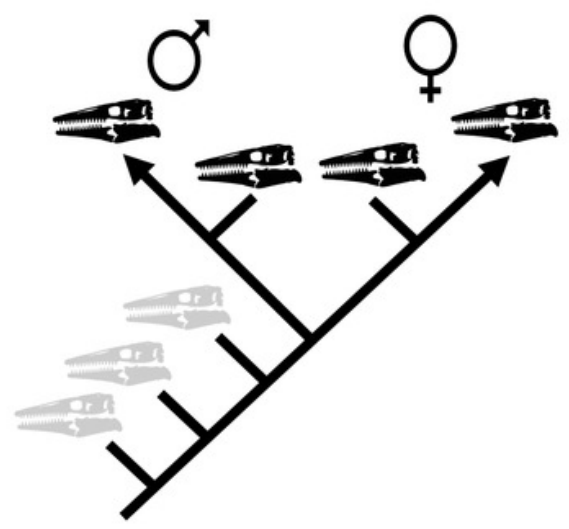

D

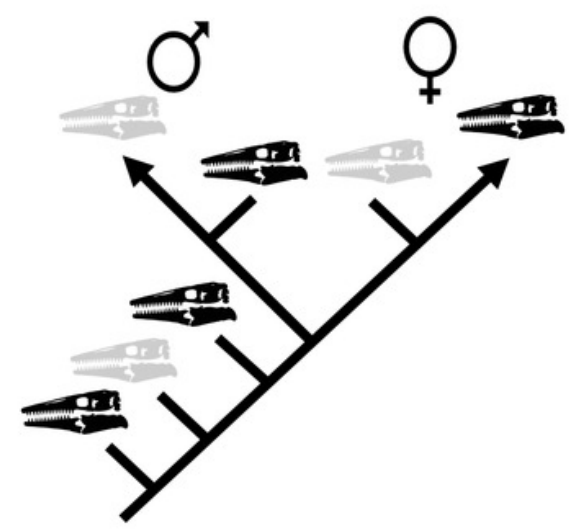

$\mathbf{F}$

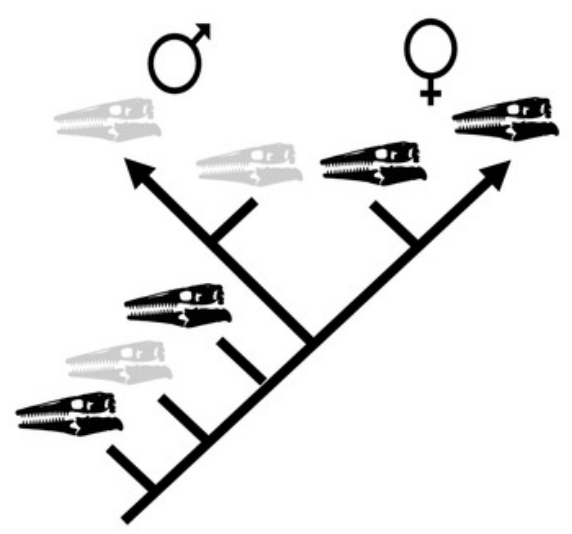




\section{Figure 5}

Ontogram of one Tylosaurus sp. specimen and 22 Tylosaurus proriger specimens based on a quantitative cladistic analysis.

The ontogram is a single tree and tree statistics are summarized in the upper left. Character states that define each growth stage are shown along the main branch, and the exemplar specimens are to the left of the main branch; the most mature individual, identified by the analysis with an artificial adult, is indicated by an arrow. The encircled numbers on the nodes are the growth stages, and the numbers to the right of them are the bootstrap and jackknife values, respectively (1000 replicates, $<50 \%$ not shown). Unambiguous character reversals are shown in red. "Immature" specimens were recovered in the lower third of the tree, "intermediate" specimens were recovered in the middle third of the tree, and "mature" specimens were recovered in the upper third of the tree. The ontogram supports the assignment of all specimens to $T$. proriger and does not show evidence of sexual dimorphism. Notes: specimen photographs are not to scale; FHSM VP-14845 is a neonate only referable to Tylosaurus sp.; KUVP 5033 is included in the analysis with all three Tylosaurus taxa, but not in the individual T. proriger ontogram; the photograph of KUVP 1032 has been inverted to face left. 
Tree Length: 82

Cl: 0.6463

HI: 0.3537

RI: 0.7563

RC: 0.4888

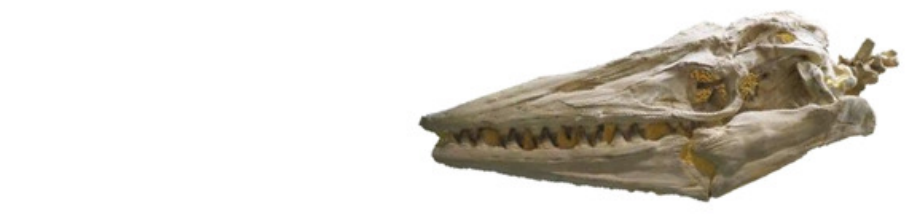

FHSM VP-3

(17)

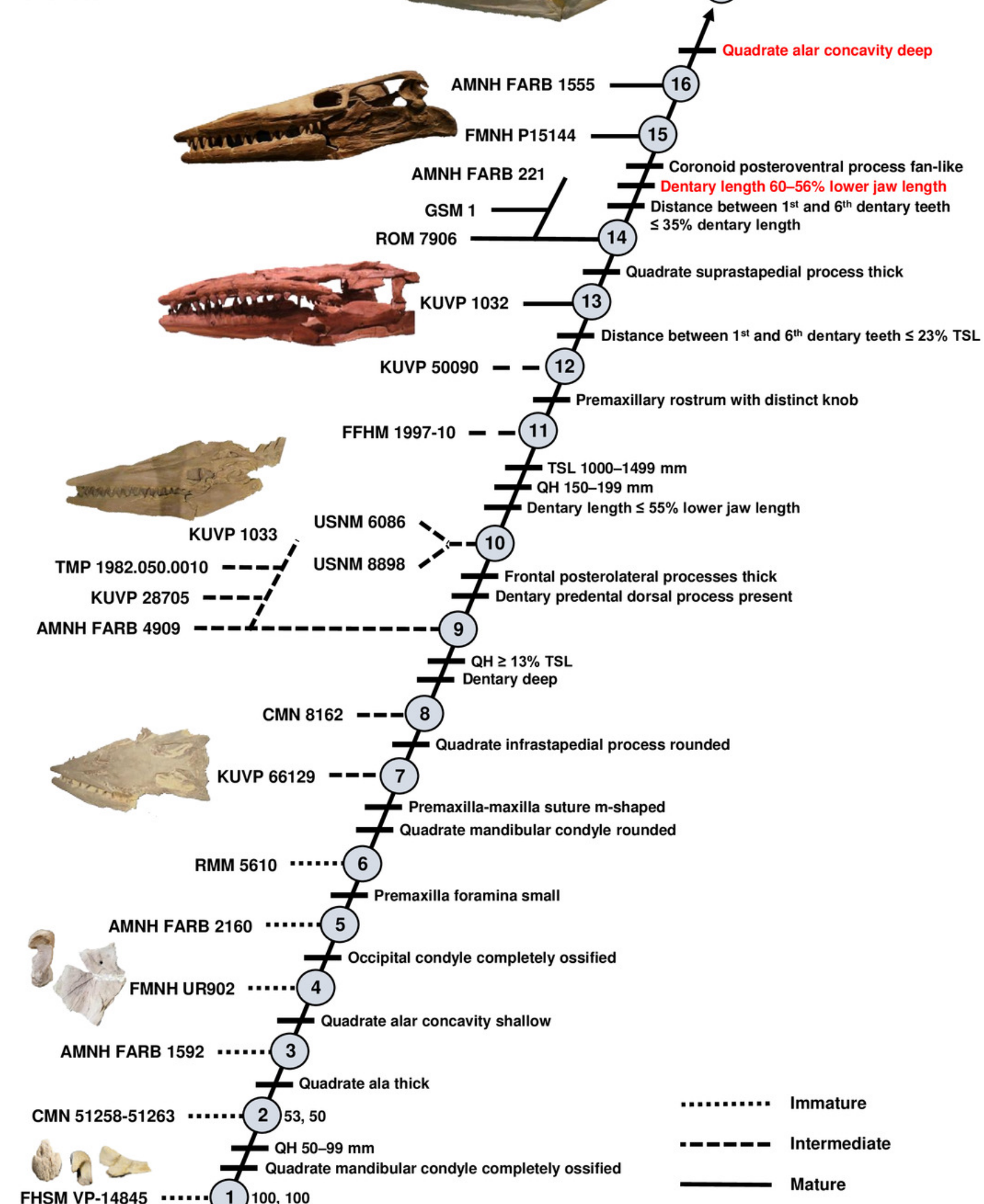

FHSM VP-14845 100,100

Character reversals are shown in red. 


\section{Figure 6}

Variation in Tylosaurus quadrate shape.

(A) $T$. proriger FMNH UR902. (B) $T$. proriger AMNH FARB 4909. (C) $T$. proriger AMNH FARB 1555. The infrastapedial process is either broadly pointed (A) or expanded, rounded, and semicircular (B, C). The suprastapedial process is either slender (B) or robust (A, C). The tympanic ala is either thick (A) or thin (B, C) and the alar concavity is either deep (B) or shallow $(A, C)$. Distinct deflection of the mandibular condyle is either present $(A)$ or absent $(B, C)$. Abbreviations: isp, infrastapedial process of the quadrate; ssp, suprastapedial process of the quadrate. Note: the photograph of FMNH UR902 has been inverted to face left. 
$5 \mathrm{~cm}$

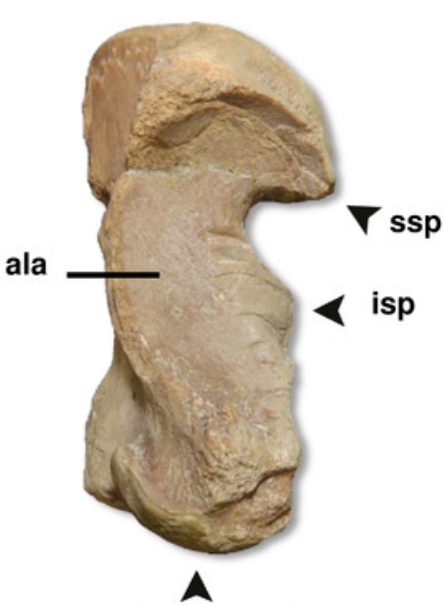

mandibular condyle

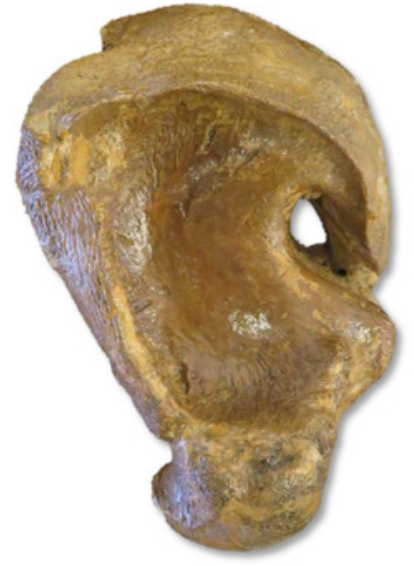

B

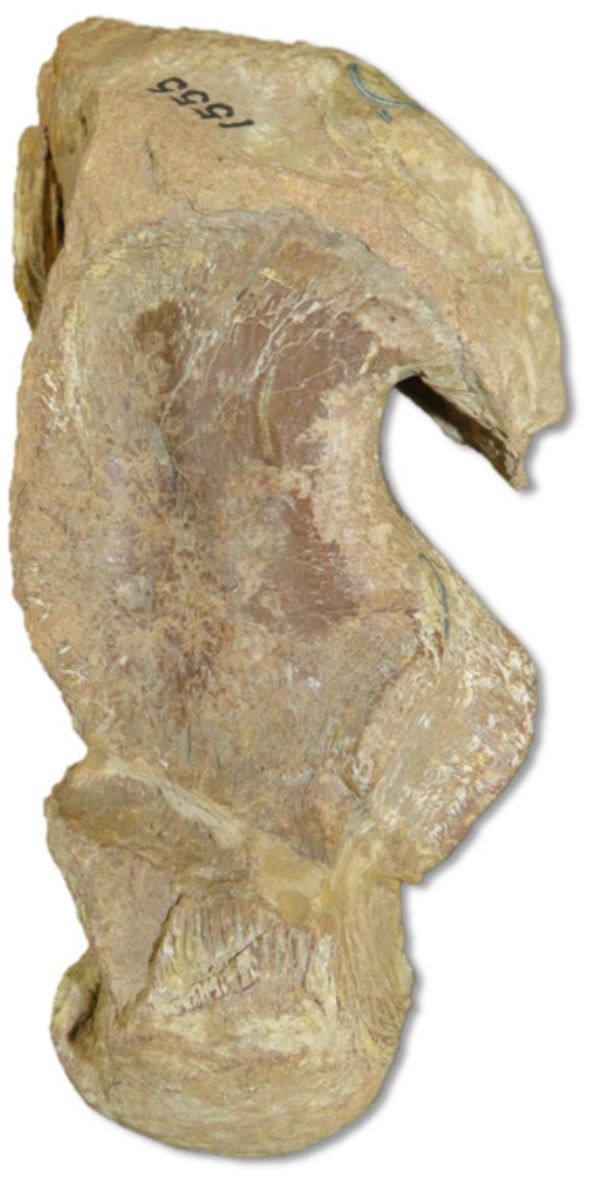

C 


\section{Figure 7}

Variation in Tylosaurus premaxillae.

Intraspecific variation of Tylosaurus premaxilla rostrum shape (A-B) and foramina size (C-E). In less mature individuals, the premaxillary rostrum is acute in lateral view ( $A ; T$. proriger AMNH FARB 4909) and the foramina are large ( $C ; T$. nepaeolicus FHSM VP-14840), whereas in more mature individuals, the rostrum is rounded and distinctly knobbed ( $B$; $T$. proriger FMNH P15144) and the foramina are either small (D; T. nepaeolicus FHSM VP-7262) or both small and large (E; T. proriger FHSM VP-3). Notes: the photographs of FMNH P15144 and FHSM VP-14040 have been inverted to face left; FHSM VP-14840 was originally identified as T. kansasensis; specimen photographs are not to scale. 
A

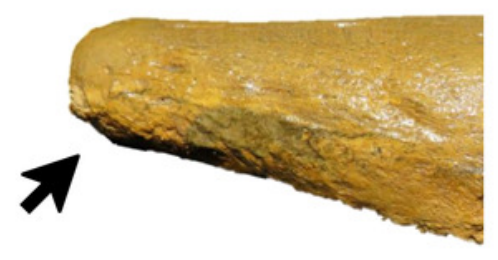

C

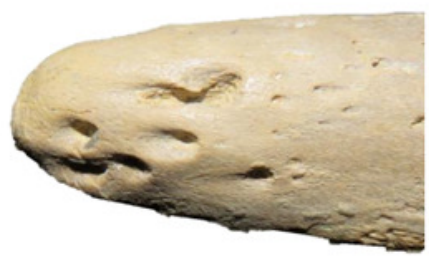

B

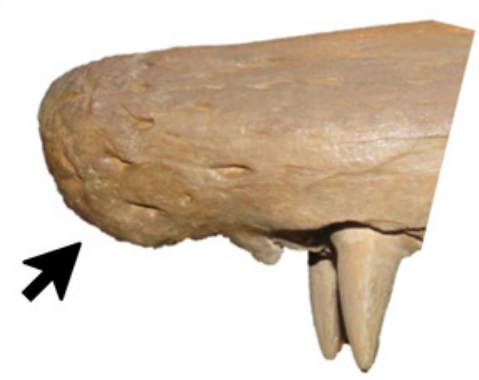

D

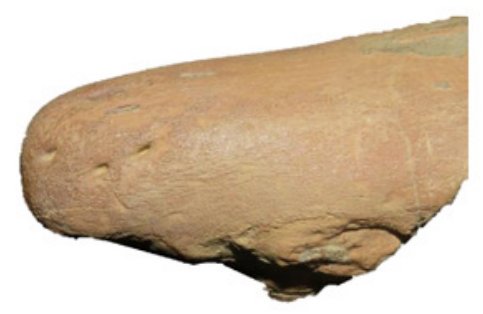

E

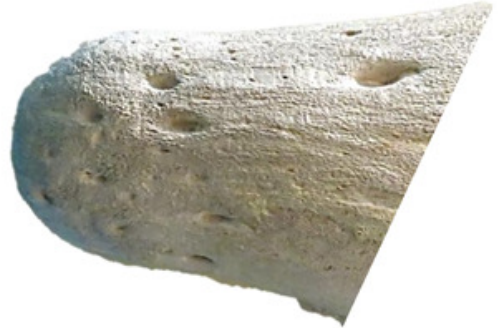




\section{Figure 8}

Variation in premaxilla-maxilla suture shape.

(A, B) Rectangular (T. proriger AMNH FARB 4909). (B) U-shaped (T. proriger FHSM VP-3). (C, D) M-shaped (T. proriger FMNH P15144). Notes: the photograph of AMNH FARB 4909 has been inverted to face left; specimen photographs are not to scale. 
A

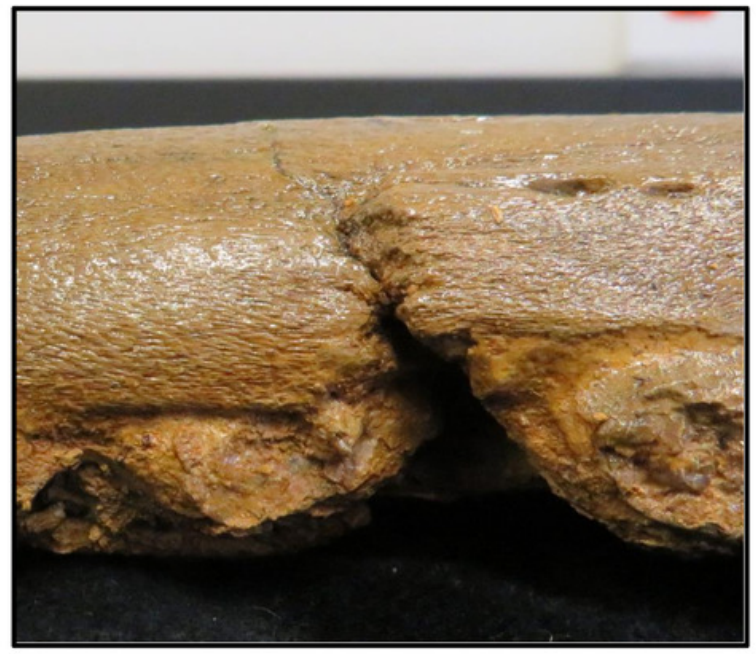

C

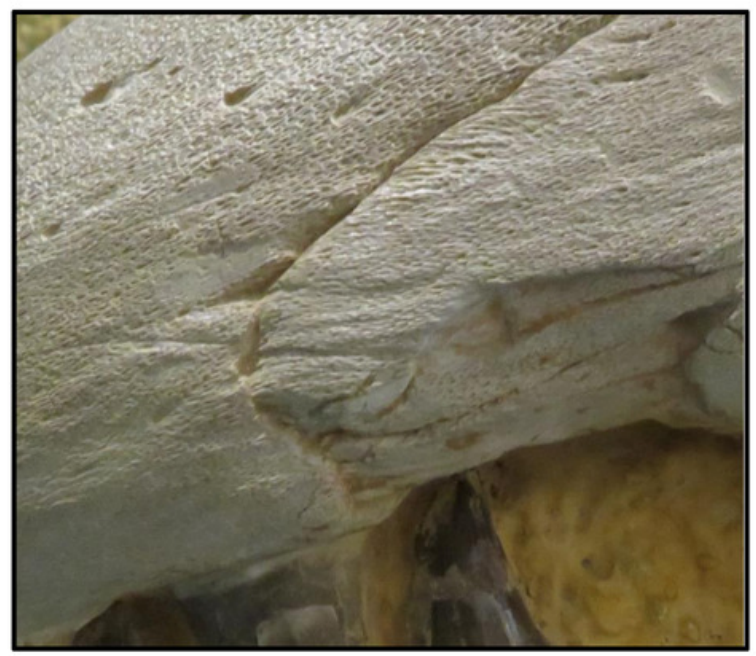

$\mathbf{E}$

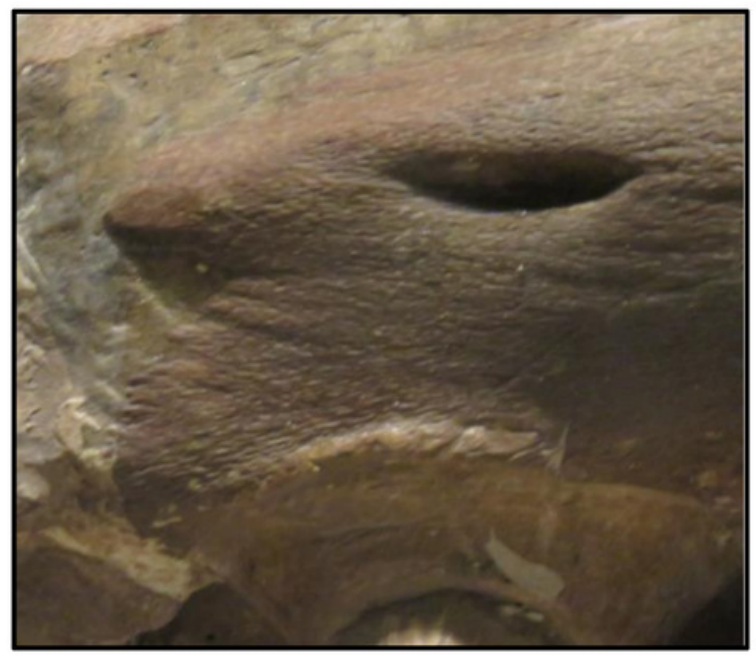

B

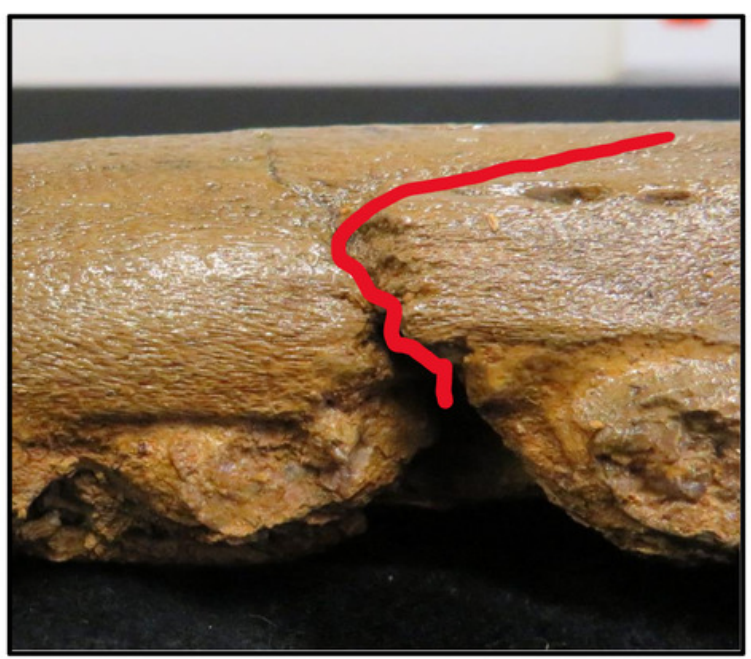

D

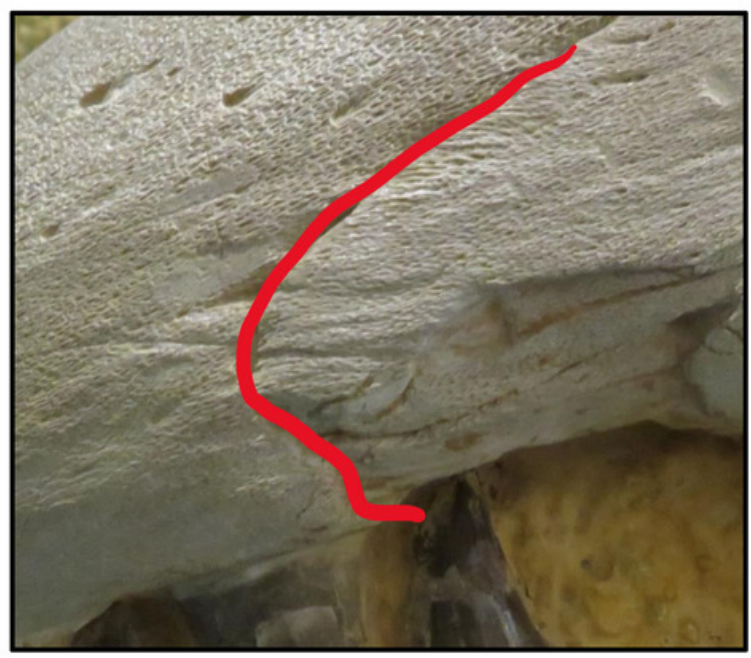

$\mathbf{F}$

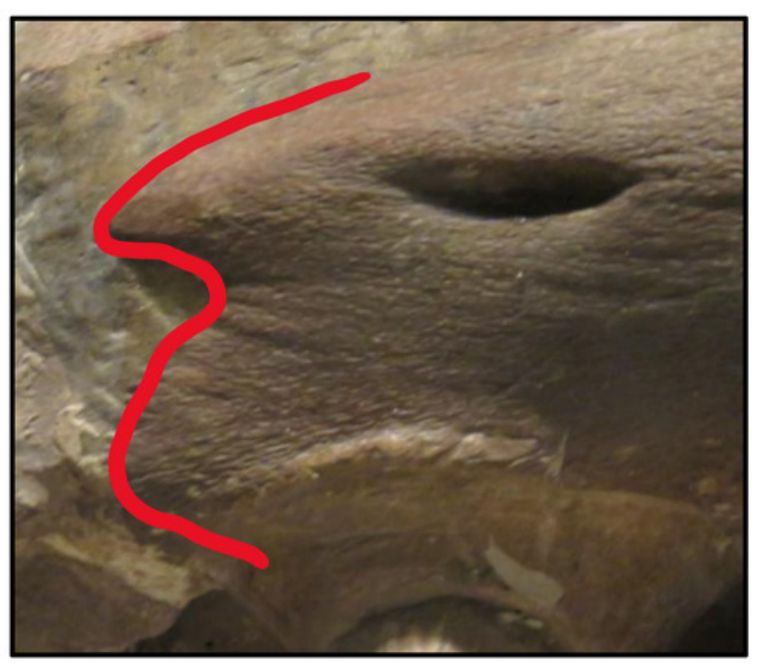




\section{Figure 9}

Variation in frontal-parietal medial suture flange shape.

(A, B) Flanges large (T. nepaeolicus FHSM VP-2295). (C, D) Flanges small ( $T$. nepaeolicus FHSM VP-15631). Notes: FHSM VP-2295 is the holotype of $T$. kansasensis; specimen photographs are not to scale.

A

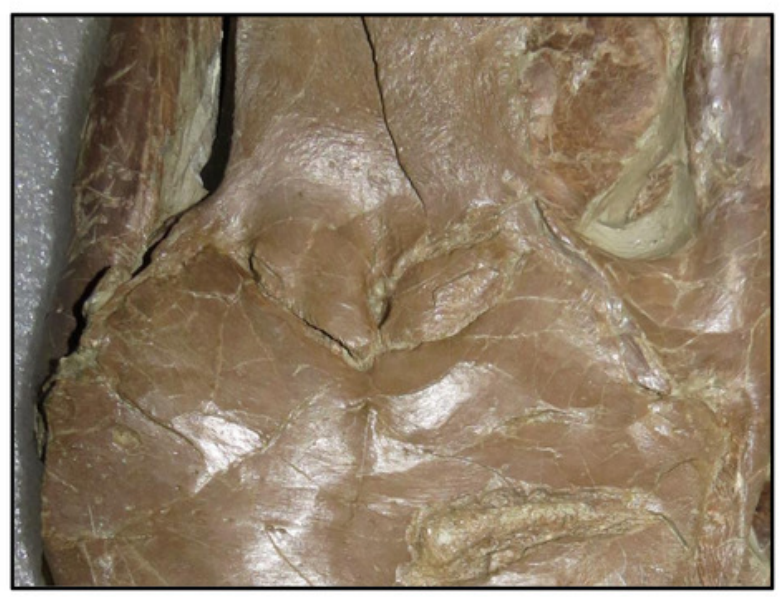

C

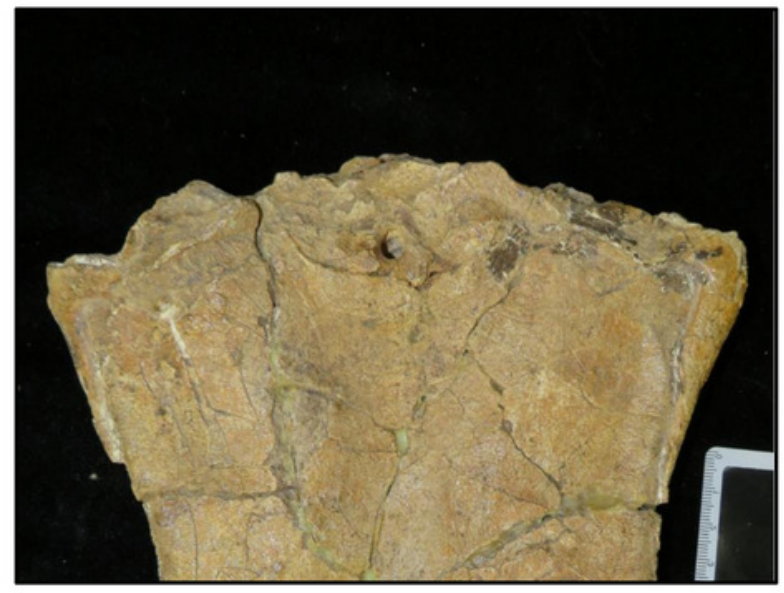

B

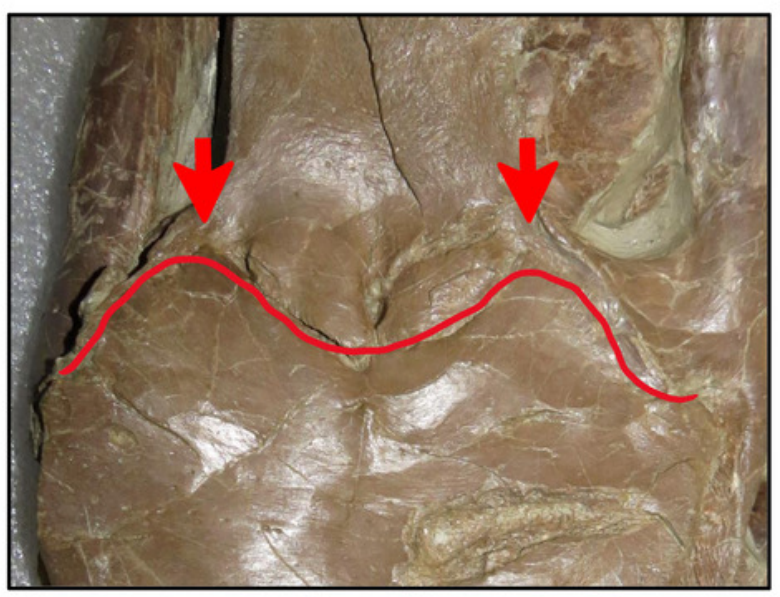

D

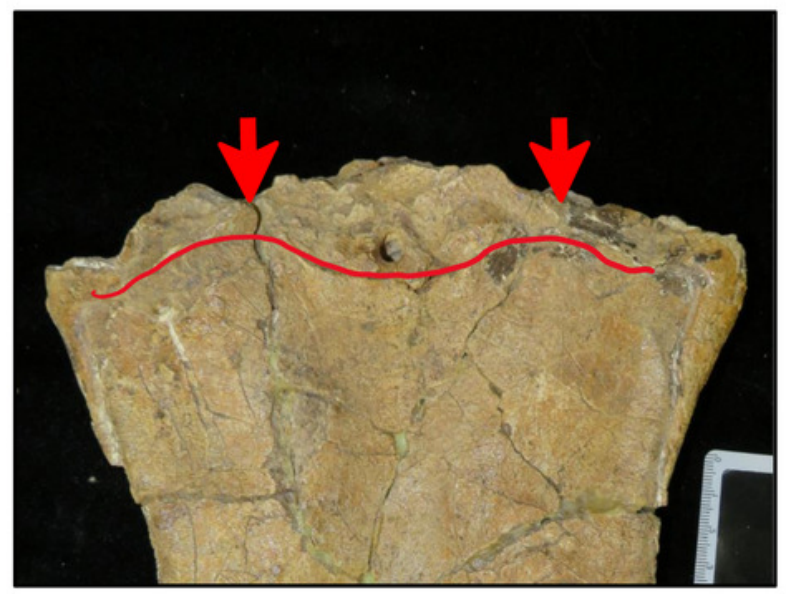




\section{Figure 10}

Variation in frontal posterolateral process shape.

(A, B) Slender (T. proriger KUVP 28705). (C, D) Robust (T. proriger KUVP 65636). Note: specimen photographs are not to scale.

A

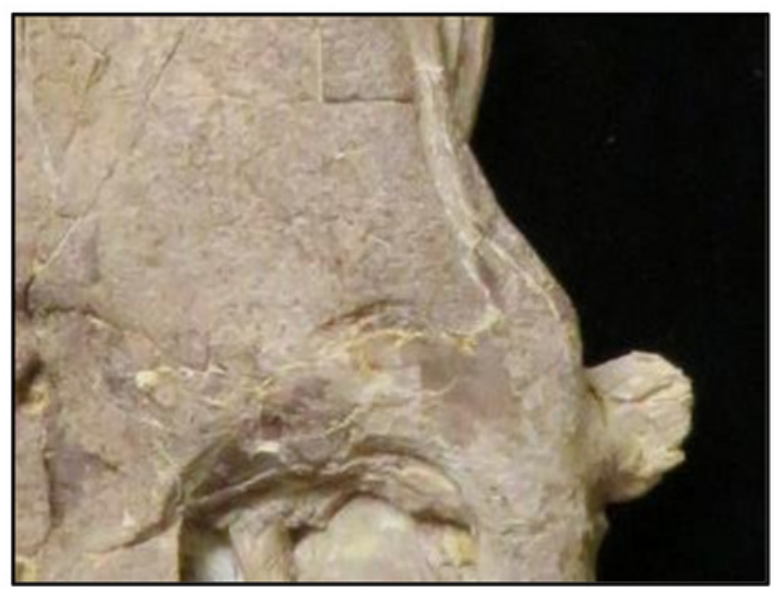

C

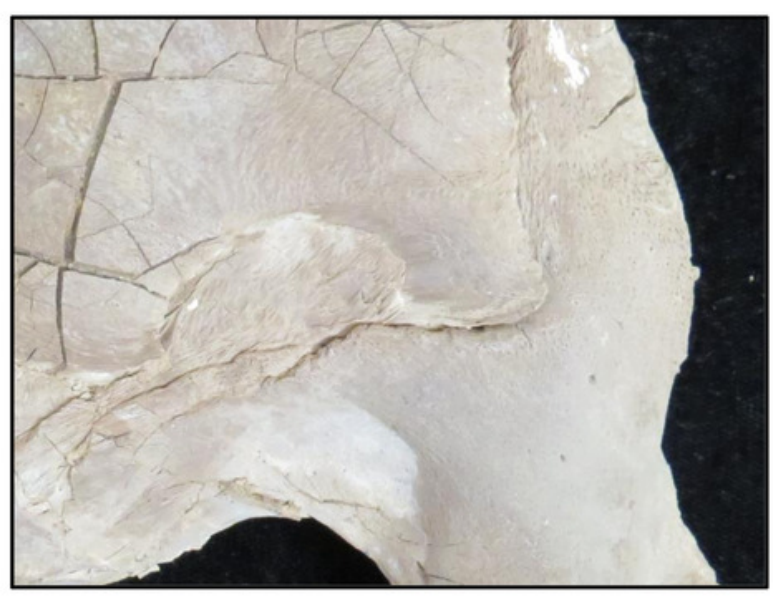

B

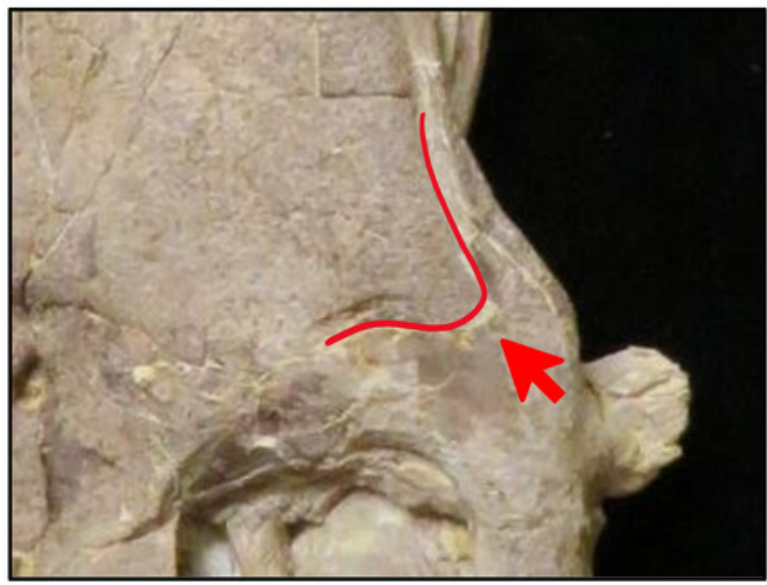

D

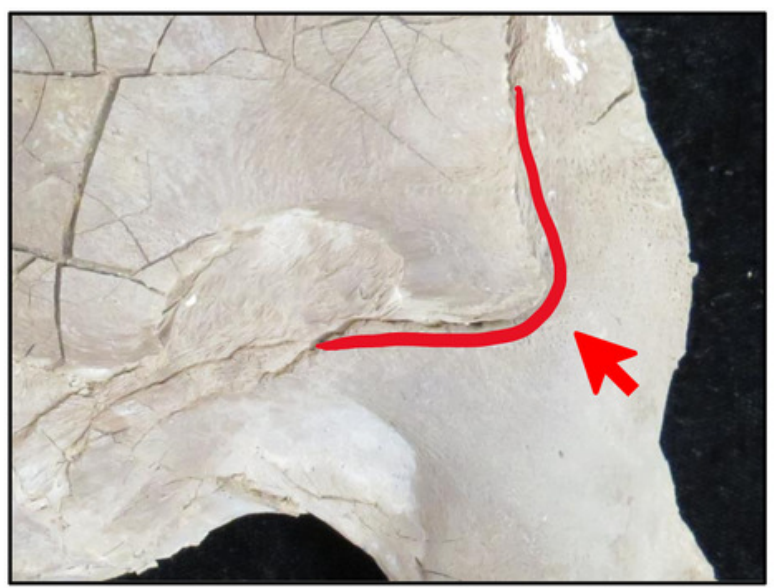


Figure 11

Presence of dorsal ridge on predental process of the dentary.

(A) Absent (T. proriger AMNH FARB 4909). (B) Present (T. proriger FMNH UR820). Note: specimen photographs are not to scale.

A

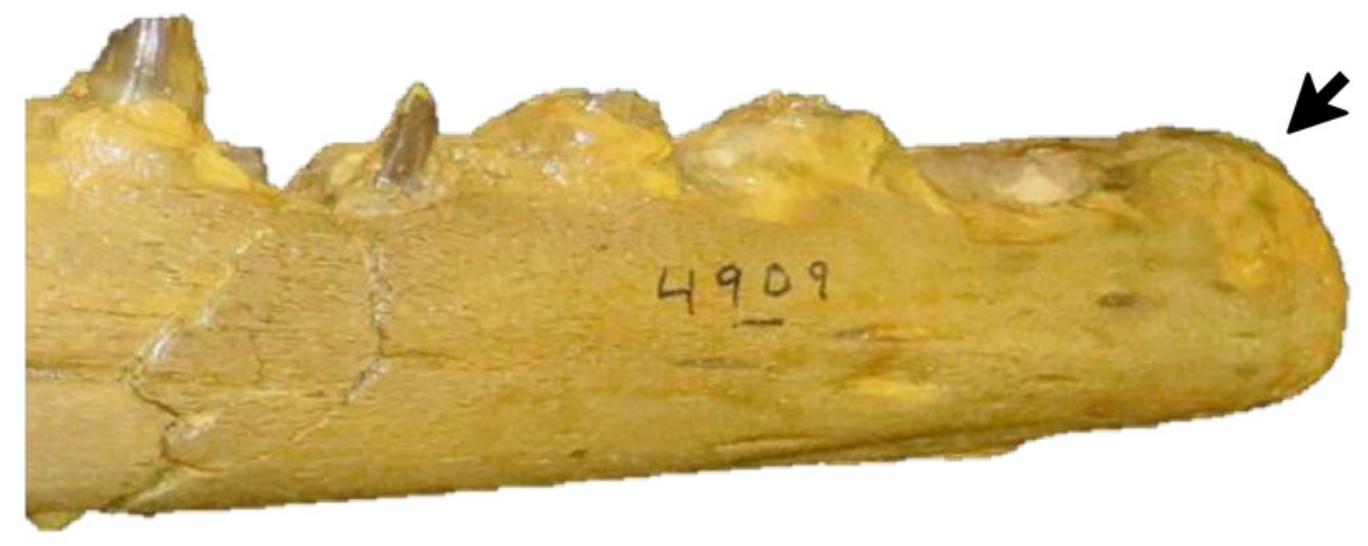

B

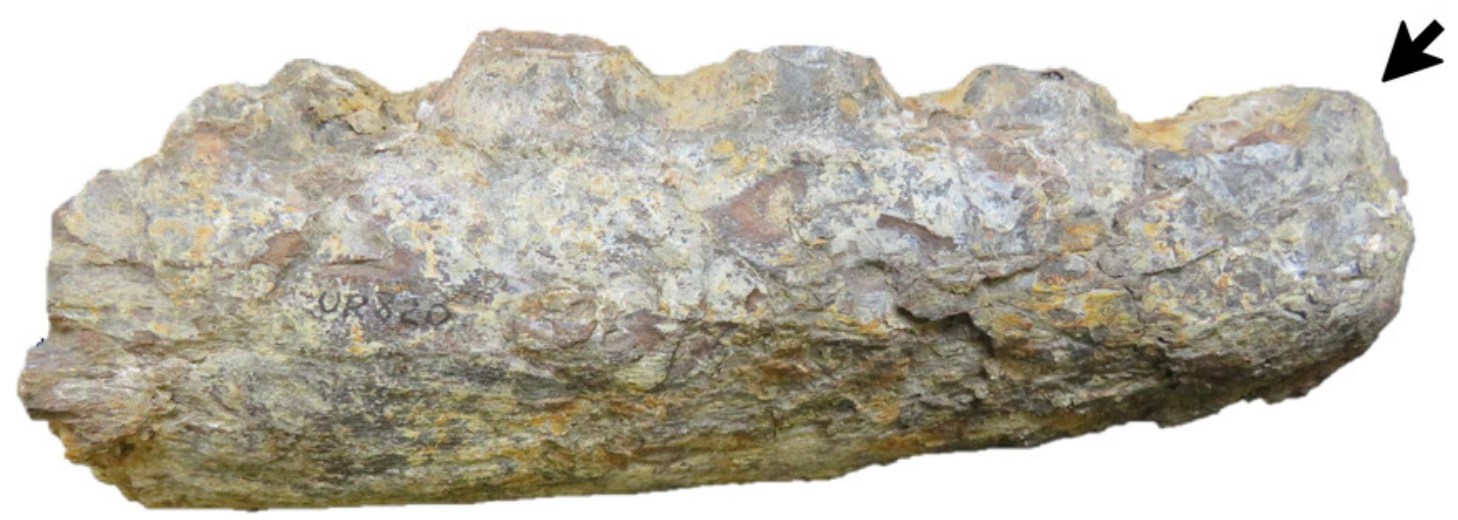




\section{Figure 12}

Presence and shape of the coronoid posteroventral process.

(A) Absent (Tylosaurus sp. FHSM VP-14845). (B) Present as bump (T. proriger FHSM VP-3). (C) Fan-like (T. proriger KUVP 5033). Notes: the photograph of KUVP 5033 has been inverted to face left; specimen photographs are not to scale. 
A

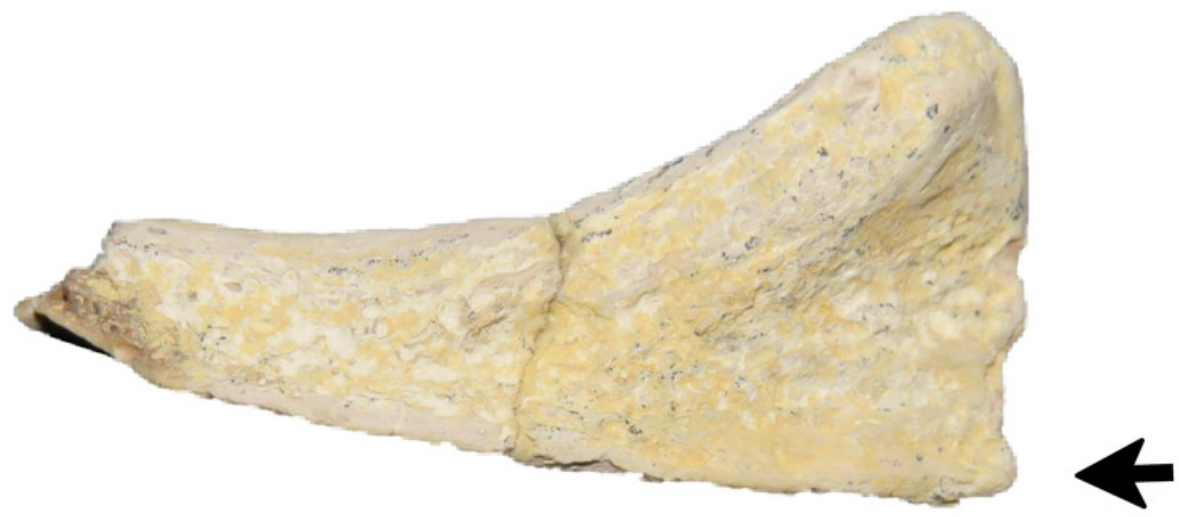

B

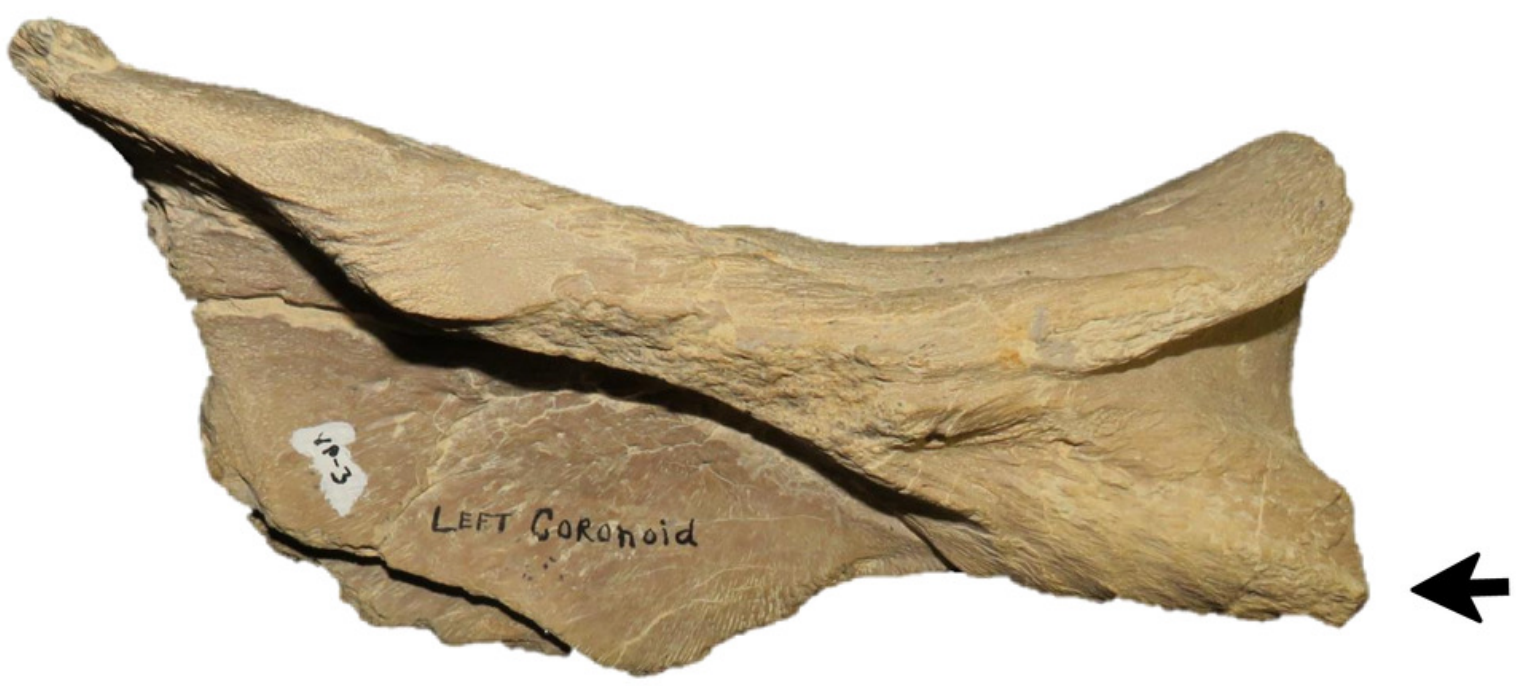

C

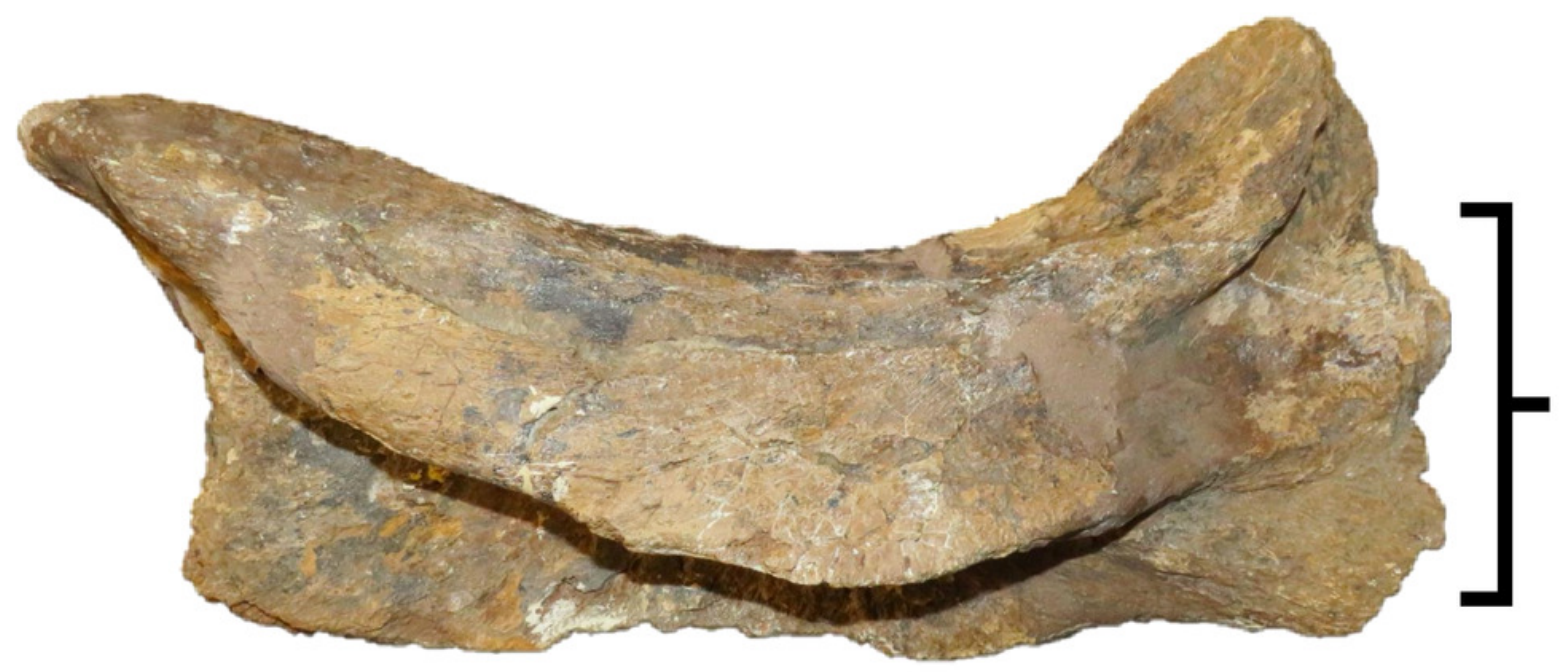




\section{Figure 13}

Ontogram of one Tylosaurus sp. specimen, 11 Tylosaurus kansasensis specimens, and seven Tylosaurus nepaeolicus specimens based on a quantitative cladistic analysis.

Specimens identified as $T$. nepaeolicus are shown in magenta, and specimens identified as $T$. kansasensis are shown in yellow; the type specimen of each taxon is indicated by an asterisk. The ontogram is a single tree and tree statistics are summarized in the upper left. Character states that define each growth stage are shown along the main branch, and the exemplar specimens are to the left of the main branch; the most mature individuals, identified by the analysis with an artificial adult, are indicated by arrows. The encircled numbers on the nodes are the growth stages, and the numbers to the right of them are the bootstrap and jackknife values, respectively (1000 replicates, $<50 \%$ not shown).

Unambiguous character reversals are shown in red. "Immature" specimens were recovered in the lower third of the tree, "intermediate" specimens were recovered in the middle third of the tree, and "mature" specimens were recovered in the upper third of the tree. The ontogram does not bifurcate and thus supports synonymy of $T$. kansasensis with $T$. nepaeolicus and that $T$. kansasensis represent juveniles of $T$. nepaeolicus (Jiménez-Huidobro, Simões, \& Caldwell, 2016), and does not show evidence for sexual dimorphism. Note: specimen photographs are not to scale; FHSM VP-14845 is a neonate only referable to Tylosaurus sp.; the photographs of FGM V-43, FHSM VP-2209, and FHSM VP-78 have been inverted to face left. 
Tree Length: 87

Cl: 0.5862

HI: 0.4138

RI: 0.6211

RC: 0.3641

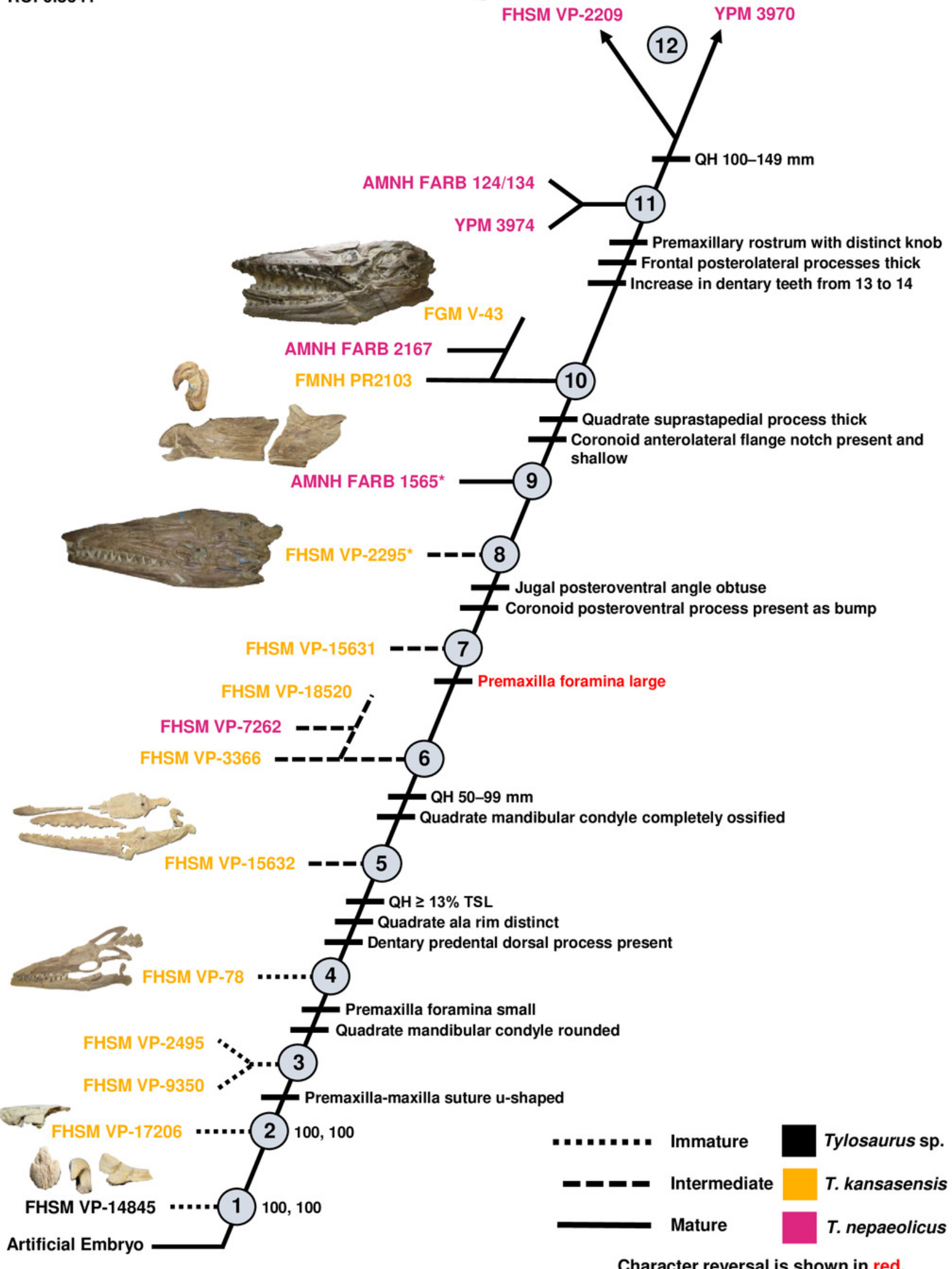




\section{Figure 14}

Ontogram of one Tylosaurus sp. (Tsp.), eight Tylosaurus kansasensis (Tk), five Tylosaurus nepaeolicus (Tn), and 16 Tylosaurus proriger (Tp) based on a quantitative cladistic analysis.

The ontogram is based on a strict consensus of two trees, each with a length of 145 steps, a $\mathrm{Cl}$ of 0.40 , an $\mathrm{HI}$ of 0.60 , an RI of 0.60 , and an RC of 0.24 . Holotypes are indicated by asterisks. Character states that diagnose each growth stage are shown along the main branch, and the exemplar specimens are to the left of the main branch; the most mature individual, identified by the analysis with an artificial adult, is indicated by an arrow. Character states that distinguish the group of mature $T$. nepaeolicus from the group of mature $T$. proriger are also shown. The encircled numbers on the nodes are the growth stages, and the numbers below and to the right of them are the bootstrap and jackknife values, respectively (1000 replicates, $<50 \%$ not shown). Unambiguous character reversals are shown in red. In the individual analyses, "immature" specimens were recovered in the lower third of the tree, "intermediate" specimens were recovered in the middle third of the tree, and "mature" specimens were recovered in the upper third of the tree. Because all "mature" $T$. proriger specimens are recovered as more mature than all $T$. nepaeolicus, the hypothesis of anagenesis in WIS Tylosaurus is supported; additionally, all T. nepaeolicus specimens (except for the holotype) are recovered as more mature than all specimens of $T$. kansasensis, supporting the hypothesis that $T$. kansasensis are juveniles (Jiménez-Huidobro, Simões, \& Caldwell, 2016). Abbreviations: cr, coronoid; d, dentary; DL, dentary length; eccp, ectopterygoid process of the pterygoid; $\mathbf{f}$, frontal; isp, infrastapedial process of the quadrate; p, parietal; pm, premaxilla; q, quadrate; ssp, suprastapedial process of the quadrate. 


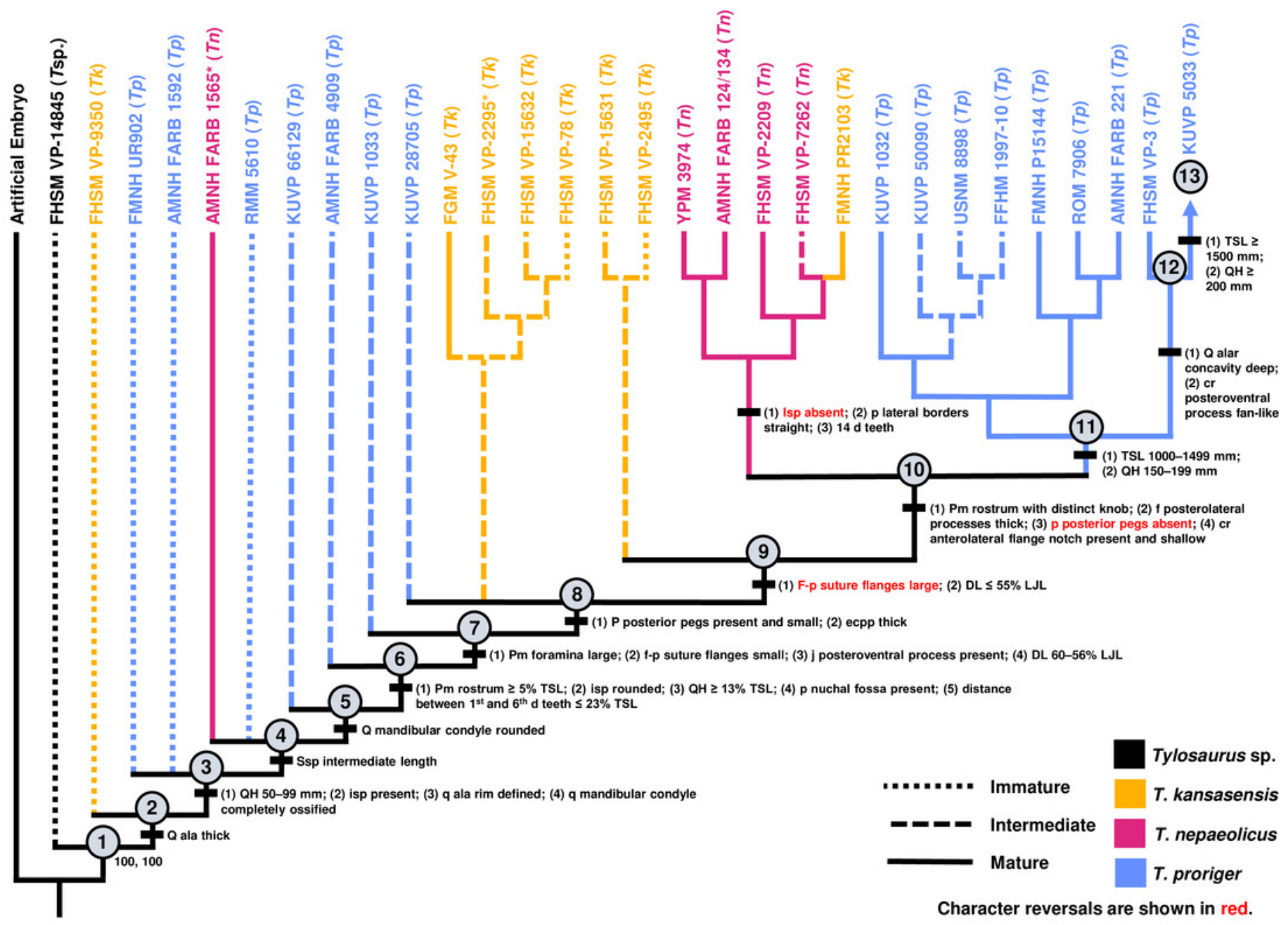


Figure 15

Variation in pterygoid ectopterygoid process shape.

(A) Slender (T. proriger AMNH FARB 4909). (B) Wide and flat (T. proriger FHSM VP-3). Note: specimen photographs are not to scale. 
A

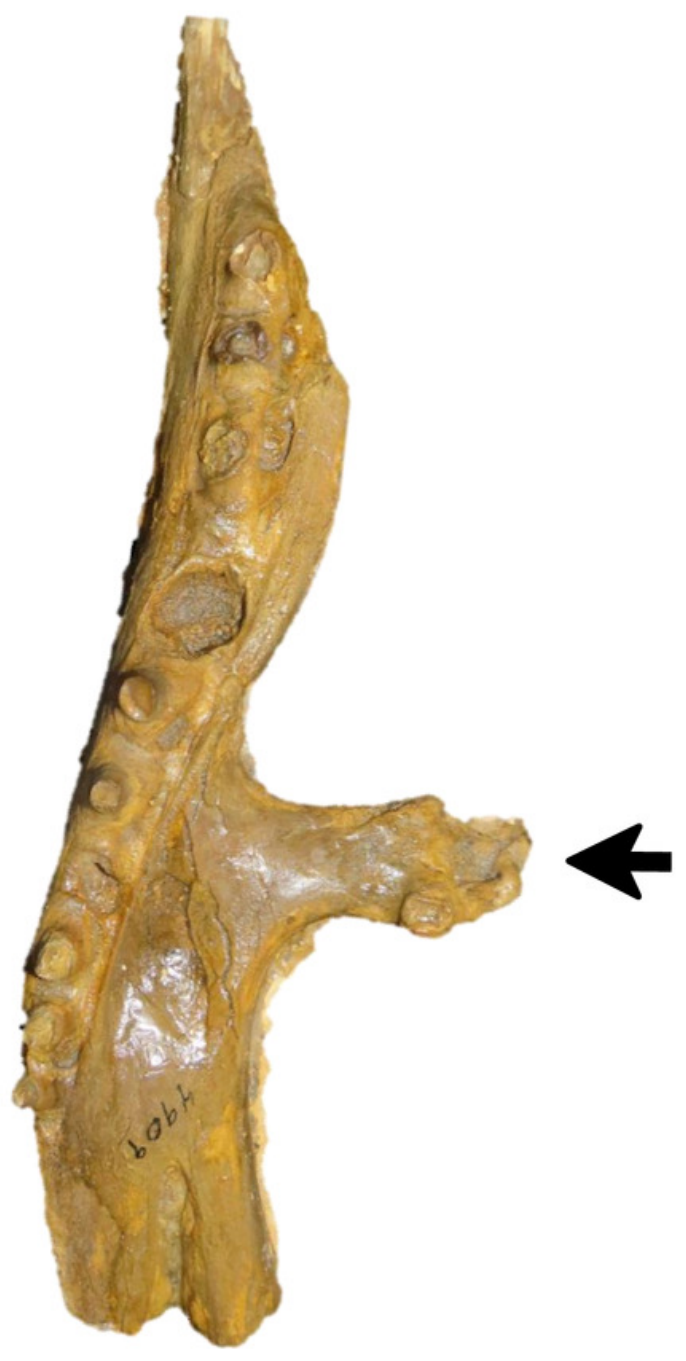

B

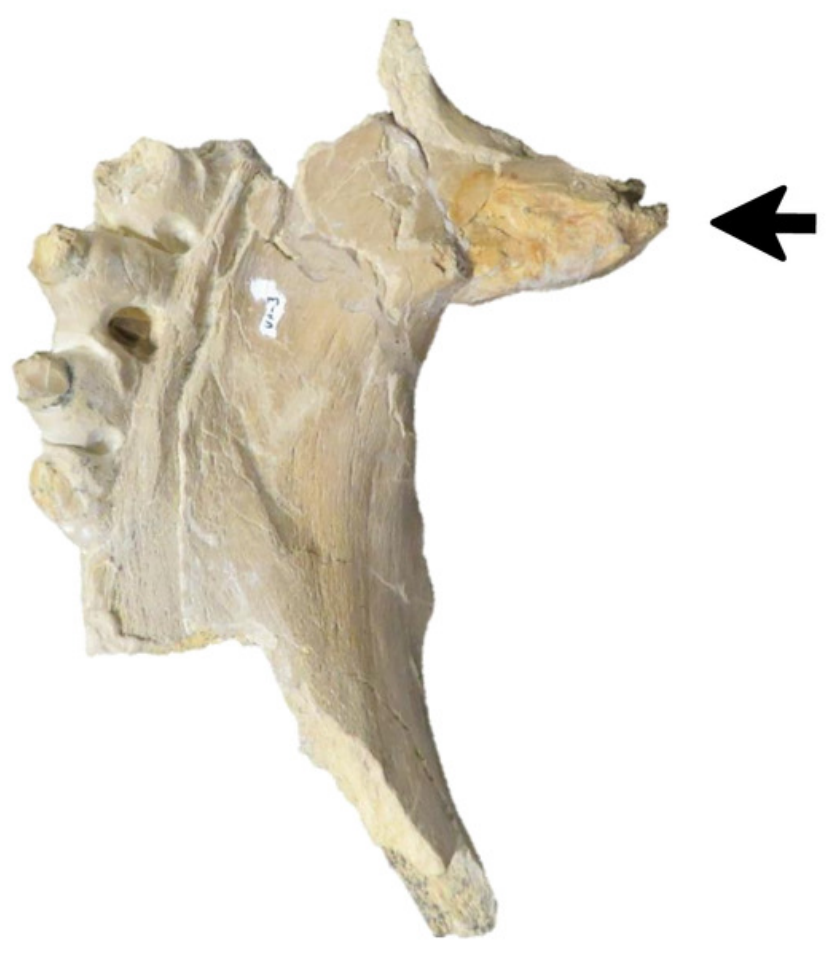




\section{Figure 16}

Variation in parietal lateral border shape.

(A, B) Convex (T. nepaeolicus FHSM VP-78). (C, D) Slightly convex to straight (T. nepaeolicus FHSM VP-2209). Notes: FHSM VP-78 was previously identified as T. kansasensis; specimen photographs are not to scale.

A

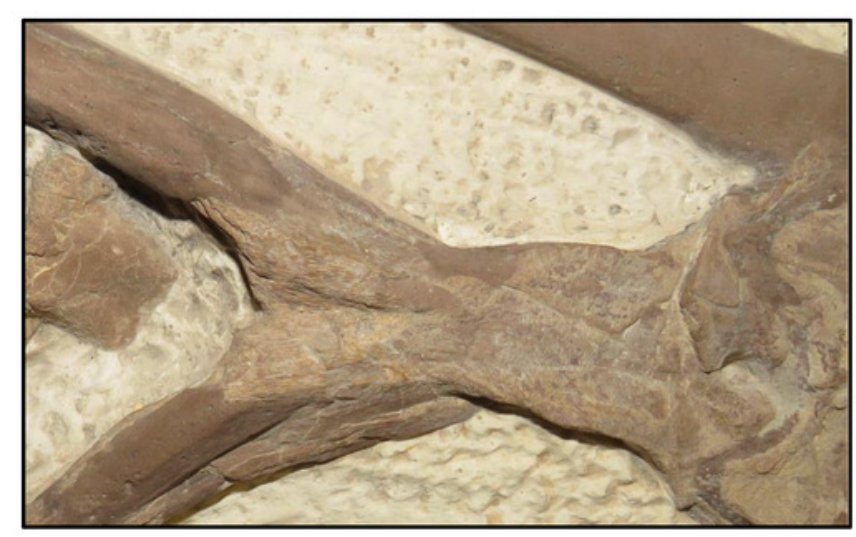

C

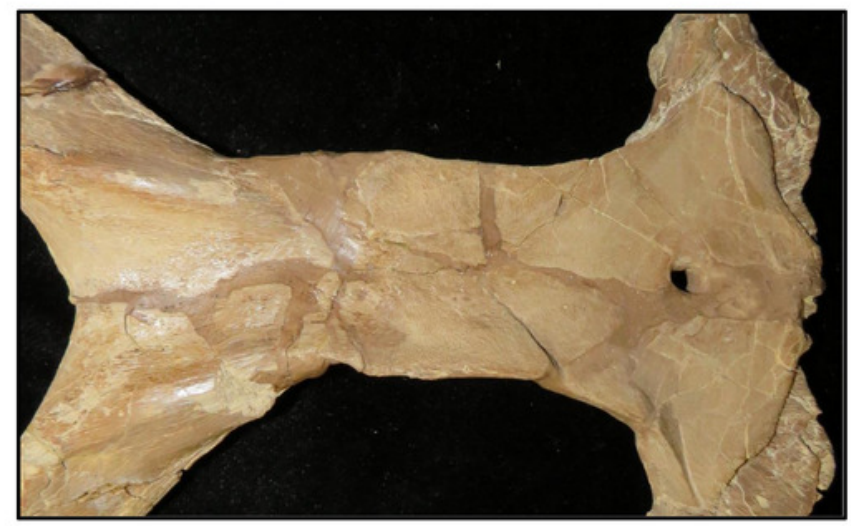

B

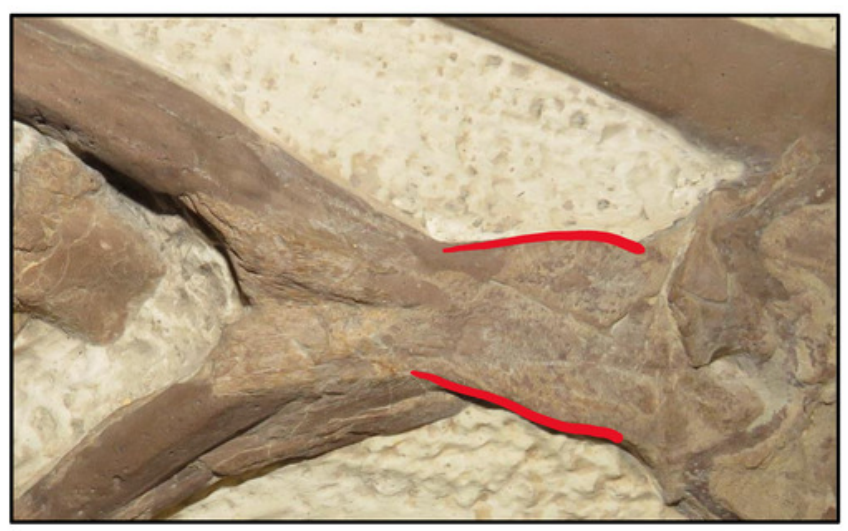

D

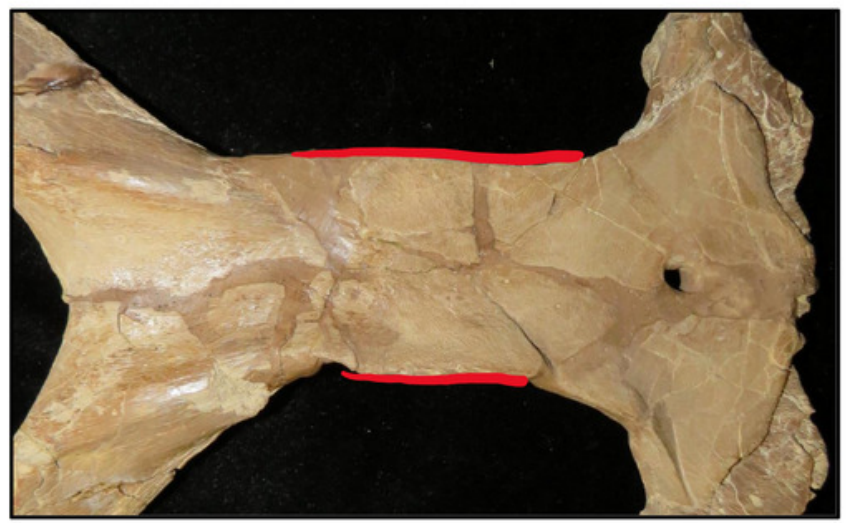




\section{Figure 17}

Size and maturity are positively correlated in Tylosaurus proriger.

(A) Scatterplot and statistics for TSL data. (B) Scatterplot and statistics for QH data. The growth stages and size data for TSL and QH of each $T$. proriger specimen included in the growth series (for which measurements were available) were converted into ranks and plotted. Congruence between size rank and growth stage rank was tested with Spearman rank-order correlation. Both TSL and QH have a significant positive correlation with growth stage in this species. Shapiro-Wilk tests determined that growth rank, size rank, and raw measurement data are normally distributed. 
A

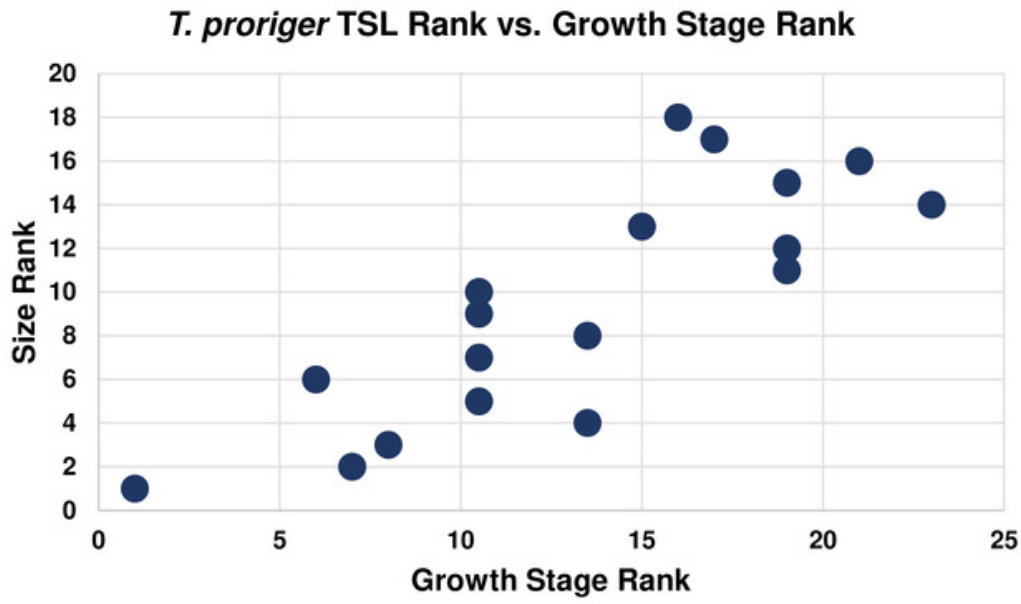

Spearman Correlation

$r_{S(0.05,18)}=0.824$

$p<0.001$

Shapiro-Wilk

Growth Ranks $p=0.618$

Size Ranks $p=0.558$

Measurements $p=0.463$

B

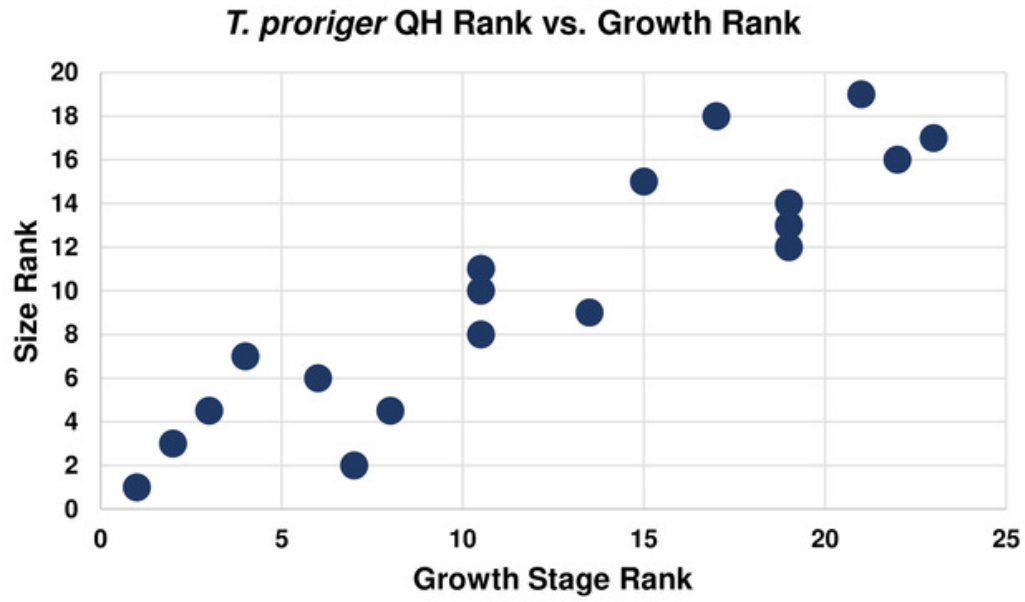

Spearman Correlation

$r_{S(0.05,17)}=0.897$

$p<0.001$

Shapiro-Wilk

Growth Ranks $p=0.220$

Size Ranks $p=0.525$

Measurements $p=0.126$ 


\section{Figure 18}

Size and maturity are positively correlated in Tylosaurus nepaeolicus.

(A) Scatterplot and statistics for TSL data. (B) Scatterplot and statistics for QH data. The growth stages and size data for TSL and QH of each $T$. nepaeolicus specimen included in the growth series (for which measurements were available) were converted into ranks and plotted. Congruence between size rank and growth stage rank was tested with Spearman rank-order correlation. Both TSL and QH have a significant positive correlation with growth stage in this taxon. Shapiro-Wilk tests determined that TSL (but not QH) growth rank, size rank, and raw measurement data are normally distributed. 
A

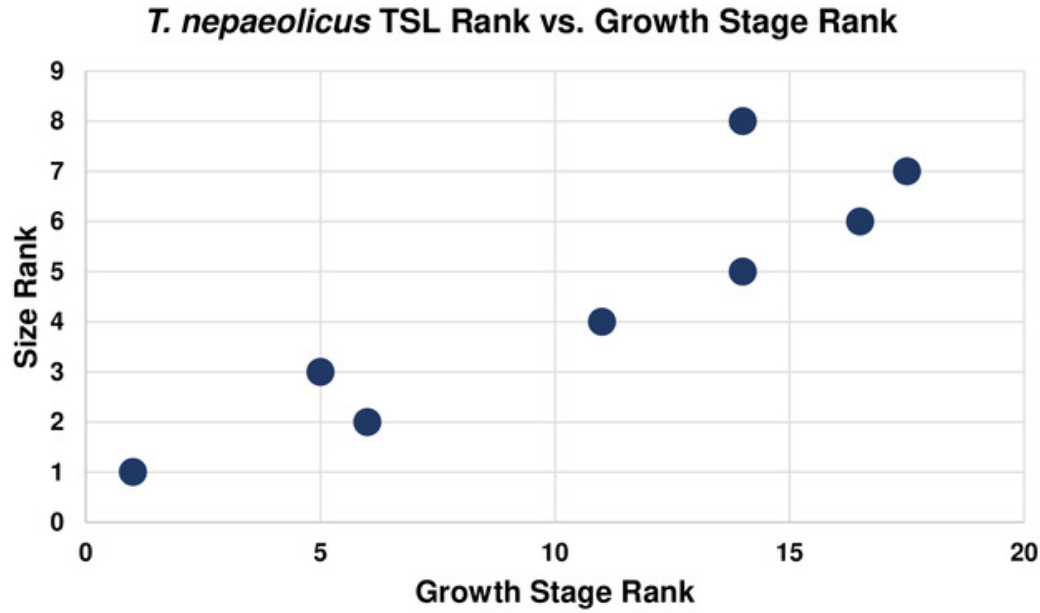

Spearman Correlation

$r_{S(0.05,8)}=0.874$

$p=0.005$

Shapiro-Wilk

Growth Ranks $p=0.444$

Size Ranks $p=0.933$

Measurements $p=0.294$

B

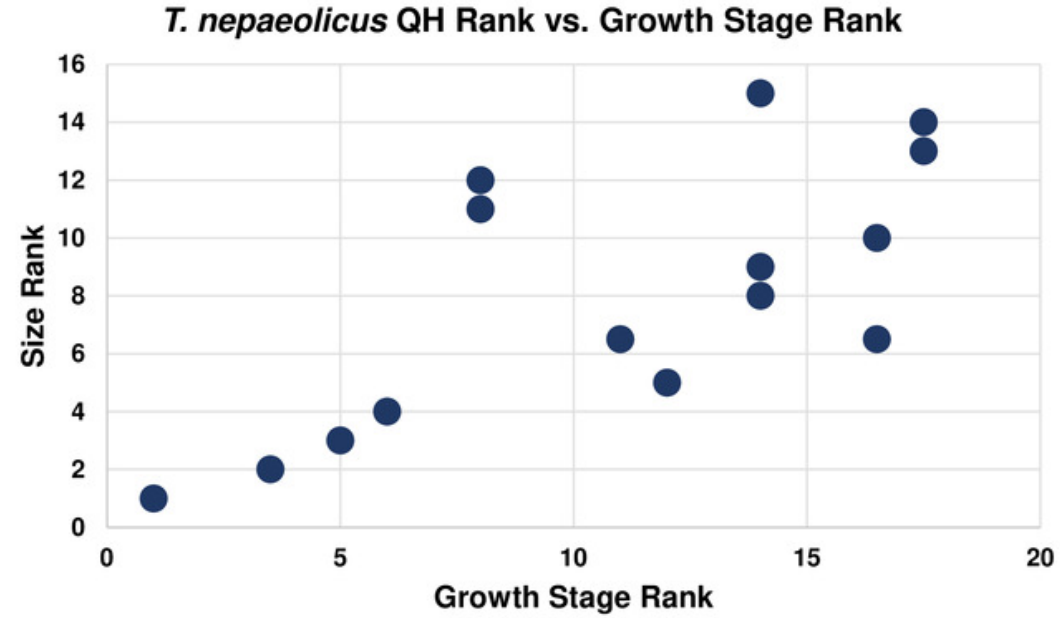

Spearman Correlation

$r_{S(0.05,15)}=0.719$

$p=0.003$

Shapiro-Wilk

Growth Ranks $p=0.048$

Size Ranks $p=0.475$

Measurements $p=0.950$ 


\section{Figure 19}

Size and maturity are positively correlated in WIS Tylosaurus species.

(A) Scatterplot and statistics for TSL data. (B) Scatterplot and statistics for QH data. The growth stages and size data for TSL and QH of each specimen (for which measurements were available) included in the growth series including all three Tylosaurus taxa were converted into ranks and plotted. Congruence between size rank and growth stage rank was tested with Spearman rank-order correlation. Both TSL and QH have a significant positive correlation with growth stage. Shapiro-Wilk tests determined that growth rank, size rank, and raw measurement data are normally distributed. 
A

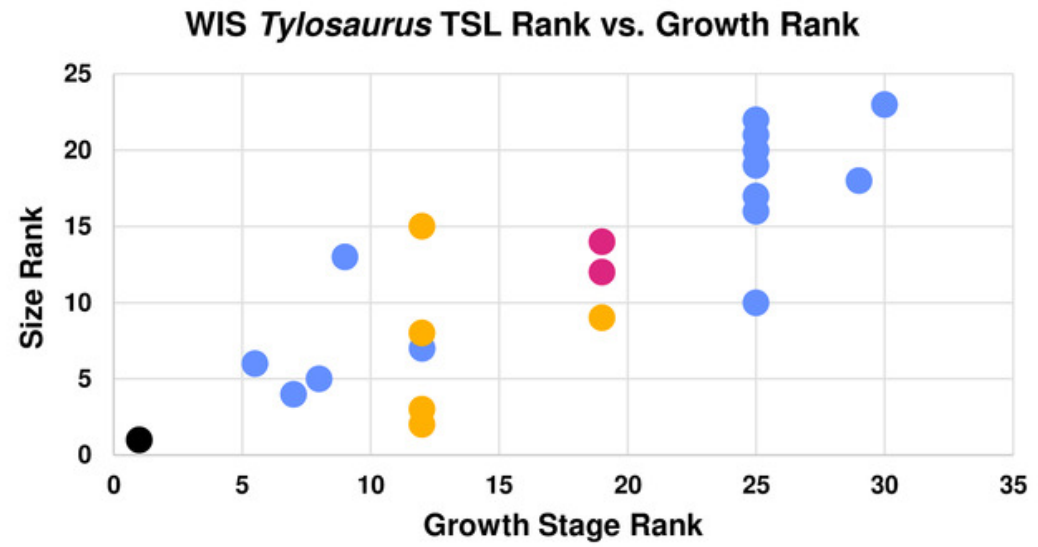

Spearman Correlation

$r_{S(0.05,22)}=0.841$

$p<0.001$

Shapiro-Wilk

Growth Ranks $p=0.055$

Size Ranks $p=0.337$

Measurements $p=0.472$

B

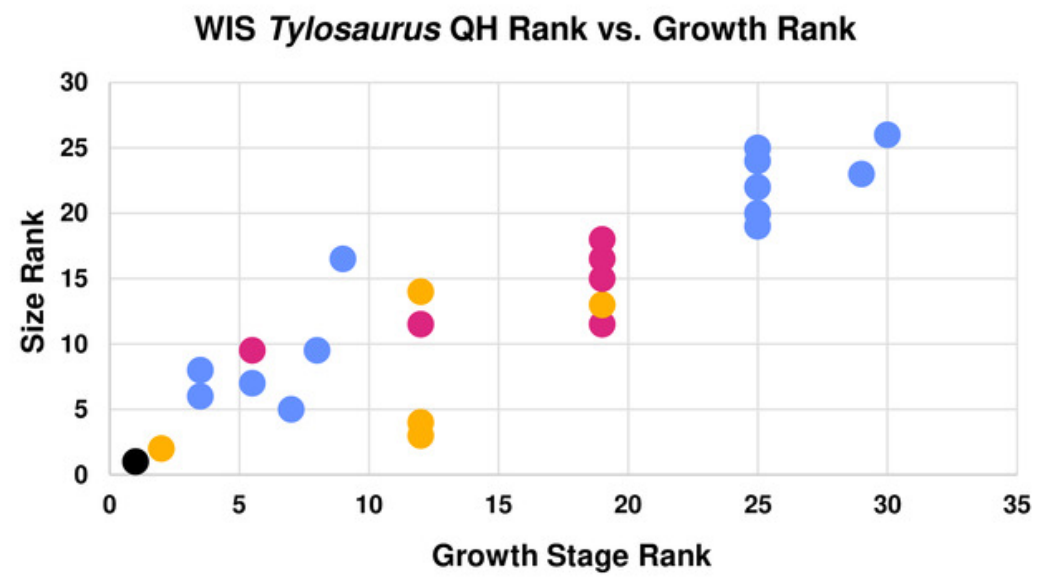

Spearman Correlation

$r_{S(0.05,25)}=0.884$

$p<0.001$

Shapiro-Wilk

Growth Ranks $p=0.147$

Size Ranks $p=0.592$

Measurements $p=0.299$

Tylosaurus sp.

T. kansasensis

T. nepaeolicus

T. proriger 


\section{Figure 20}

Quadrate growth in WIS Tylosaurus.

Growth series of Tylosaurus sp. (A), T. nepaeolicus (B-G) and T. proriger (H-M) quadrates. (A) FHSM VP-14845. (B) FHSM VP-9350. (C) FHSM VP-15632. (D) FHSM VP-2295. (E) FGM V-43. (F) AMNH FARB 2167. (G) AMNH FARB 124/134. (H) FMNH UR902. (I) AMNH FARB 4909. (J) KUVP 1033. (K) AMNH FARB 1555. (L) FHSM VP-3. (M) KUVP 5033. Scale bar is $5 \mathrm{~cm}$. Notes: FHSM VP-14845 is ventrally incomplete; the photographs of FMNH UR902, FHSM VP-15632, FGM V-43, and AMNH FARB 124/134 have been inverted to face left.

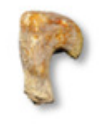

B

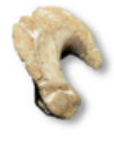

C

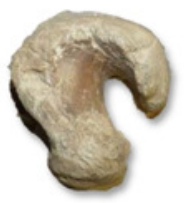

D

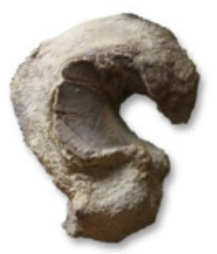

E

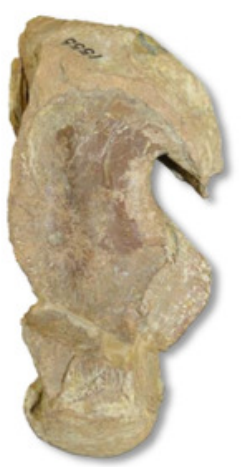

K

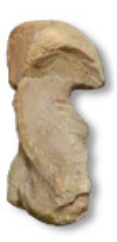

H

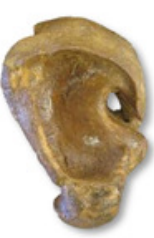

I

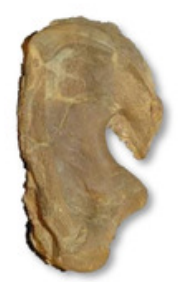

J

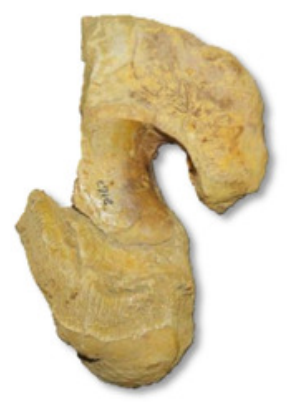

F

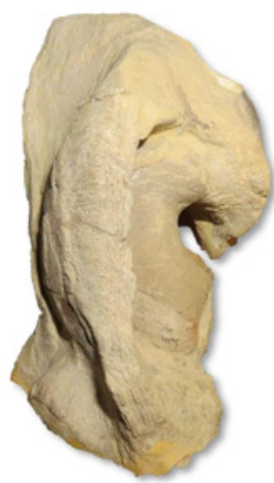

L

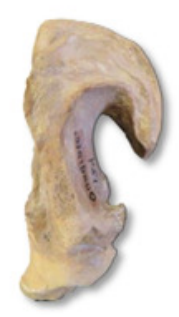

G

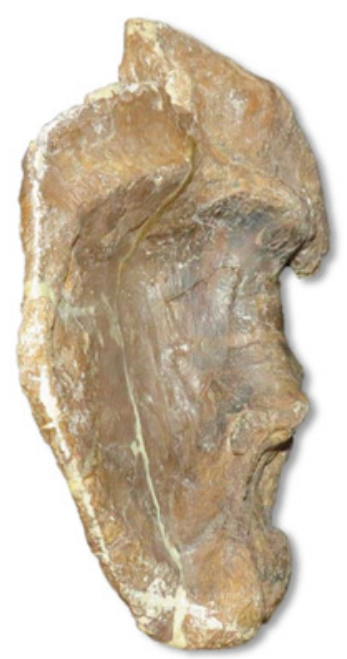

M 


\section{Table $\mathbf{1}$ (on next page)}

Measurements, in millimeters, of all specimens included in this project for which measurement data was available.

Measurements are rounded to the nearest whole millimeter. (A) Total skull length. (B)

Premaxilla predental rostrum length. (C) Length between first and sixth maxillary teeth. (D)

Quadrate height. (E) Lower jaw length. (F) Dentary length. (G) Dentary height. (H) Length between first and sixth dentary teeth. Measurement sources are listed in Table S1. Estimates made by the author using scale bars in the literature or due to incomplete material are indicated by a single asterisk, estimates from the literature are indicated by two asterisks, and missing measurements are indicated by question marks. Notes: TMP 1982.050 .0010 is a cast of LACMNH 28964; CMN 51258 through 51263 are fragments from a single individual (Stewart and Mallon, 2018); AMNH FARB 124 and 134 are a skull and jaws, respectively, from a single individual (Jiménez-Huidobro and Caldwell, 2019); PRM 2546 is a cast of CCMGE 10/2469, and both were referenced for coding (Grigoriev, 2014); a measurement was published for (B) CMN 8162 (Stewart \& Mallon, 2018), but it is inaccurate due to restoration of the specimen (T. Konishi, 2019, pers. comm.). 


\begin{tabular}{|c|c|c|c|c|c|c|c|c|}
\hline Specimen & $\mathbf{A}$ & B & $\mathbf{C}$ & D & $\mathbf{E}$ & $\mathbf{F}$ & $\mathbf{G}$ & $\mathbf{H}$ \\
\hline \multicolumn{9}{|l|}{ Tylosaurus sp. } \\
\hline FHSM VP-14845 & $300 * *$ & 3 & $?$ & $30^{*}$ & $?$ & $?$ & $?$ & $?$ \\
\hline FHSM VP-14841 & $?$ & 13 & $?$ & $?$ & $?$ & $?$ & $?$ & $?$ \\
\hline FHSM VP-14842 & $?$ & 14 & $?$ & $?$ & $?$ & $?$ & $?$ & $?$ \\
\hline FHSM VP-14843 & $?$ & 11 & $?$ & $?$ & $?$ & $?$ & $?$ & $?$ \\
\hline FHSM VP-14844 & $?$ & 15 & $?$ & $?$ & $?$ & $?$ & $?$ & $?$ \\
\hline \multicolumn{9}{|l|}{ T. proriger } \\
\hline RMM 5610 & $611 * *$ & $21 * *$ & $130 * *$ & $72 *$ & $?$ & $?$ & $?$ & $?$ \\
\hline CMN 51258-51263 & $?$ & $?$ & $?$ & $70 *$ & $?$ & $?$ & $?$ & $?$ \\
\hline CMN 8162 & 574 & $?$ & 127 & 71 & 575 & 364 & $60 *$ & 172 \\
\hline KUVP 5033 & $1700^{*}$ & $87^{*}$ & $330 *$ & 225 & $1850^{*}$ & $900 *$ & $222 *$ & $315^{*}$ \\
\hline FHSM VP-3 & 1130 & 58 & 225 & 165 & 1228 & 694 & 152 & 218 \\
\hline FMNH P15144 & 1201 & 63 & 259 & 173 & 1343 & 761 & 84 & 239 \\
\hline AMNH FARB 221 & $1180^{*}$ & $?$ & $?$ & $135^{*}$ & $1132 *$ & $617^{*}$ & 87 & $?$ \\
\hline AMNH FARB 4909 & 610 & 42 & 143 & 78 & 695 & 416 & 71 & 138 \\
\hline AMNH FARB 1555 & $?$ & $?$ & $?$ & 152 & $?$ & $?$ & $?$ & $?$ \\
\hline USNM 6086 & 585 & $?$ & 142 & 79 & 650 & 373 & $?$ & 163 \\
\hline USNM 8898 & 710 & $40^{*}$ & 223 & $?$ & 935 & 565 & $?$ & 215 \\
\hline YPM 1268 & $?$ & $?$ & 141 & 78 & $?$ & $?$ & $?$ & 130 \\
\hline YPM 3977 & $?$ & 33 & $?$ & 82 & $?$ & 399 & $?$ & 144 \\
\hline YPM 4002 & $?$ & 36 & 234 & $?$ & $?$ & $?$ & $?$ & 220 \\
\hline YPM 3981 & $?$ & 57 & $?$ & 158 & $?$ & $?$ & $?$ & $?$ \\
\hline KUVP 1032 & 1212 & 57 & 268 & 170 & 1351 & 716 & $126^{*}$ & 260 \\
\hline AMNH FARB 1585 & $?$ & $?$ & 83 & $?$ & $?$ & $?$ & $?$ & $?$ \\
\hline KUVP 66129 & 506 & 19 & 129 & 63 & 553 & $345^{*}$ & 47 & 120 \\
\hline FFHM 1997-10 & 1016 & 61 & 284 & 150 & 1220 & 667 & $?$ & 251 \\
\hline TMP 1982.050.0010 & 810 & 46 & 186 & 111 & 872 & 543 & $?$ & 174 \\
\hline FMNH UR902 & $?$ & $?$ & $?$ & 75 & $?$ & $?$ & $?$ & $?$ \\
\hline FMNH UR820 & $?$ & 54 & $?$ & $?$ & $?$ & $?$ & $?$ & $?$ \\
\hline GSM 1 & 980 & 62 & 241 & 133 & 1092 & 603 & $?$ & 223 \\
\hline ROM 7906 & 1005 & 53 & 256 & 144 & 1245 & $?$ & $?$ & 235 \\
\hline AMNH FARB 2160 & $?$ & 20 & $?$ & $?$ & $?$ & $?$ & $?$ & $?$ \\
\hline AMNH FARB 1560 & $?$ & 41 & $?$ & $?$ & $?$ & $?$ & $?$ & $?$ \\
\hline AMNH FARB 1592 & $?$ & $?$ & $?$ & 71 & $?$ & $?$ & $?$ & $?$ \\
\hline FHSM VP-6907 & $?$ & 45 & $?$ & $?$ & $?$ & $?$ & $?$ & 165 \\
\hline KUVP 1033 & 813 & 44 & 193 & 106 & 931 & 538 & 99 & 182 \\
\hline KUVP 50090 & 1300 & $49 *$ & $272 *$ & $?$ & $1415^{*}$ & $780 *$ & 159 & $360 *$ \\
\hline KUVP 28705 & 615 & 31 & $138 *$ & $?$ & $?$ & $?$ & $?$ & $?$ \\
\hline KUVP 65636 & $1180^{*}$ & 56 & 149 & 150 & $1200 *$ & 635 & 122 & 219 \\
\hline KUVP 1020 & $?$ & $?$ & $?$ & 89 & $?$ & $?$ & $?$ & $?$ \\
\hline \multicolumn{9}{|l|}{ T. nepaeolicus } \\
\hline AMNH FARB 1565 & $?$ & $?$ & $?$ & 78 & 660 & $?$ & $?$ & $?$ \\
\hline AMNH FARB 124/134 & 717 & 19 & 176 & 92 & 828 & 444 & 85 & 180 \\
\hline YPM 3980 & $?$ & $?$ & 181 & 110 & $?$ & $?$ & $?$ & $?$ \\
\hline YPM 3970 & $?$ & $?$ & $?$ & 121 & $?$ & $?$ & $?$ & $?$ \\
\hline YPM 3969 & $?$ & $25^{*}$ & $?$ & $?$ & $?$ & $?$ & $?$ & $?$ \\
\hline YРM 3974 & $?$ & 23 & 139 & $82 *$ & $?$ & 391 & $?$ & 149 \\
\hline AMNH FARB 1561 & $?$ & 41 & $?$ & $?$ & $?$ & $?$ & $?$ & $?$ \\
\hline FHSM VP-7262 & $?$ & 44 & 175 & 106 & $?$ & $585^{*}$ & 94 & 170 \\
\hline FHSM VP-2209 & $851 *$ & 44 & 201 & 133 & 1002 & 580 & 107 & 192 \\
\hline YPM 3979 & $?$ & 10 & 85 & $?$ & $?$ & 236 & $?$ & 83 \\
\hline YPM 3992 & $?$ & $?$ & 99 & 46 & $?$ & 247 & $?$ & 90 \\
\hline YPM 4000 & $?$ & 28 & $?$ & 68 & $?$ & 355 & $?$ & 135 \\
\hline YPM 3976 & $?$ & 33 & $?$ & 109 & $?$ & $?$ & $?$ & $?$ \\
\hline
\end{tabular}




\begin{tabular}{ccccccccc} 
AMNH FARB 2167 & $?$ & $?$ & $?$ & $155^{*}$ & $?$ & $?$ & $?$ \\
\hline T. kansasensis & & & & & & & \\
\hline FHSM VP-2295 & 650 & 27 & 154 & 82 & 724 & 404 & 72 & 130 \\
FHSM VP-78 & 378 & 14 & 75 & 43 & 440 & 251 & 41 & 81 \\
FHSM VP-2495 & $?$ & $?$ & 102 & $?$ & 510 & 273 & 50 & 94 \\
FHSM VP-3366 & $?$ & 35 & 164 & 93 & $?$ & 441 & $?$ & 164 \\
FHSM VP-9350 & $?$ & 11 & $?$ & 37 & 370 & 183 & 32 & 65 \\
FHSM VP-13742 & $?$ & $28^{*}$ & $?$ & $?$ & 980 & 509 & $95 *$ & 176 \\
FHSM VP-14848 & $?$ & $?$ & $?$ & 24 & $?$ & $?$ & $?$ & $?$ \\
FHSM VP-15631 & $?$ & 22 & $?$ & $?$ & 760 & $?$ & $?$ & $127 *$ \\
FHSM VP-15632 & $360^{*}$ & $16 *$ & 82 & 45 & 414 & 240 & 39 & 71 \\
FGM V-43 & 890 & 39 & 173 & 97 & 830 & 475 & 81 & 157 \\
MCZ 1589 & $?$ & 20 & $?$ & $?$ & $809 * *$ & 460 & $?$ & $?$ \\
YPM 40796 & $?$ & $?$ & $?$ & $?$ & $430 * *$ & 240 & $?$ & $?$ \\
LACMNH 127815 & $650 * *$ & $?$ & $?$ & $?$ & $730^{* *}$ & 410 & $?$ & $?$ \\
TMM 40092-27 & $?$ & 14 & $?$ & $?$ & $?$ & $?$ & $?$ & $?$ \\
TMM 81051-64 & $?$ & 13 & $?$ & $?$ & $?$ & $?$ & $?$ & $?$ \\
IPB R322 & $350^{*}$ & $?$ & $75 *$ & $40 *$ & $410^{*}$ & $250^{*}$ & $?$ & $?$ \\
FHSM VP-17206 & $?$ & 26 & $?$ & $?$ & $?$ & $?$ & $?$ & $?$ \\
FHSM VP-14840 & $?$ & 13 & $?$ & $?$ & $?$ & $?$ & $?$ & $?$ \\
FMNH PR2103 & 653 & 32 & $140 *$ & 87 & 723 & 415 & 84 & 134 \\
FMNH UC1342 & $?$ & $?$ & $?$ & $?$ & $?$ & 352 & 68 & 127 \\
FHSM VP-18520 & $?$ & 31 & 169 & $?$ & $?$ & $?$ & $?$ & $?$
\end{tabular}




\section{Table 2 (on next page)}

Known tooth counts of specimens included in this project.

Missing counts are indicated by question marks. If tooth counts were available for both left and right bones, the number of teeth on the left bone is listed first. 


\begin{tabular}{|c|c|c|c|}
\hline Specimen & Maxillary Teeth & Dentary Teeth & Pterygoid Teeth \\
\hline \multicolumn{4}{|l|}{ T. proriger } \\
\hline CMN 8162 & 13 & 13 & $?$ \\
\hline FHSM VP-3 & 13 & 13 & $?$ \\
\hline FMNH P15144 & 13 & 14 & 10 \\
\hline AMNH FARB 4909 & $?$ & 13 & 10 \\
\hline KUVP 1032 & 13 & 13 & 10 \\
\hline KUVP 66129 & $?$ & 12 & $?$ \\
\hline FFHM 1997-10 & 13 & 13 & $?$ \\
\hline KUVP 1033 & 13 & 13 & $?$ \\
\hline KUVP 28705 & 13 & $?$ & 10 \\
\hline KUVP 65636 & 12 & 13 & $?$ \\
\hline \multicolumn{4}{|l|}{ T. nepaeolicus } \\
\hline AMNH FARB 124/134 & 13 & 14 & 8,9 \\
\hline FHSM VP-7262 & 12 & 12 & 10,9 \\
\hline FHSM VP-2209 & 13 & 14 & $?$ \\
\hline \multicolumn{4}{|l|}{ T. kansasensis } \\
\hline FHSM VP-2295 & 13 & 13 & $?$ \\
\hline FHSM VP-78 & $?$ & 12 & $?$ \\
\hline FHSM VP-2495 & $?$ & 13 & $?$ \\
\hline FHSM VP-3366 & $?$ & $11-12$ & $?$ \\
\hline FHSM VP-9350 & $?$ & 13 & $?$ \\
\hline FHSM VP-13742 & $?$ & 13 & $?$ \\
\hline FHSM VP-15632 & 12 & 15,13 & $\geq 11$ \\
\hline FGM V-43 & 13 & 13,12 & 8 \\
\hline IPB R322 & 12 & $?$ & $?$ \\
\hline FMNH PR2103 & 13 & 10,12 & 13,11 \\
\hline FMNH UC1342 & $?$ & 13 & $?$ \\
\hline
\end{tabular}




\section{Table 3(on next page)}

Optimized synontomorphies supporting the growth stages of Tylosaurus proriger.

Reversals are bold, phylogenetic characters are indicated by an asterisk, and characters that are purportedly diagnostic of $T$. proriger are indicated by two asterisks. 


\begin{tabular}{|c|c|c|}
\hline Growth Stage & Unambiguous & Ambiguous \\
\hline 1 & $\mathrm{n} / \mathrm{a}$ & $\mathrm{n} / \mathrm{a}$ \\
\hline 2 & $\begin{array}{l}\text { QH between } 50-99 \mathrm{~mm} \text {, quadrate } \\
\text { mandibular condyle ossified }\end{array}$ & $\begin{array}{c}\text { TSL between } 400-800 \mathrm{~mm} \text {, quadrate ala rim } \\
\text { distinct, coronoid posteroventral process } \\
\text { present as bump }\end{array}$ \\
\hline 3 & Quadrate tympanic ala thick** & None \\
\hline 4 & Quadrate alar concavity shallow & None \\
\hline 5 & Occipital condyle ossified & $\begin{array}{l}\text { Quadrate suprastapedial process } \\
\text { intermediate length**, quadrate } \\
\text { suprastapedial process not curved medially* }\end{array}$ \\
\hline 6 & Premaxillary rostrum foramina small & None \\
\hline 7 & $\begin{array}{l}\text { Premaxilla-maxilla suture m-shaped, } \\
\text { quadrate mandibular condyle rounded }\end{array}$ & None \\
\hline 8 & Quadrate infrastapedial process rounded & $\begin{array}{c}\text { Premaxillary rostrum } \geq 5 \% \text { TSL, parietal } \\
\text { nuchal fossa present }\end{array}$ \\
\hline 9 & $\mathrm{QH} \geq 13 \% \mathrm{TSL}$, dentary deep & Jugal posteroventral process present* \\
\hline 10 & $\begin{array}{c}\text { Frontal posterolateral processes thick*, } \\
\text { dorsal ridge of dentary predental process } \\
\text { present }\end{array}$ & $\begin{array}{c}\text { Pterygoid ectopterygoid process thick, } \\
\text { coronoid anterolateral notch present and } \\
\text { shallow }\end{array}$ \\
\hline 11 & $\begin{array}{c}\text { TSL between } 1000-1499 \mathrm{~mm}, \mathrm{QH} \text { between } \\
150-199 \mathrm{~mm} \text {, dentary length } \leq 55 \% \text { lower } \\
\text { jaw length }\end{array}$ & None \\
\hline 12 & Premaxillary rostrum distinctly knobbed & None \\
\hline 13 & $\begin{array}{c}\text { Distance between } 1^{\text {st }} \text { and } 6^{\text {th }} \text { dentary teeth } \leq \\
23 \% \text { TSL }\end{array}$ & None \\
\hline 14 & Quadrate suprastapedial process thick & Dentary slender \\
\hline 15 & $\begin{array}{c}\text { Distance between } 1^{\text {st }} \text { and } 6^{\text {th }} \text { dentary teeth } \leq \\
35 \% \text { dentary length, dentary length } \\
\text { between } 60-\mathbf{5 6 \%} \% \text { lower jaw length, } \\
\text { coronoid posteroventral process present and } \\
\text { fan-like }\end{array}$ & None \\
\hline 16 & None & $\begin{array}{l}\text { Premaxilla-maxilla suture u-shaped, } \\
\text { dentary deep }\end{array}$ \\
\hline 17 & Quadrate alar concavity deep & None \\
\hline
\end{tabular}




\section{Table 4(on next page)}

Optimized synontomorphies supporting the growth stages of Tylosaurus kansasensis/nepaeolicus.

Reversals are bold, phylogenetic characters are indicated by an asterisk, and characters that are purportedly diagnostic of $T$. kansasensis or T. nepaeolicus are indicated by two asterisks. 


\begin{tabular}{|c|c|c|}
\hline Growth Stage & Unambiguous & Ambiguous \\
\hline 1 & $\overline{\mathrm{n} / \mathrm{a}}$ & $\mathrm{n} / \mathrm{a}$ \\
\hline 2 & None & $\begin{array}{c}\text { Quadrate tympanic ala thick**, quadrate alar } \\
\text { concavity shallow** }\end{array}$ \\
\hline 3 & Premaxilla-maxilla suture u-shaped & None \\
\hline 4 & $\begin{array}{l}\text { Premaxillary rostrum foramina small**, } \\
\text { quadrate mandibular condyle rounded }\end{array}$ & $\begin{array}{c}\text { Frontal-parietal suture flanges small**, jugal } \\
\text { ascending ramus thick, pterygoid } \\
\text { ectopterygoid process thick, basioccipital } \\
\text { ossified }\end{array}$ \\
\hline 5 & $\begin{array}{c}\mathrm{QH} \geq 13 \% \mathrm{TSL}, \text { quadrate ala rim defined, } \\
\text { dorsal ridge of dentary predental process } \\
\text { present }\end{array}$ & $\begin{array}{c}\text { Quadrate suprastapedial process } \\
\text { intermediate length**, parietal posterior } \\
\text { pegs absent* }\end{array}$ \\
\hline 6 & $\begin{array}{l}\text { QH between } 50-99 \mathrm{~mm} \text {, quadrate } \\
\text { mandibular condyle ossified }\end{array}$ & $\begin{array}{l}\text { TSL between } 400-800 \mathrm{~mm} \text {, quadrate } \\
\text { infrastapedial process present }{ }^{* *} \text {, frontal- } \\
\text { parietal suture flanges large* }\end{array}$ \\
\hline 7 & Premaxillary rostrum foramina large** & Dentary deep \\
\hline 8 & $\begin{array}{c}\text { Jugal posteroventral angle obtuse }{ }^{* *} \text {, } \\
\text { coronoid posteroventral process present as } \\
\text { bump* }\end{array}$ & None \\
\hline 9 & None & Parietal lateral borders straight** \\
\hline 10 & $\begin{array}{l}\text { Quadrate suprastapedial process thick, } \\
\text { coronoid anterolateral notch present and } \\
\text { shallow }\end{array}$ & None \\
\hline 11 & $\begin{array}{l}\text { Premaxillary rostrum distinctly knobbed, } \\
\text { frontal posterolateral processes thick, } \\
\text { increase in dentary teeth* (13 to } 14)\end{array}$ & Frontal dorsal crest absent** \\
\hline 12 & QH between 150-199 mm & $\begin{array}{c}\text { TSL between } 800-999 \mathrm{~mm} \text {, premaxillary } \\
\text { rostrum } \geq 5 \% \text { TSL, premaxilla-maxilla } \\
\text { suture rectangular }\end{array}$ \\
\hline
\end{tabular}




\section{Table 5 (on next page)}

Optimized synontomorphies supporting the growth stages of the analysis including all three taxa.

Reversals are bold, phylogenetic characters are indicated by an asterisk, and characters that are purportedly diagnostic of $T$. proriger, $T$. kansasensis, or T. nepaeolicus are indicated by two asterisks. 


\begin{tabular}{|c|c|c|}
\hline Growth Stage & Unambiguous & Ambiguous \\
\hline 1 & $\overline{\mathrm{n} / \mathrm{a}}$ & $\mathrm{n} / \mathrm{a}$ \\
\hline 2 & Quadrate tympanic ala thick** & $\begin{array}{l}\text { TSL between } 400-800 \mathrm{~mm} \text {, quadrate alar } \\
\text { concavity shallow** }\end{array}$ \\
\hline 3 & $\begin{array}{c}\text { QH between 50-99 mm, quadrate } \\
\text { infrastapedial process present**, quadrate } \\
\text { ala rim defined, quadrate mandibular } \\
\text { condyle ossified }\end{array}$ & $\begin{array}{c}\text { Premaxillary rostrum foramina small**, } \\
\text { coronoid posteroventral process present as } \\
\text { bump* }\end{array}$ \\
\hline 4 & $\begin{array}{c}\text { Quadrate suprastapedial process } \\
\text { intermediate length** }\end{array}$ & Basioccipital ossified \\
\hline 5 & Quadrate mandibular condyle rounded & $\begin{array}{l}\text { Premaxilla-maxilla suture m-shaped, parietal } \\
\text { foramen bordering or invading frontal* }\end{array}$ \\
\hline 6 & $\begin{array}{l}\text { Premaxillary rostrum } \geq 5 \% \mathrm{TSL}, \text { quadrate } \\
\text { infrastapedial process rounded, } \mathrm{QH} \geq 13 \% \\
\text { TSL, parietal nuchal fossa present, distance } \\
\text { between } 1^{\text {st }} \text { and } 6^{\text {th }} \text { dentary teeth } \leq 23 \% \mathrm{TSL}\end{array}$ & None \\
\hline 7 & $\begin{array}{l}\text { Premaxillary rostrum foramina large**, } \\
\text { frontal-parietal suture flanges small**, jugal } \\
\text { posteroventral process present*, dentary } \\
\text { length between } 60-56 \% \text { lower jaw length }\end{array}$ & $\begin{array}{l}\text { Parietal foramen close to frontal-parietal } \\
\text { suture* }\end{array}$ \\
\hline 8 & $\begin{array}{l}\text { Parietal posterior pegs present and small*, } \\
\text { pterygoid ectopterygoid process thick }\end{array}$ & $\begin{array}{l}\text { Premaxilla-maxilla suture u-shaped, dorsal } \\
\text { ridge of dentary predental process present }\end{array}$ \\
\hline 9 & $\begin{array}{l}\text { Frontal-parietal suture flanges large } * *, \\
\text { dentary length } \leq 55 \% \text { lower jaw length }\end{array}$ & Quadrate suprastapedial process thick \\
\hline 10 & $\begin{array}{l}\text { Premaxillary rostrum distinctly knobbed, } \\
\text { frontal posterolateral processes thick*, } \\
\text { parietal posterior pegs absent*, coronoid } \\
\text { anterolateral notch present and shallow }\end{array}$ & None \\
\hline 11 & $\begin{array}{l}\text { TSL between } 1000-1499 \mathrm{~mm}, \mathrm{QH} \text { between } \\
150-199 \mathrm{~mm}\end{array}$ & $\begin{array}{l}\text { Premaxillary rostrum foramina small**, } \\
\text { premaxilla-maxilla suture terminates at or } \\
\text { posterior to } 4^{\text {th }} \text { maxillary tooth } * *\end{array}$ \\
\hline 12 & $\begin{array}{l}\text { Quadrate alar concavity deep**, coronoid } \\
\text { posteroventral process present and fan-like }\end{array}$ & Frontal kite-shaped \\
\hline 13 & $\mathrm{TSL} \geq 1400 \mathrm{~mm}, \mathrm{QH} \geq 200 \mathrm{~mm}$ & None \\
\hline
\end{tabular}

